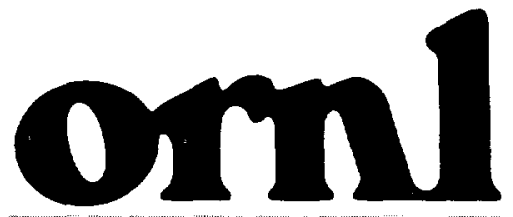

OAN TIECE

NATIONAL

LABORATORY

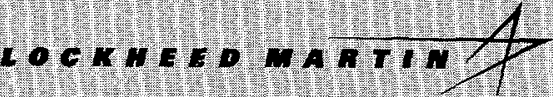

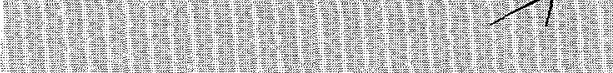

1)

\section{Whats}

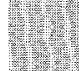

1)

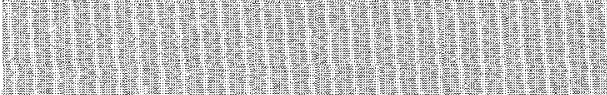

翼(E)

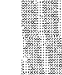

WANASED NO OPERATEO BY

LOCKHEED WARII ENERGY RESEARCH COAPORATION FOR THE UNTED STATES

DEPARTUENT OF ENERTY

\section{RECEIVED}

MAR 16999

OSTI

\title{
Studies of Flexible MOX/LEU Fuel Cycles
}

\author{
Gustavo Alonso-Vargas \\ Marvin L. Adams
}


This report was prepared as an account of work sponsored by an agency of the United States Government. Neither the United States Government nor any agency thereof, nor any of their employees, makes any warranty, express or implied, or assumes any legal liability or responsibility for the accuracy, completeness, or usefulness or any information, apparatus, product, or process disclosed, or represents that its use would not infringe privately owned rights. Reference herein to any specific commercial product, process, or service by trade name, trademark, manufacturer, or otherwise, does not necessarily constitute or imply its endorsement, recommendation, or favoring by the United States Government or any agency thereof. The views and opinions of authors expressed herein do not necessarily state or reflect those of the United States Government or any agency thereof. 


\section{DISCLAIMER}

Portions of this document may be illegible in electronic image products. Images are produced from the best available original document. 


\title{
STUDIES OF FLEXIBLE MOX/LEU FUEL CYCLES
}

\author{
Gustavo Alonso-Vargas \\ Marvin L. Adams
}

Date Published: March 1999

\author{
Report Prepared by \\ LOCKHEED MARTIN ENERGY RESEARCH CORP. \\ P.O. Box 2008 \\ Oak Ridge, Tennessee 37831-6363 \\ Under \\ Subcontract Number 85B99398V \\ Funded by \\ Office of Fissile Materials Disposition \\ United States Department of Energy \\ Prepared for \\ Computational Physics and Engineering Division \\ Oak Ridge National Laboratory \\ Oak Ridge, Tennessee 37831 \\ managed by \\ LOCKHEED MARTIN ENERGY RESEARCH CORP. \\ for the \\ U.S. DEPARTMENT OF ENERGY \\ under contract DE-96OR22464
}




\section{FINAL REPORT}

\section{STUDIES OF FLEXIBLE MOX/LEU FUEL CYCLES}

Gustavo Alonso-Vargas and Marvin L. Adams

Department of Nuclear Engineering

Texas A\&M University

Zachry 129

College Station, Texas 77843

March, 1999 


\title{
Studies of Flexible MOX/LEU Fuel Cycles Final Report, Texas A\&M University / Amarillo National Resource Center
}

\author{
Gustavo Alonso-Vargas and Marvin L. Adams, Texas A\&M University
}

\section{Introduction}

This project was a collaborative effort involving researchers from Oak Ridge National Laboratory and North Carolina State University as well as Texas A\&M University. The background, briefly, is that the United States is planning to use some of its excess weapons Plutonium ( $\mathrm{Pu}$ ) to make mixed-oxide (MOX) fuel for existing lightwater reactors (LWRs). Considerable effort has already gone into designing fuel assemblies and core loading patterns for the transition from full-uranium cores to partial-MOX and full-MOX cores. However, these designs have assumed that any time a reactor needs MOX assemblies, these assemblies will be supplied. In reality there are many possible scenarios under which this supply could be disrupted. It therefore seems prudent to verify that a reactor-based Pu-disposition program could tolerate such interruptions in an acceptable manner. Such verification was the overall aim of this project.

The task assigned to the Texas A\&M team was to use the HELIOS code ${ }^{1.2}$ to develop libraries of two-group homogenized cross sections for the various assembly designs that might be used in a Westinghouse Pressurized Water Reactor (PWR) that is burning weapons-grade MOX fuel. The NCSU team used these cross sections to develop optimized loading patterns under several assumed scenarios. Their results are documented in a companion report. ${ }^{3}$

\section{Methodology}

Our starting point in developing the library was to test the HELIOS models of $\mathrm{UO}_{2}$ and MOX assemblies. We compared the results against those from the CASMO-3 code. ${ }^{4}$ This served as useful check on our HELIOS models and in addition it is desirable for a variety of reasons to understand the relative difference between the two codes.

Our HELIOS calculations used the "hy961a" cross-section library, which is an update of the hy941a library. ${ }^{5}$ This library is based upon the evaluated nuclear data file ENDF/B-VI. ${ }^{6}$ Our final results were generated using a 34-group cross-section set for LEU assemblies and an 89-group set for MOX assemblies, as described later. Our CASMO-3 calculations used the CASMO " $K$ " libraries unless otherwise noted below; the exception was some calculations made to compare results from the " $\mathrm{J}$ " and " $\mathrm{K}$ " libraries. The main difference between the " $\mathrm{K}$ " and " $\mathrm{J}$ " libraries is an improvement in the cross sections for the higher Pu isotopes. ${ }^{7}$

When there were discrepancies between the results given by HELIOS and CASMO we investigated the cause. This led us to correct several input and code-usage mistakes, but in some cases it led us to conclude that the discrepancies resulted from certain differences in underlying cross-section libraries or code methodologies. Only when we were sure that we were correctly modeling our assemblies did we proceed to generate the different HELIOS models for the different assemblies.

From the HELIOS output files we generated the library of two-group homogenized cross sections using the ZENITH code. ZENITH input files were generated according the FORMOSA input data required. North Carolina State University provided us with the input data structure of FORMOSA.

We modeled both $\mathrm{UO}_{2}$ and MOX assemblies. Figure 1 shows the layout of one eighth of an assembly; this picture is the same for all assemblies considered. Table I provides some details about the dimensions and materials of each assembly. These details are the same as used by previous studies of the ability of Westinghouse reactors to be used for disposition of weapons $\mathrm{Pu}^{8,9}$

In Table II.a we list the different assemblies that were modeled, with their respective enrichments of ${ }^{235} \mathrm{U}$ or fissile plutonium and the numbers and types of burnable absorbers used. For each of these assemblies there is a base case and five different branch cases such that each HELIOS file produces six different ZENITH output files. Table II.b 
shows the conditions under which these cases were modeled. For the baffle model there are only four branch cases. For the full MOX cores the soluble boron is enriched to $40 \% \mathrm{~B}-10$; the partial MOX cores use natural boron (approximately 20\% B-10). We created libraries for both the natural and enriched scenarios, but only the enriched libraries were passed along to NCSU. The ZENITH output files constituted the two-group libraries used by NCSU for further analysis.

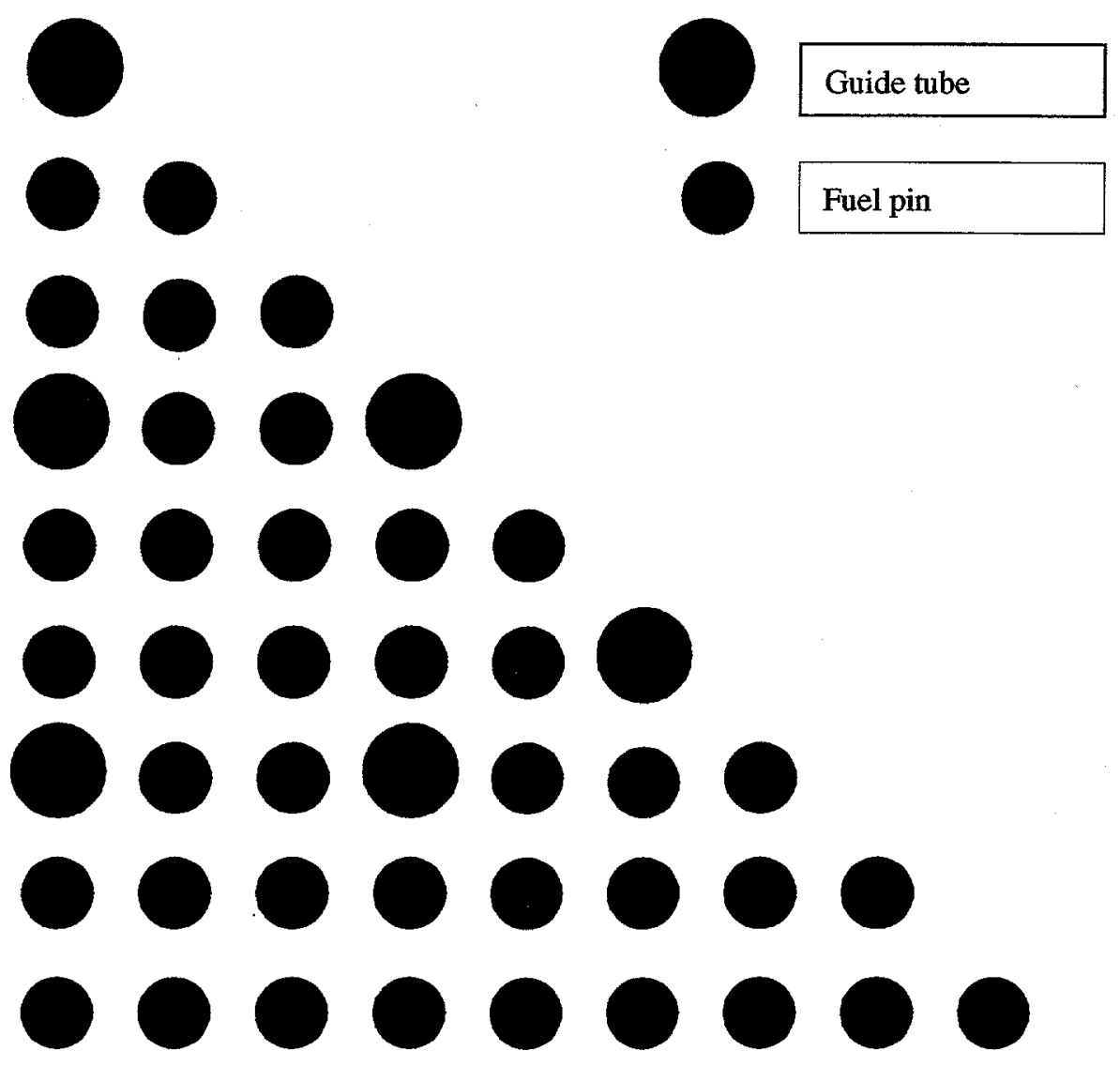

Figure 1. One eighth of an assembly.

Table II.a. MOX and $\mathrm{UO}_{2}$ assemblies that were modeled.

\begin{tabular}{|l|l|}
\hline Fuel lattice & $17 \times 17$ \\
\hline Fuel rods per assembly & 264 \\
\hline Fuel rod OD (in) & 0.360 \\
\hline Fuel pellet OD (in) & 0.3088 \\
\hline Cladding material & Zircaloy-4 \\
\hline Active Fuel Height & 144 \\
\hline Clad Thickness (in) & 0.0225 \\
\hline Pitch (in) & 0.496 \\
\hline Assembly Pitch (in) & 8.466 \\
\hline Assembly Gap (in) & 0.034 \\
\hline
\end{tabular}


Table II.a. MOX and $\mathrm{UO}_{2}$ assemblies modeled.

\begin{tabular}{|c|c|c|c|c|c|}
\hline Type & HELIOS file & Enrichment w/0 & \# IFBA & \#WABA & Boron-10 per rod \\
\hline MOX & hmhwh89h.inp & 4.0 & 0 & 0 & $0.006 \mathrm{~g} / \mathrm{cm}$ \\
\hline $\mathrm{MOX}$ & Hmhwl89g.inp & 4.0 & 0 & 12 & $0.006 \mathrm{~g} / \mathrm{cm}$ \\
\hline $\mathrm{MOX}$ & hmhwn89g.inp & 4.0 & 0 & 24 & $0.006 \mathrm{~g} / \mathrm{cm}$ \\
\hline $\mathrm{MOX}$ & hmlwh89g.inp & 4.5 & 0 & 0 & $0.006 \mathrm{~g} / \mathrm{cm}$ \\
\hline $\mathrm{MOX}$ & hmlw189g.inp & 4.5 & 0 & 12 & $0.006 \mathrm{~g} / \mathrm{cm}$ \\
\hline $\mathrm{MOX}$ & hmlwn89g.inp & 4.5 & 0 & 24 & $0.006 \mathrm{~g} / \mathrm{cm}$ \\
\hline $\mathrm{UO}_{2}$ & hu35ni.inp & 3.5 & 0 & 0 & $1.5 \mathrm{mg} / \mathrm{in}$ \\
\hline $\mathrm{UO}_{2}$ & hu3516i.inp & 3.5 & 16 & 0 & $1.5 \mathrm{mg} / \mathrm{in}$ \\
\hline $\mathrm{UO}_{2}$ & hu3548i.inp & 3.5 & 48 & 0 & $1.5 \mathrm{mg} / \mathrm{in}$ \\
\hline $\mathrm{UO}_{2}$ & hu3564i.inp & 3.5 & 64 & 0 & $1.5 \mathrm{mg} / \mathrm{in}$ \\
\hline $\mathrm{UO}_{2}$ & hu3580i.inp & 3.5 & 80 & 0 & $1.5 \mathrm{mg} / \mathrm{in}$ \\
\hline $\mathrm{UO}_{2}$ & hu35104i.inp & 3.5 & 104 & 0 & $1.5 \mathrm{mg} / \mathrm{in}$ \\
\hline $\mathrm{UO}_{2}$ & hu35128i.inp & 3.5 & 128 & 0 & $1.5 \mathrm{mg} / \mathrm{in}$ \\
\hline $\mathrm{UO}_{2}$ & hulni.inp & 4.0 & 0 & 0 & $1.5 \mathrm{mg} / \mathrm{in}$ \\
\hline $\mathrm{UO}_{2}$ & hul16i.inp & 4.0 & 16 & 0 & $1.5 \mathrm{mg} / \mathrm{in}$ \\
\hline $\mathrm{UO}_{2}$ & hul48i.inp & 4.0 & 48 & 0 & $1.5 \mathrm{mg} / \mathrm{in}$ \\
\hline $\mathrm{UO}_{2}$ & hul64i.inp & 4.0 & 64 & 0 & $1.5 \mathrm{mg} / \mathrm{in}$ \\
\hline $\mathrm{UO}_{2}$ & hul80i.inp & 4.0 & 80 & 0 & $1.5 \mathrm{mg} / \mathrm{in}$ \\
\hline $\mathrm{UO}_{2}$ & hul104i.inp & 4.0 & 104 & 0 & $1.5 \mathrm{mg} / \mathrm{in}$ \\
\hline $\mathrm{UO}_{2}$ & hul128i.inp & 4.0 & 128 & 0 & $1.5 \mathrm{mg} / \mathrm{in}$ \\
\hline $\mathrm{UO}_{2}$ & huhni.inp & 4.5 & 0 & 0 & $1.5 \mathrm{mg} / \mathrm{in}$ \\
\hline $\mathrm{UO}_{2}$ & huh16i.inp & 4.5 & 16 & 0 & $1.5 \mathrm{mg} / \mathrm{in}$ \\
\hline $\mathrm{UO}_{2}$ & huh48i.inp & 4.5 & 48 & 0 & $1.5 \mathrm{mg} / \mathrm{in}$ \\
\hline $\mathrm{UO}_{2}$ & huh64i.inp & 4.5 & 64 & 0 & $1.5 \mathrm{mg} / \mathrm{in}$ \\
\hline $\mathrm{UO}_{2}$ & huh80i.inp & 4.5 & 80 & 0 & $1.5 \mathrm{mg} / \mathrm{in}$ \\
\hline $\mathrm{UO}_{2}$ & huh104i.inp & 4.5 & 104 & 0 & $1.5 \mathrm{mg} / \mathrm{in}$ \\
\hline $\mathrm{UO}_{2}$ & huh128i.inp & 4.5 & 128 & 0 & $1.5 \mathrm{mg} / \mathrm{in}$ \\
\hline $\mathrm{BAFLE}_{2}$ & hmhwhref34.inp & 4.5 & 0 & 24 & $0.006 \mathrm{~g} / \mathrm{cm}$ \\
\hline
\end{tabular}

Table II.b. Base and branch conditions used in the HELIOS model.

\begin{tabular}{|c|c|c|c|}
\hline Case & $\begin{array}{c}\text { Fuel Temperature } \\
(\mathrm{K})\end{array}$ & $\begin{array}{c}\text { Moderator Temperature } \\
(\mathrm{K})\end{array}$ & $\begin{array}{c}\text { Boron concentration } \\
(\mathrm{PPM})\end{array}$ \\
\hline Base & 963 & 582.95 & 1000 \\
\hline Fuel Temperature Low & 582.95 & 582.95 & 1000 \\
\hline Moderator Temperature Low & 963 & 564.59 & 1000 \\
\hline Moderator Temperature High & 963 & 599.32 & 1000 \\
\hline Boron concentration Low & 963 & 582.95 & 0 \\
\hline Boron concentration High & 963 & 582.95 & 2000 \\
\hline
\end{tabular}

\section{Results}

\section{III.A. Verification of correct use and understanding of HELIOS/ZENITH}

We began our work by building a HELIOS model of a $\mathrm{UO}_{2}$ assembly and comparing results against those from CASMO-3. The assembly type tested had $4.203 \mathrm{w} / \mathrm{o}$ of ${ }^{235} \mathrm{U}$ enrichment with integral fuel burnable absorber (IFBA) coatings incorporated onto 128 fuel pins. The infinite multiplication factor and absolute difference between results given by CASMO-3 and HELIOS are shown in Table III (along with results from a MOX assembly described later). 
Table III. Multiplication factor for uranium and MOX assemblies.

\begin{tabular}{|c|c|c|c|c|c|c|}
\hline & \multicolumn{2}{|c|}{$4.203 \% w$ of ${ }^{235} U$} & & \multicolumn{2}{|c|}{$3.992 \% w$ of fissile $\mathrm{Pu}$} & \\
\hline $\mathrm{BU}$ & HELIOS & CASMO 70K & Difference & HELIOS & CASMO 70K & difference \\
\hline 0 & 1.11832 & 1.11716 & 0.00116 & 1.14394 & 1.15140 & 0.00746 \\
\hline 500 & 1.09231 & 1.09137 & 0.00094 & 1.11523 & 1.12168 & 0.00645 \\
\hline 1500 & 1.10314 & 1.10225 & 0.00089 & 1.10461 & 1.11101 & 0.00640 \\
\hline 2500 & 1.11226 & 1.11139 & 0.00087 & 1.09712 & 1.10348 & 0.00636 \\
\hline 5000 & 1.12340 & 1.12257 & 0.00083 & 1.08311 & 1.08953 & 0.00642 \\
\hline 7500 & 1.12371 & 1.12319 & 0.00052 & 1.07169 & 1.07803 & 0.00634 \\
\hline 10000 & 1.11702 & 1.11676 & 0.00026 & 1.06189 & 1.06809 & 0.00620 \\
\hline 12500 & 1.10583 & 1.10575 & 0.00008 & 1.05303 & 1.05913 & 0.00610 \\
\hline 15000 & 1.09180 & 1.09193 & 0.00013 & 1.04462 & 1.05065 & 0.00603 \\
\hline 17500 & 1.07600 & 1.07618 & 0.00018 & 1.03620 & 1.04221 & 0.00601 \\
\hline 20000 & 1.05915 & 1.05923 & 0.00008 & 1.02744 & 1.03352 & 0.00608 \\
\hline 22500 & 1.04174 & 1.04186 & 0.00012 & 1.01809 & 1.02426 & 0.00617 \\
\hline 25000 & 1.02407 & 1.02404 & 0.00003 & 1.00806 & 1.01429 & 0.00623 \\
\hline 27500 & 1.00635 & 1.00611 & 0.00024 & 0.99733 & 1.00356 & 0.00623 \\
\hline 30000 & 0.98872 & 0.98819 & 0.00053 & 0.98599 & 0.99207 & 0.00608 \\
\hline 32500 & 0.97127 & 0.97031 & 0.00096 & 0.97416 & 0.97994 & 0.00578 \\
\hline 35000 & 0.95396 & 0.95270 & 0.00126 & 0.96203 & 0.96735 & 0.00532 \\
\hline 37500 & 0.93715 & 0.93518 & 0.00197 & 0.94973 & 0.95449 & 0.00476 \\
\hline 40000 & 0.92060 & 0.91803 & 0.00257 & 0.93739 & 0.94150 & 0.00411 \\
\hline 42500 & 0.90443 & 0.90123 & 0.00320 & 0.92512 & 0.92848 & 0.00336 \\
\hline 45000 & 0.88868 & 0.88483 & 0.00385 & 0.91301 & 0.91557 & 0.00256 \\
\hline 47500 & 0.87341 & 0.86888 & 0.00453 & 0.90109 & 0.90284 & 0.00175 \\
\hline 50000 & 0.85862 & 0.85341 & 0.00521 & 0.88944 & 0.89033 & 0.00089 \\
\hline 52500 & 0.84439 & 0.83850 & 0.00589 & 0.87808 & 0.87811 & 0.00003 \\
\hline 55000 & 0.83075 & 0.82420 & 0.00655 & 0.86701 & 0.86619 & -0.00082 \\
\hline 57500 & 0.81772 & 0.81055 & 0.00717 & 0.85627 & 0.85461 & -0.00166 \\
\hline 60000 & 0.80533 & 0.79760 & 0.00773 & 0.84586 & 0.84339 & -0.00247 \\
\hline
\end{tabular}

Figure 2.a shows the behavior of the multiplication factor from HELIOS and CASMO-3, with several different cross-section libraries employed in the CASMO-3 runs. These were the 40-group and 70-group "J" libraries (denoted CASMO-40 and CASMO-70 in the figure) and the 70-group " $\mathrm{K}$ " library (denoted CASMO-70K). The " $\mathrm{K}$ " library was designed by Studsvik (the company that maintains and sells CASMO) to contain improved cross section data for Pu isotopes. We see that the different CASMO libraries cause smaller differences than the difference between CASMO and HELIOS. An important note is that we used only the 34-group library in the HELIOS runs.

Several runs were made in order to see if these discrepancies were related to the burnup step. When the number of burnup steps in CASMO was increased, the difference was smaller, however if we increase the number of burnup steps in HELIOS in order to have the same burnup steps as in CASMO, the difference returned to approximately its original value. Thus, we do not believe that burnup step is the source of a significant part of the difference; we believe instead that this difference stems from the different libraries and numerical approximations used in each code, and not to any parameters that are under the user's control.

We turned next to a MOX assembly with an average of 3.992 w/o of fissile Pu, composed of four different pin enrichments and containing 24 wet annular burnable absorber (WABA) rods. In this case CASMO-3 and HELIOS differ at BOC, with CASMO higher. As was true for the uranium assembly, CASMO-3 depletes faster than HELIOS, which in the MOX case means the two codes approach the same k-infinity late in the cycle. The infinite 
multiplication factor and absolute difference between results given by CASMO-3 and HELIOS are shown in Table III and Figure 2.b.

In the case of the MOX assembly we hypothesized that the differences were caused by differences in cross sections libraries. To test this hypothesis we replaced the weapons-grade plutonium in the assembly first with pure ${ }^{239} \mathrm{Pu}$ and then with pure ${ }^{241} \mathrm{Pu}$. This, of course, isolates the differences in the two cross section libraries for these two fissile isotopes.

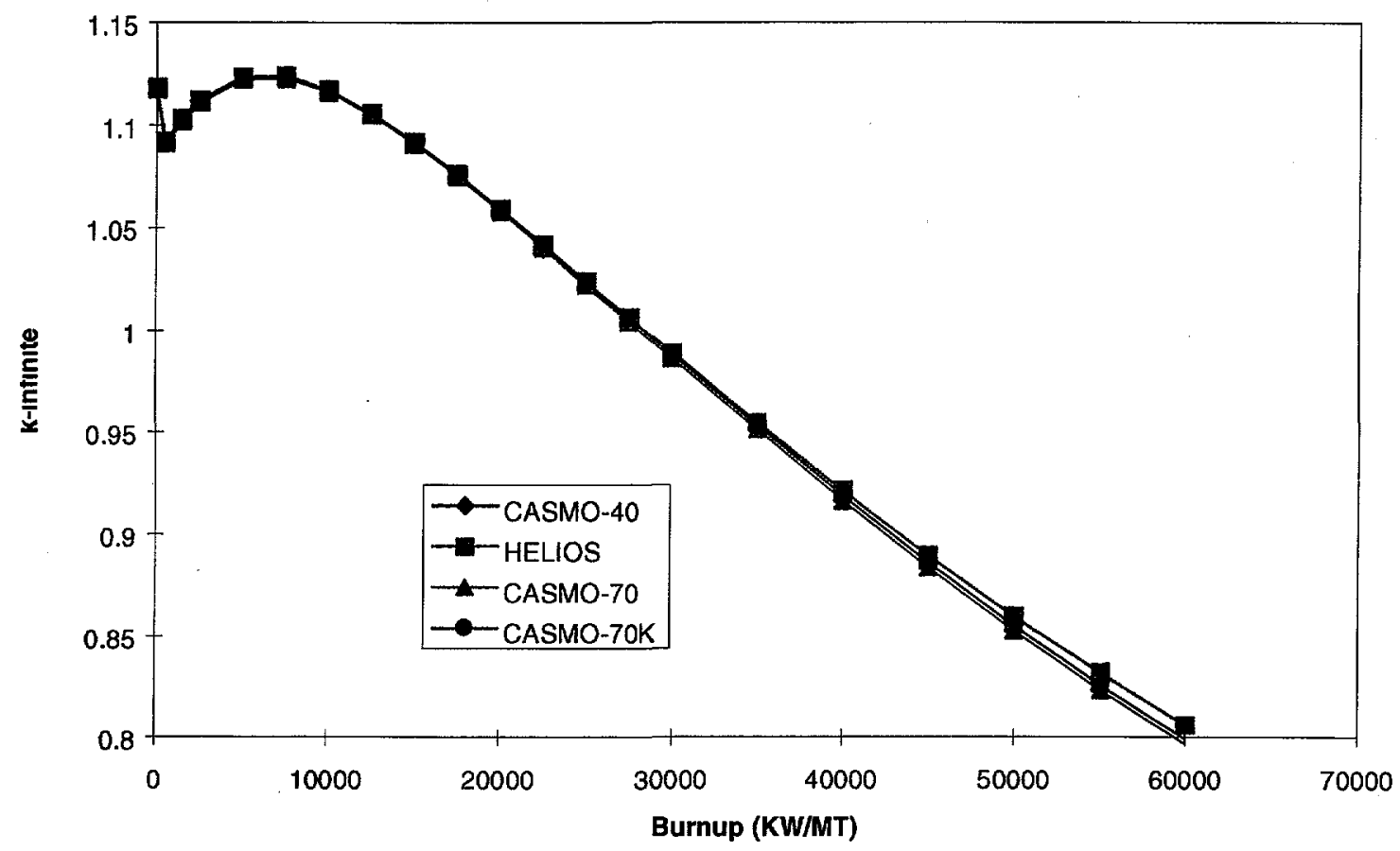

Figure 2.a. Behavior of multiplication factor for the $\mathrm{UO}_{2}$ assembly.

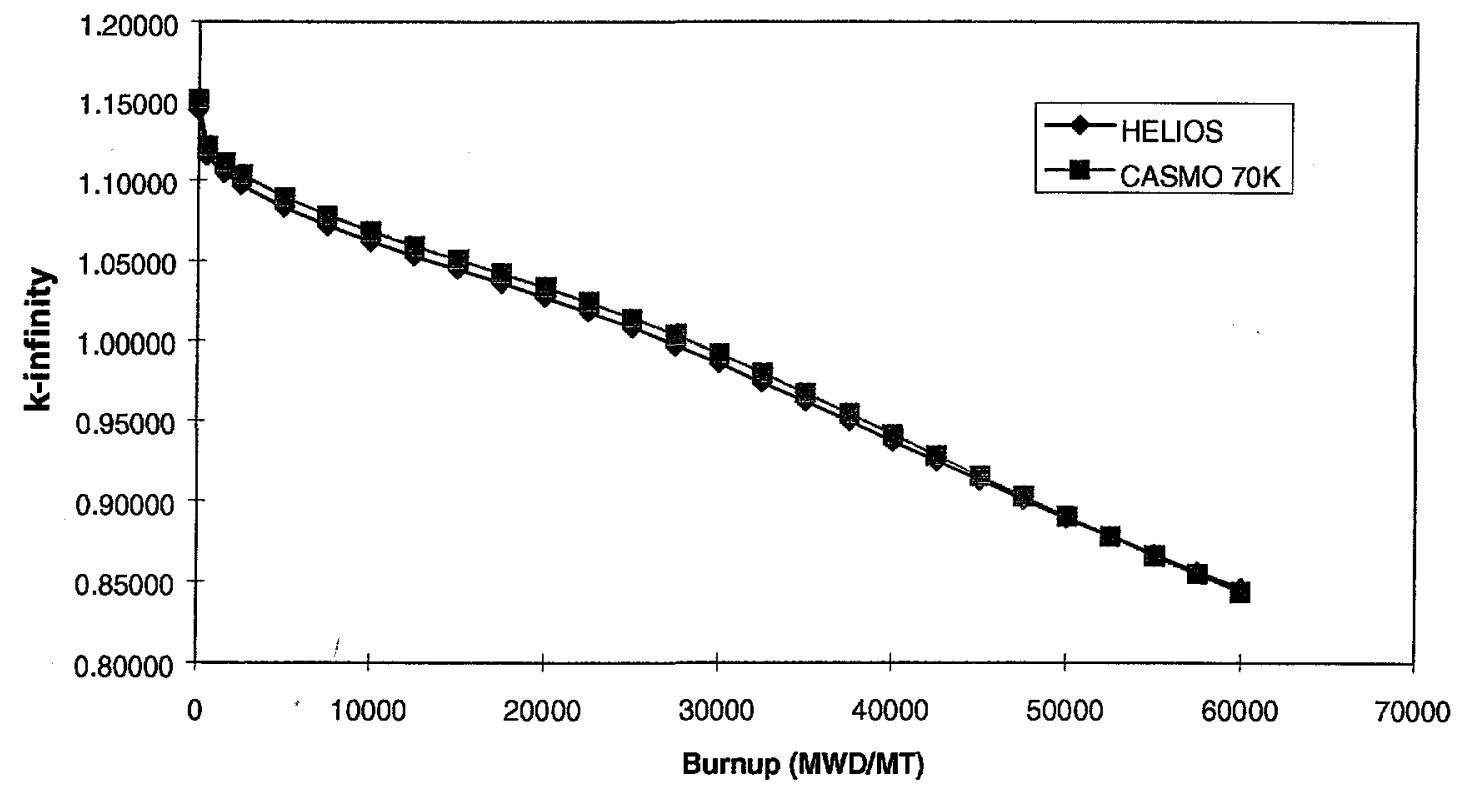

Figure 2.b. Behavior of multiplication factor for the MOX assembly. 
The results from the pure ${ }^{239} \mathrm{Pu}$ case were as expected, showing the same trends as in the original weapons-grade MOX runs. These results are given in the Table IV.

Table IV. k-infinity results with pure ${ }^{239} \mathrm{Pu}$.

\begin{tabular}{|c|c|c|c|}
\hline Burnup (GWD/MT) & HELIOS & CASMO & Difference \\
\hline 0 & 1.14254 & 1.14992 & 0.00738 \\
\hline 40 & 0.93781 & 0.94202 & 0.00421 \\
\hline 50 & 0.88993 & 0.89097 & 0.00104 \\
\hline 60 & 0.84635 & 0.84406 & -0.00229 \\
\hline
\end{tabular}

If we compare the MOX results from Table III against Table IV, we see that the differences between the two codes have the same sign but smaller magnitude. On the other hand, there is a very different trend for the ${ }^{241} \mathrm{Pu}$ case. This is shown in Table V. At BOC there is a very large difference $(2000 \mathrm{pcm})$ between the two codes, with a different sign than in the pure ${ }^{239} \mathrm{Pu}$ case. That is, the CASMO library appears to have slightly more reactive ${ }^{239} \mathrm{Pu}$ and considerably less reactive ${ }^{241} \mathrm{Pu}$ than the HELIOS library.

Table V. K-infinity results with pure ${ }^{241} \mathrm{Pu}$.

\begin{tabular}{|c|c|c|c|}
\hline $\mathrm{Bu}(\mathrm{GWD} / \mathrm{MT})$ & HELIOS & CASMO & Difference \\
\hline 0 & 1.44485 & 1.42466 & -0.02019 \\
\hline 40 & 0.88829 & 0.87289 & -0.01426 \\
\hline 50 & 0.79332 & 0.77625 & -0.01707 \\
\hline 60 & 0.74200 & 0.72660 & -0.01520 \\
\hline
\end{tabular}

The results shown in Table V help to explain why the difference between the CASMO and HELIOS results changes sign in the other two cases. When almost pure ${ }^{239} \mathrm{Pu}$ is present at $\mathrm{BOC}$, then ${ }^{240} \mathrm{Pu}$ and ${ }^{241} \mathrm{Pu}$ will build up over time. At high burnup, much of the reactivity is due to the ${ }^{241} \mathrm{Pu}$, which explains why the CASMO k-infinity drops below that of HELIOS.

Moving forward in the comparison of results coming from these two codes, we encountered an unforeseen difficulty, namely a considerable disagreement between the Moderator Temperature Coefficient (MTC) predicted by HELIOS and the MTC predicted by CASMO-3, for a simple Low-Enriched Uranium (LEU) assembly.

We ran HELIOS for a base case and five branch cases for a Westinghouse LEU assembly with no control rods and no burnable absorbers. The key parameters for the base and branch cases are shown in Table VI below.

Table VI. Parameters of Base and Branch Cases

\begin{tabular}{|c|c|c|c|c|c|c|}
\hline Case & Base & Branch 1 & Branch 2 & Branch 3 & Branch 4 & Branch 5 \\
\hline Fuel Temp (K) & $\mathbf{9 6 3}$ & $\mathbf{5 8 2 . 9 5}$ & 963 & 963 & 963 & 963 \\
\hline Mod. Temp (K) & $\mathbf{5 8 2 . 9 5}$ & 582.95 & $\mathbf{5 9 9 . 3 2}$ & $\mathbf{5 6 4 . 5 9}$ & 582.95 & $\mathbf{5 8 2 . 9 5}$ \\
\hline Boron Conc. (ppm) & $\mathbf{1 0 0 0}$ & 1000 & 1000 & 1000 & $\mathbf{2 0 0 0}$ & $\mathbf{0}$ \\
\hline
\end{tabular}

In Table VII below we present, for each branch at each depletion step, the ratio of the HELIOS $k_{\text {base }} k_{\text {branch }}$ to the CASMO-3 prediction of the same $\Delta k$. These $\Delta k$ 's are approximately proportional to various reactivity coefficients. The base cases agree reasonably well between the two codes. We see that the fuel temperature coefficients from the two codes agree within a few percent except for a $9 \%$ outlier at 5 GWD/MT. The boron worth, despite being computed over fairly large changes in boron concentration, is in similarly good agreement.

The two codes seem to disagree significantly, however, on Moderator Temperature Coefficients (MTC). To determine the source of this disagreement we looked beyond $\mathrm{k}$-infinity and studied the two-group assemblyaveraged cross sections. There are two reasons for this. First, there is a tight connection between k-infinity and the cross sections; studying the latter might help us understand the differences in the former. Second, these cross 
sections-not k-infinity-are the quantities that would be used later in the full-core analysis. Results are shown in Tables VIII and IX. (The ratio of changes in downscattering cross section is not shown; the ratios were in all cases between 0.99 and 1.00.)

Table VII. Ratio of branch $\Delta k^{\prime}$ s: $\Delta k_{\text {HELIOS }} / \Delta k_{\text {CASMO }}$.

\begin{tabular}{|c|c|c|c|c|c|}
\hline $\begin{array}{c}\text { Exposure } \\
\text { (GWD/MT) }\end{array}$ & $\begin{array}{c}\text { Branch 1 } \\
\left(\text { High } T_{F}\right)\end{array}$ & $\begin{array}{c}\text { Branch } 2 \\
\left(\text { High } T_{M}\right)\end{array}$ & $\begin{array}{l}\text { Branch } 3 \\
\left.\text { (Low } T_{M}\right)\end{array}$ & $\begin{array}{l}\text { Branch } 4 \\
\text { (High B) }\end{array}$ & $\begin{array}{l}\text { Branch } 5 \\
\text { (Low B) } \\
\end{array}$ \\
\hline 0 & 1.0297 & 1.5935 & 1.9782 & 0.9906 & 0.9611 \\
\hline 5 & 1.0903 & 1.2353 & 5.2727 & 0.9825 & 0.9877 \\
\hline 10 & 1.0376 & 1.3938 & 1.6163 & 0.9849 & 0.9819 \\
\hline 20 & 1.0123 & 1.3597 & 1.2647 & 0.9843 & 0.9754 \\
\hline 30 & 1.0097 & 1.4469 & 1.2296 & 0.9849 & 0.9718 \\
\hline 40 & 0.9686 & 1.7746 & 0.8415 & 0.9928 & 0.9647 \\
\hline 50 & 1.0057 & 1.9372 & 1.7917 & 0.9910 & 0.9669 \\
\hline 60 & 1.0758 & 2.1935 & -1.7037 & 0.9862 & 0.9723 \\
\hline
\end{tabular}

Table VIII. Ratio of branch $\Delta \Sigma$ 's and $\Delta k$ for High Moderator Temperature Branch: $\Delta x_{\text {HELIOS }} / \Delta x_{\text {CASMO }}$

\begin{tabular}{|c|c|c|c|c|c|}
\hline $\mathrm{Bu}$ & Abs-1 & Abs-2 & nufiss-1 & nufiss-2 & k-inf \\
\hline 0 & 0.97 & 0.98 & 0.94 & 0.98 & 1.47 \\
\hline 5 & 0.98 & 0.98 & 0.98 & 0.95 & 1.04 \\
\hline 10 & 0.99 & 0.98 & 1.00 & 0.96 & 1.23 \\
\hline 20 & 0.98 & 0.97 & 1.00 & 0.93 & 1.28 \\
\hline 30 & 1.01 & 0.96 & 0.98 & 0.89 & 1.30 \\
\hline 40 & 1.04 & 0.95 & 0.99 & 0.74 & 1.61 \\
\hline 50 & 1.04 & 0.95 & 0.99 & 0.50 & 1.77 \\
\hline 60 & 1.03 & 0.98 & 0.99 & 0.82 & 2.03 \\
\hline
\end{tabular}

Table IX. Ratio of branch $\Delta \Sigma$ 's and $\Delta k$ for Low Moderator Temperature Branch: $\Delta x_{\text {HELIOS }} / \Delta x_{\text {CASMO }}$.

\begin{tabular}{|c|c|c|c|c|c|}
\hline $\mathrm{Bu}$ & Abs-1 & Abs-2 & nufiss-1 & nufiss-2 & k-inf \\
\hline 0 & 0.97 & 0.99 & 0.91 & 0.96 & 1.9574 \\
\hline 5 & 0.97 & 0.99 & 0.95 & 0.96 & 4.9200 \\
\hline 10 & 0.98 & 0.98 & 1.00 & 0.94 & 1.6477 \\
\hline 20 & 0.96 & 0.98 & 0.97 & 0.92 & 1.3043 \\
\hline 30 & 0.95 & 0.97 & 0.95 & 0.88 & 1.3488 \\
\hline 40 & 0.94 & 0.97 & 0.96 & 0.89 & 1.0494 \\
\hline 50 & 0.94 & 0.96 & 0.96 & 0.20 & 3.0526 \\
\hline 60 & 0.95 & 0.94 & 0.96 & 1.60 & -1.6667 \\
\hline
\end{tabular}

Two things stand out in Tables VIII and IX. First, the two codes agree far more closely on the change in each cross section than they do on the change in k-infinity. For example, in some cases the codes agree within $6 \%$ on the change in each cross section, but differ by $>60 \%$ on the change in k-infinity. This seems somewhat contradictory at first, and led us to investigate further the relationship between changes in the cross sections and changes in kinfinity, as we shall discuss below. Second, there appears to be significant disagreement between the codes on the change in the group-2 $v \Sigma_{f}$ at high burnups. We shall discuss this disagreement first.

Table $\mathrm{X}$ shows the behavior of the relative change in fission cross sections $(\Delta \Sigma / \Sigma)$ for both codes and for high and low moderator temperature branches. A careful examination shows that at high burnups, where Tables VIII and IX showed that the ratio of the $\Delta v \Sigma_{f 2}$ 's from the two codes is large, this ratio is approximately $0 / 0$, because the change 
in the cross section is very small (and in fact changes sign, passing through zero). Thus, we conclude that the two codes are actually calculating the changes in the two-group homogenized cross sections, as functions of changes in moderator temperature, remarkably consistently.

Table X. Cross sections changes for the Moderator-Temperature Branch cases.

\begin{tabular}{|c|c|c|c|c|c|c|c|c|}
\hline & \multirow{2}{*}{\multicolumn{4}{|c|}{$\frac{\text { Moderator (base-branch)/base }}{\text { nufiss2 }}$}} & \multicolumn{4}{|c|}{ moderator (base-branch)/base } \\
\hline & & & & & \multicolumn{4}{|c|}{ nufiss1 } \\
\hline & CASMO & nufiss2 & \multicolumn{2}{|c|}{ HELIOS } & \multicolumn{2}{|c|}{ CASMO } & \multicolumn{2}{|c|}{ HELIOS } \\
\hline $\mathrm{Bu}$ & $\mathrm{MH}$ & $\mathrm{ML}$ & $\mathrm{MH}$ & $\mathrm{ML}$ & $\mathrm{MH}$ & ML & $\overline{\mathrm{MH}}$ & $\mathrm{ML}$ \\
\hline 0 & 0.013809 & -0.014267 & 0.013298 & -0.013556 & 0.007617 & -0.006525 & 0.007252 & -0.006017 \\
\hline 5 & 0.010387 & -0.010700 & 0.009752 & -0.010185 & 0.007398 & -0.006319 & 0.007294 & -0.006055 \\
\hline 10 & 0.008288 & -0.008721 & 0.007805 & -0.008049 & 0.007273 & -0.006090 & 0.007331 & -0.006085 \\
\hline 20 & 0.005654 & -0.005847 & 0.005183 & -0.005309 & 0.007514 & -0.006424 & 0.007491 & -0.006223 \\
\hline 30 & 0.003746 & -0.003885 & 0.003263 & -0.003331 & 0.007949 & -0.006813 & 0.007730 & -0.006436 \\
\hline 40 & 0.002056 & -0.002056 & 0.001487 & -0.001784 & 0.008156 & -0.007042 & 0.008065 & -0.006738 \\
\hline 50 & 0.000506 & -0.000422 & 0.000245 & -0.000082 & 0.008622 & -0.007422 & 0.008460 & -0.007093 \\
\hline 60 & -0.001023 & 0.000930 & -0.000804 & 0.001430 & 0.009084 & -0.007783 & 0.008888 & -0.007411 \\
\hline
\end{tabular}

The next question is why the ratios of the $\Delta \mathrm{k}$ 's are so large when the changes in two-group cross sections are so small. Table $X$, which shows the actual relative cross-section changes $(\Delta \Sigma / \Sigma)$ for each code, offers a possible explanation for the discrepancies at late burnups. Note that the change in the group-2 fission cross section is very small at late burnups. Note further that each $\mathrm{k}$ calculation is iterative and that each code converges this iteration only to some pre-set tolerance. This iteration is on the k-eigenvalue itself as well as the scalar flux, and typically the fluxes are not converged as tightly as $\mathrm{k}$. Because the cross sections come from the scalar fluxes that are generated during this iterative process, it follows that if the iteration is not converged tightly, the cross sections will not have many digits of precision. A small difference of two such numbers will of course be imprecise. This appears to be a likely cause for the large discrepancies in the two codes' $\Delta k$ 's at late burnups.

However, because the changes in $\Delta v \Sigma_{f 2}$ at earlier burnups are large enough to have some significant digits, the above argument does not seem to explain the large $\Delta k_{\infty}$ ratio at those small burnups. To explore the reasons for this, we explored the relationship between $k$ and the two-group cross sections. We found that if power iteration is used for the fine-group assembly-level k-eigenvalue calculation, and standard homogenization techniques are used for the two-group assembly-averaged cross sections, then there is a simple and direct relationship between the $\mathrm{k}$-eigenvalue and the two-group cross sections, regardless of how tightly the eigenvalue calculation is converged. Details are in Appendix A; Eq. (8) from that appendix shows the relationship between the k-infinity at the end of any iteration and the two-group homogenized cross sections:

$$
k^{(n+1)}=\frac{\overline{v \Sigma}_{f 1} \Phi_{1}+\overline{v \Sigma}_{f 2} \frac{\bar{\Sigma}_{1 \rightarrow 2}^{\text {net }}}{\bar{\Sigma}_{a 2}} \Phi_{1}}{\left[\bar{\Sigma}_{a 1}+\left(\bar{\Sigma}_{1 \rightarrow 2}-\bar{\Sigma}_{2 \rightarrow 1} \frac{\Phi_{2}}{\Phi_{1}}\right)\right] \Phi_{1}}=\frac{\overline{v \Sigma}_{f 1}}{\bar{\Sigma}_{a 1}+\bar{\Sigma}_{1 \rightarrow 2}^{\text {net }}}+\frac{\bar{\Sigma}_{1 \rightarrow 2}^{\text {net }}}{\bar{\Sigma}_{a 1}+\bar{\Sigma}_{1 \rightarrow 2}^{\text {net }}} \frac{\overline{v \Sigma}_{f 2}}{\bar{\Sigma}_{a 2}}=\frac{\overline{v \Sigma}_{f 1}}{\bar{\Sigma}_{r 1}}+\frac{\bar{\Sigma}_{1 \rightarrow 2}^{\text {net }}}{\bar{\Sigma}_{r 1}} \frac{\overline{v \Sigma}_{f 2}}{\bar{\Sigma}_{a 2}} .
$$

We recognize that this result rests on some assumptions that are somewhat questionable. First, it assumes that power iteration is used as shown in Appendix A; in truth, CASMO and HELIOS do deviate somewhat from this "pure" power iteration. Second, both codes actually compute their k-infinities from a calculation that is performed after the two-dimensional transport $\mathrm{k}$-eigenvalue calculation; this computation uses the two-group constants as input. Nevertheless, Appendix A is useful in that it shows the relationship in question in the limit that the codes' results approach the result of power iteration on the two-dimensional transport equation. To test whether the $k_{\infty}$ 's reported by the two codes are in fact close to this limit, we employed Eq. (8) to calculate "two-group $k$ " values and compared them against the reported $\mathrm{k}$-infinity values. The results, taken from a typical LEU assembly, are shown in Table XI. Note that the CASMO results are reasonably self-consistent but the HELIOS ones are not. 
Table XI. Reported $k$ 's, 2-Group $k$ 's, and their differences.

\begin{tabular}{|l|lll|lll|}
\hline & HELIOS & & & CASMO & & \\
\cline { 2 - 7 } Burnup & reported $k$ & 2-Group $k$ & 2G-report & Reported $k$ & 2-Group $k$ & 2G-report \\
\hline 0 & 1.13803 & 1.14054 & $\mathbf{- 0 . 0 0 2 5 1}$ & 1.13884 & 1.13842 & $\mathbf{0 . 0 0 0 4 2}$ \\
5 & 1.13813 & 1.14140 & $\mathbf{- 0 . 0 0 3 2 7}$ & 1.13827 & 1.13785 & $\mathbf{0 . 0 0 0 4 2}$ \\
10 & 1.13219 & 1.13546 & $\mathbf{- 0 . 0 0 3 2 7}$ & 1.13213 & 1.13171 & $\mathbf{0 . 0 0 0 4 2}$ \\
20 & 1.07706 & 1.08051 & $\mathbf{- 0 . 0 0 3 4 5}$ & 1.07705 & 1.07688 & $\mathbf{0 . 0 0 0 1 7}$ \\
30 & 1.00787 & 1.01142 & $\mathbf{- 0 . 0 0 3 5 5}$ & 1.00782 & 1.00781 & $\mathbf{0 . 0 0 0 0 1}$ \\
40 & 0.93993 & 0.94285 & $\mathbf{- 0 . 0 0 2 9 2}$ & 0.93938 & 0.93937 & $\mathbf{0 . 0 0 0 0 1}$ \\
50 & 0.87600 & 0.87880 & $\mathbf{- 0 . 0 0 2 7 9}$ & 0.87432 & 0.87416 & $\mathbf{0 . 0 0 0 1 6}$ \\
60 & 0.81893 & 0.82184 & $\mathbf{- 0 . 0 0 2 9 1}$ & 0.81618 & 0.81575 & $\mathbf{0 . 0 0 0 4 3}$ \\
\hline
\end{tabular}

After some investigation we found that the source of the HELIOS inconsistency is that the downscattering cross section it reports is not corrected [as in Eq. (7) of Appendix A] to be a net quantity. [The CASMO downscattering cross section is corrected as in Eq. (7).] It is possible to give ZENITH instructions to correct this cross section; the TAMU team developed and tested an input file that does this. After this correction, the HELIOS "two-group $k$ " is brought into reasonable agreement with the reported $k$, as shown in Table XII.

Table XII. Reported $k$ 's, 2-Group $k$ 's, and their differences, with corrected net downscattering.

\begin{tabular}{|l|llr|llc|}
\hline & HELIOS & & & CASMO & \\
\cline { 2 - 6 } Burnup & reported $k$ & 2-Group $k$ & 2G-report & Reported $k$ & 2-Group $k$ & 2G-report \\
\hline 0 & 1.13803 & 1.13766 & $\mathbf{0 . 0 0 0 3 7}$ & 1.13884 & 1.13842 & $\mathbf{0 . 0 0 0 4 2}$ \\
5 & 1.13813 & 1.13832 & $\mathbf{- 0 . 0 0 0 1 9}$ & 1.13827 & 1.13785 & $\mathbf{0 . 0 0 0 4 2}$ \\
10 & 1.13219 & 1.13206 & $\mathbf{0 . 0 0 0 1 3}$ & 1.13213 & 1.13171 & $\mathbf{0 . 0 0 0 4 2}$ \\
20 & 1.07706 & 1.07682 & $\mathbf{0 . 0 0 0 2 4}$ & 1.07705 & 1.07688 & $\mathbf{0 . 0 0 0 1 7}$ \\
30 & 1.00787 & 1.00765 & $\mathbf{0 . 0 0 0 2 2}$ & 1.00782 & 1.00781 & $\mathbf{0 . 0 0 0 0 1}$ \\
40 & 0.93993 & 0.93909 & $\mathbf{0 . 0 0 0 8 4}$ & 0.93938 & 0.93937 & $\mathbf{0 . 0 0 0 0 1}$ \\
50 & 0.87600 & 0.87508 & $\mathbf{0 . 0 0 0 9 2}$ & 0.87432 & 0.87416 & $\mathbf{0 . 0 0 0 1 6}$ \\
60 & 0.81893 & 0.81821 & $\mathbf{0 . 0 0 0 7 2}$ & 0.81618 & 0.81575 & $\mathbf{0 . 0 0 0 4 3}$ \\
\hline
\end{tabular}

Thus, this exercise has shown that HELIOS users must take care to instruct ZENITH to output a net downscattering cross section, unless the global two-group diffusion code will itself explicitly calculate upscattering. Without this correction, the reactivity of the assemblies in the global calculation would be artificially high by a few hundred pcm, as shown in the fourth column of Table XI, which could lead to significant systematic errors in the prediction of cycle length.

Another significant point is that if HELIOS and CASMO disagree on MTC, then global calculations using the two codes' cross section tables will also disagree on MTC. This follows from the consistency between the twogroup cross sections (which the global code uses to calculate $k$ 's) and $k$ 's reported by HELIOS and CASMO, from which their MTC estimates are computed.

The next task was to consider a branch case, in which there is a base $k$ calculation and then another $k$ calculation for a different ("branch") state of the assembly. Our first aim was to determine the relationship between the change in $k$ and the change in the two-group cross sections. Equation (8) of Appendix A makes this a relatively simple task, although the algebraic details are somewhat tedious. These algebraic details are shown in the second section of Appendix A. The final result is that for a given branch, the ratio of $\Delta k$ 's from the two codes depends upon ratios of combinations of relative changes and also upon ratios of base-case quantities. Some of these combinations are actually differences of differences in cross sections. This leaves open the interesting possibility that the ratio of MTCs computed by the two codes can be much different than the ratio of the change in any cross section, even though (as we showed above) each $k$ depends in a simple and direct way upon the two-group cross sections. In 
Appendix A we use our derived expression to show that in fact this is what is happening in our comparisons. In other words, we now understand the mathematical reason that the two codes can agree closely on changes in the two-group constants while disagreeing on changes in $\mathbf{k}$. The origin of this apparent contradiction is not related to iterative convergence, to errors in the codes, or to errors in input.

In summary, once the work described in this section (and Appendix A) was completed, we were confident that we understood how to properly use HELIOS to generate the desired cross section tables, and we were confident that the results would be reasonable.

On final check that we made compared the HELIOS 34-group and 89-group libraries. (ORNL researchers had discovered significant discrepancies between MOX results with the two libraries.) In Figure 3 and Table XIII we show k-infinities from four HELIOS runs: an LEU assembly and a MOX assembly, using the two different group structures for each. We see that the differences are small for the LEU assembly, but uncomfortably large for the MOX. We therefore decided that all MOX cross section tables to be given to NCSU would be generated using the 89-group library, and all LEU tables using the 34-group library.

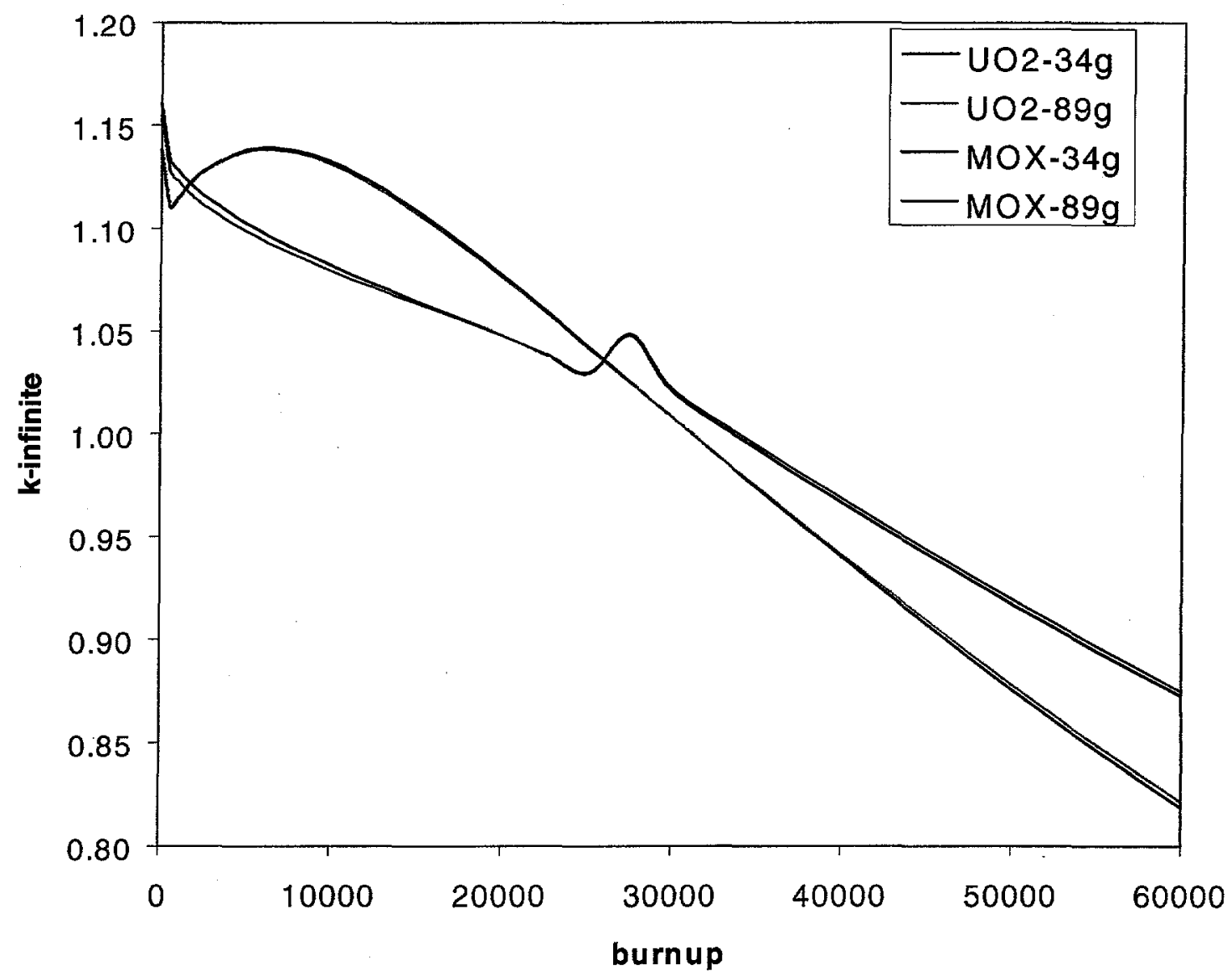

Figure 3. MOX and LEU results from HELIOS with different numbers of energy groups. 
Table XIII. Comparison k-infinity given by HELIOS with different group libraries.

\begin{tabular}{|l|l|l|l|l|l|l|}
\hline & $\mathrm{UO}_{2} 4.5$ w/O with 128 IFBA & \multicolumn{3}{|l|}{ MOX 4.5 w/O with 24 WABA } \\
\hline Burnup & $34 \mathrm{groups}$ & 89 groups & $\%$ of difference & 34 groups & $89 \mathrm{groups}$ & $\%$ of difference \\
\hline 0 & 1.13803 & 1.13734 & 0.060668 & 1.16063 & 1.15482 & 0.503109 \\
\hline 500 & 1.11116 & 1.11060 & 0.050423 & 1.13392 & 1.12830 & 0.498094 \\
\hline 1000 & 1.11524 & 1.11478 & 0.041264 & 1.12817 & 1.12272 & 0.485428 \\
\hline 1500 & 1.12006 & 1.11964 & 0.037512 & 1.12359 & 1.11830 & 0.473039 \\
\hline 2500 & 1.12813 & 1.12770 & 0.038131 & 1.11630 & 1.11134 & 0.446308 \\
\hline 5000 & 1.13813 & 1.13740 & 0.064181 & 1.10266 & 1.09860 & 0.369561 \\
\hline 7500 & 1.13840 & 1.13738 & 0.089680 & 1.09146 & 1.08825 & 0.294969 \\
\hline 10000 & 1.13219 & 1.13098 & 0.106987 & 1.08175 & 1.07929 & 0.227928 \\
\hline 12500 & 1.12171 & 1.12041 & 0.116029 & 1.07292 & 1.07116 & 0.164308 \\
\hline 15000 & 1.10843 & 1.10713 & 0.117421 & 1.06456 & 1.06340 & 0.109084 \\
\hline 17500 & 1.09332 & 1.09211 & 0.110795 & 1.05629 & 1.05568 & 0.057783 \\
\hline 20000 & 1.07706 & 1.07599 & 0.099443 & 1.04779 & 1.04765 & 0.013363 \\
\hline 22500 & 1.06013 & 1.05926 & 0.082133 & 1.03887 & 1.03913 & -0.025021 \\
\hline 25000 & 1.04283 & 1.04219 & 0.061409 & 1.02941 & 1.03002 & -0.059222 \\
\hline 27500 & 1.02536 & 1.02498 & 0.037074 & 1.04821 & 1.04877 & -0.053396 \\
\hline 30000 & 1.00787 & 1.00776 & 0.010915 & 1.02028 & 1.02151 & -0.120410 \\
\hline 35000 & 0.97362 & 0.97412 & -0.051328 & 0.99266 & 0.99433 & -0.167952 \\
\hline 40000 & 0.93993 & 0.94105 & -0.119016 & 0.96636 & 0.96833 & -0.203443 \\
\hline 45000 & 0.90728 & 0.90894 & -0.182630 & 0.94129 & 0.94343 & -0.226832 \\
\hline 50000 & 0.87600 & 0.87815 & -0.244833 & 0.91737 & 0.91962 & -0.244666 \\
\hline 55000 & 0.84644 & 0.84900 & -0.301531 & 0.89453 & 0.89682 & -0.255347 \\
\hline 60000 & 0.81893 & 0.82177 & -0.345595 & 0.87283 & 0.87512 & -0.261678 \\
\hline
\end{tabular}

\section{III.B. HELIOS/ZENITH Results}

After we were confident in our proper use of the code and in its ability to deliver reasonable cross sections, we applied it to the assemblies listed in Table I to generate a large collection of cross-section files. These files were passed along to NCSU for use in full-core modeling.

All non-proprietary details of our geometric models are documented in our HELIOS input files, which are available electronically. We present some sample files in Appendices B, C, and D. Each assembly was a standard 17x17 array of pins of standard Westinghouse diameter and pitch. We employed both WABA and IFBA burnable absorbers, as shown in Table I. We used boron enriched to $40 \%$ in the coolant, but natural enrichment $(19.6 \%)$ in the burnable absorbers. Central instrumentation tubes were filled with water.

HELIOS does not generate cross section files directly; its output is post-processed by the ZENITH code, whose output files constitute the two-group cross section libraries. We used the following naming convention for MOX files:

where:

zmXwY89gZ.out ,

$$
\begin{array}{ll}
\mathrm{X}=\text { enrichment } & =\mathrm{h} \text { or } 1 \text { for high }(4.5 \mathrm{w} / \mathrm{o} \text { fissile) or low }(4.0 \mathrm{w} / \mathrm{o} \text { fissile }) \\
\mathrm{Y}=\text { number of WABA rods } & =\mathrm{h} \text { or } 1 \text { or } \mathrm{n} \text { for } 24 \text { or } 12 \text { or none, } \\
\mathrm{Z}=\text { case (branch) number } & =1,2, \ldots, 6
\end{array}
$$

We use the following convention for uranium files: where:

\section{ZuXYiZ.out ,}




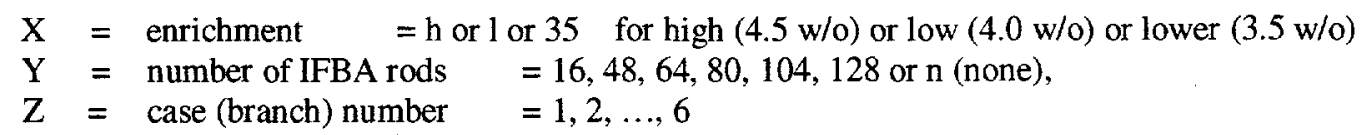

We use the following convention for baffle/reflector files:

zmhwhrefZ.out ,

where:

$\mathrm{Z}=$ case (branch) number $=1,2, \ldots, 5$

Appendix E shows a ZENITH input file for a fuel assembly, and Appendix F contains a ZENITH file that produces cross sections for the reflector + baffle region.

\section{References}

1. J. J. Cassal et al, "HELIOS: Geometric Capability of a New Fuel-Assembly Program," Proc. Int. Topl. Mtg. Advances in Mathematics, Computations, and Reactor Physics, Pittsburgh, Pennsylvania, April 28-May 2, 1991, p. 10.21-1 (1991).

2. E. A. Villarino, R. J. J. Stamm'ler, A. A. Ferri and J.J. Casal, "HELIOS: Angularly Dependent Collision Probabilities," Nucl. Sci. Eng. 112, 16-31 (1992).

3. I. Ariani and P. J. Turinsky, "Evaluation of Mixed LEU-MOX Loading Patterns for LWRs Originating from the Inability to deliver MOX Assemblies (Westinghouse Reload Core Study)," ORNL/SUB/99-19XSY063V2 (1999).

4. M. Edenius, K. S. Smith, and D. Ver Plank, "New Data and Methods for CASMO and SIMULATE," Proc. Topl. Mtg. Advances in Reactor Physics and Safety, Saratoga Springs, New York, September 17-19, Vol. 2, p. 1115 (1986). Published by U.S. Nuclear Regulatory Commission.

5. A. Ferri, "Generation and Contents of the ENDF/B-VI based HELIOS Library hy941a," Scandpower Technical Note TN2/44.70.13, 22 Nov. (1994).

6. P. F. Rose, "ENDF-201 ENDF/B-VI Summary Documentation," BNL-NCS-17541 (1992).

7. K. S. Smith, private communication. (1997).

8. A. A. Alsaed, "Disposition of Weapons-Grade Plutonium in Westinghouse Reactors," MS Thesis, Department of Nuclear Engineering, Texas A\&M University (1996). See also A. A. Alsaed and M. L. Adams, "Disposition of Weapons-Grade Plutonium in Westinghouse Reactors," Amarillo National Resource Center Technical Report ANRCP-1998-1 (1998).

9. "Implementation of Weapons Grade MOX Fuel in Existing Pressurized Water Reactors," DOE/SF/19683-7 (1996). 


\section{Appendix A: Relationship between $k$ and homogenized 2-group constants.}

We begin with the equations that are used in an assembly-level transport calculation. If power iteration is used for the fine-group eigenvalue calculation, then:

$$
\begin{aligned}
& \int_{\partial A} \hat{n} \cdot \vec{J}_{g}^{(n+1)}(\vec{r}) d^{2} r+\int_{A}\left[\Sigma_{a, g}(\vec{r})+\sum_{g^{\prime} \neq g} \Sigma_{s, g \rightarrow g^{\prime}}(\vec{r})\right] \phi_{g}^{(n+1)}(\vec{r}) d^{3} r \\
& \left.=\iint_{A} \sum_{g^{\prime} \neq g} \Sigma_{s, g^{\prime} \rightarrow g}(\vec{r}) \phi_{g^{\prime}}^{(n+1)}(\vec{r})+\frac{1}{k^{(n)}} \chi_{g} \sum_{g^{\prime}} v \Sigma_{f, g^{\prime}}(\vec{r}) \phi_{g}^{(n)}(\vec{r})\right\} d^{3} r, g=1, \ldots, G,
\end{aligned}
$$

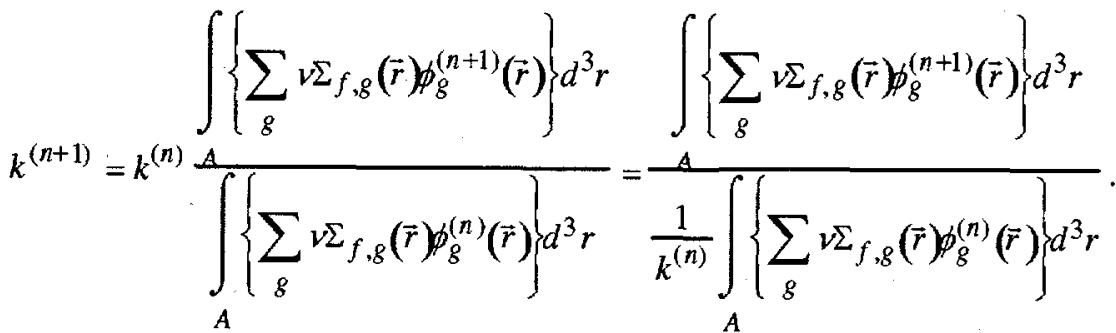

Here the integrals over $A$ are over the assembly volume, and the integral over $\partial A$ is over the assembly surface. The parenthetical superscript represents iteration index. Each surface is treated as a reflecting boundary; in many methods this reflection is enforced for each group at each iteration, making the surface term in Eq. (1a) zero. (This will often depend on how tightly the code converges its within-group iteration.) Equations (1) contain integrals and a continuous spatial variable $r$, but this is simply a notational convenience. In the actual calculation spatial quantities are discretized; nevertheless, they satisfy a form of Eqs. (1) in which spatial integrals are represented as sums of products of spatial-cell volumes times cell-averaged quantities.

If Eq. (1a) is summed over all "fast" groups the result is:

$$
\begin{aligned}
& \int_{\text {fast } g}\left[\Sigma_{a, g}(\vec{r})+\sum_{g^{\prime} \neq g} \Sigma_{s, g \rightarrow g^{\prime}}(\vec{r})\right] \phi_{g}^{(n+1)}(r) d^{3} r \\
& =\int\left\{\sum_{\text {fast }} \sum_{g^{\prime} \neq g} \Sigma_{s, g^{\prime} \rightarrow g}(\vec{r}) \phi_{g}^{(n+1)}(\vec{r})+\frac{1}{k^{(n)}} \sum_{\text {fast } g} x_{g} \sum_{g^{\prime}} v \Sigma_{f, g^{\prime}}(\vec{r}) \phi_{g^{\prime}}^{(n)}(\vec{r})\right\} d^{3} r .
\end{aligned}
$$

Many of the scattering terms now cancel from the right and left sides of the equation; the only ones remaining are those that involve scattering between "fast" and "thermal" groups:

$$
\begin{aligned}
& \int_{\text {fast } g}\left[\Sigma_{a, g}(\vec{r})+\sum_{\text {thermal } g^{\prime}} \Sigma_{s, g \rightarrow g^{\prime}}(\vec{r})\right] \phi_{g}^{(n+1)}(\vec{r}) d^{3} r \\
& =\int\left\{\sum_{\text {fast } g} \sum_{\text {thermal } g^{\prime}} \Sigma_{s, g^{\prime} \rightarrow g}(\vec{r}) \phi_{g^{\prime}}^{(n+1)}(\vec{r})+\frac{1}{k^{(n)}} \sum_{\text {fast } g} \chi_{g} \sum_{g^{\prime}} v \Sigma_{f, g^{\prime}}(\vec{r}) \phi_{g}^{(n)}(\vec{r})\right\} d^{3} r .
\end{aligned}
$$


Now we shall assume that $\chi_{g}$ is zero for thermal groups, and thus sums to 1 over the fast groups. Then the "fast" equation becomes:

$$
\begin{aligned}
& \int_{A} \sum_{\text {fast } g}\left[\Sigma_{a, g}(\vec{r})+\sum_{\text {thermal } g^{\prime}} \Sigma_{s \rightarrow g^{\prime}}(\vec{r})\right] \phi_{g}^{(n+1)}(\vec{r}) d^{3} r \\
& =\int_{A}\left\{\sum_{\text {fast } g} \sum_{\text {thermal } g^{\prime}} \Sigma_{s, g^{\prime} \rightarrow g}(\vec{r}) \phi_{g^{\prime}}^{(n+1)}(\vec{r})+\frac{1}{k^{(n)}} \sum_{g^{\prime}} v \Sigma_{f, g^{\prime}}(\vec{r}) \phi_{g^{\prime}}^{(n)}(\vec{r})\right\} d^{3} r .
\end{aligned}
$$

Under the same assumptions, summing Eq. (1a) over all thermal groups yields:

$$
\int_{A} \sum_{\text {thermal } g}\left[\Sigma_{a, g}(\vec{r})+\sum_{\text {fast } g^{\prime}} \Sigma_{s, g \rightarrow g^{\prime}}(\vec{r})\right] \phi_{g}^{(n+1)}(\vec{r}) d^{3} r=\int_{A} \sum_{\text {thermal } g} \sum_{\text {fast } g^{\prime}} \Sigma_{s, g^{\prime} \rightarrow g}(\vec{r}) \phi_{g^{\prime}}^{(n+1)}(\vec{r}) d^{3} r
$$

The second term on the right-hand side of Eq. (3a) is the denominator of the right-hand side of Eq. (1b). Substitute this into Eq. (1b):

$$
k^{(n+1)}=\frac{\int\left\{\sum_{A} v \Sigma_{f, g}(\vec{r}) \phi_{g}^{(n+1)}(\vec{r})\right\} d^{3} r}{\int_{A}\left\{\sum_{\text {fast } g}\left[\Sigma_{a, g}(\vec{r})+\sum_{\text {thermal } g^{\prime}} \Sigma_{s, g \rightarrow g^{\prime}}(\vec{r})\right] \phi_{g}^{(n+1)}(\vec{r})-\sum_{\text {thermal }} \sum_{\text {fast } g^{\prime}} \Sigma_{s, g \rightarrow g^{\prime}}(\vec{r}) \phi_{g}^{(n+1)}(\vec{r})\right\} d^{3} r} .
$$

It is important to note that this equation is satisfied at the end of each iteration, regardless of whether or not the iteration has converged.

Now we recall the standard definitions of assembly-averaged two-group scalar fluxes and cross sections:

$$
\Phi_{1} \equiv \frac{\int \sum_{\text {fast } g} \phi_{g}^{(n+1)}(\vec{r}) d^{3} r}{\int d^{3} r}=\frac{1}{A} \int_{A} \sum_{\text {fast } g} \phi_{g}^{(n+1)}(\vec{r}) d^{3} r
$$

where $A$ is the assembly volume,

$$
\begin{aligned}
\Phi_{2} \equiv & \frac{1}{A} \int_{A} \sum_{\text {thermal } g} \phi_{g}^{(n+1)}(\vec{r}) d^{3} r \\
\bar{\Sigma}_{a 1} \equiv & \frac{\int \sum_{\text {fast } g} \Sigma_{a, g}(\vec{r}) \phi_{g}^{(n+1)}(\vec{r}) d^{3} r}{\int \sum_{A} \phi_{g}^{(n+1)}(\vec{r}) d^{3} r}=\frac{1}{\Phi_{1} A} \int_{A} \sum_{\text {fast } g} \Sigma_{a, g}(\vec{r}) \phi_{g}^{(n+1)}(\vec{r}) d^{3} r,
\end{aligned}
$$




$$
\bar{\Sigma}_{a 2} \equiv \frac{\int \sum_{A} \sum_{a, g}(\vec{r}) \phi_{g}^{(n+1)}(\vec{r}) d^{3} r}{\int_{A} \sum_{\text {thermal } g} \phi_{g}^{(n+1)}(\vec{r}) d^{3} r}=\frac{1}{\Phi_{2} A} \int_{A} \sum_{\text {thermalg }} \Sigma_{a, g}(\vec{r}) \phi_{g}^{(n+1)}(\vec{r}) d^{3} r
$$

with very similar expressions for the average $v \Sigma_{f 1}$ and $v \Sigma_{f 2}$, and finally

$$
\begin{gathered}
\bar{\Sigma}_{1 \rightarrow 2} \equiv \frac{\int \sum_{\text {fast } g} \sum_{\text {thermal } g^{\prime}} \Sigma_{s, g \rightarrow g^{\prime}}(\vec{r}) \phi_{g}^{(n+1)}(\vec{r}) d^{3} r}{\int_{A} \sum_{\text {fast } g} \phi_{g}^{(n+1)}(\vec{r}) d^{3} r}=\frac{1}{\Phi_{1} A} \int \sum_{A} \sum_{\text {fast } g} \sum_{\text {thermal } \Sigma^{\prime}} \sum_{s \rightarrow g^{\prime}}(\vec{r}) \phi_{g}^{(n+1)}(\vec{r}) d^{3} r, \\
\bar{\Sigma}_{2 \rightarrow 1} \equiv \frac{\int_{A} \sum_{\text {thermal g }} \sum_{\text {fast } g^{\prime}} \Sigma_{s, g \rightarrow g^{\prime}}(\vec{r}) \phi_{g}^{(n+1)}(\vec{r}) d^{3} r}{\int_{A} \sum_{\text {thermal } g} \phi_{g}^{(n+1)}(\vec{r}) d^{3} r}=\frac{1}{\Phi_{2} A} \int_{A} \sum_{\text {thermal }} \sum_{g \text { fast } g^{\prime}} \Sigma_{s, g \rightarrow g^{\prime}}(\vec{r}) \phi_{g}^{(n+1)}(\vec{r}) d^{3} r .
\end{gathered}
$$

Now if we use all of this in Eq. (4) we find:

$$
\begin{aligned}
& \int\left\{\sum_{g} v \Sigma_{f, g}(\vec{r}) \phi_{g}^{(n+1)}(\vec{r}) d^{3} r\right.
\end{aligned}
$$

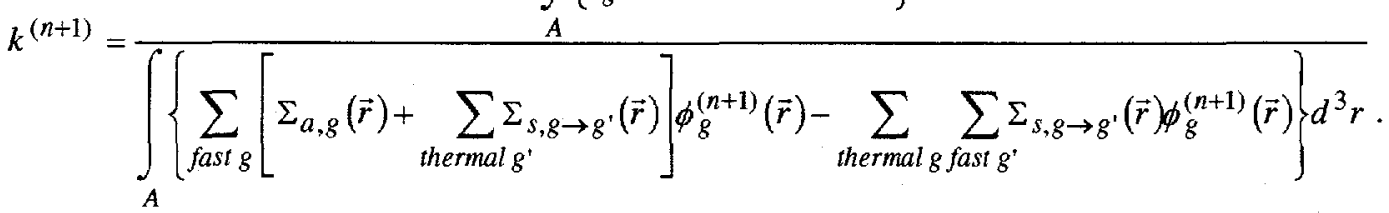

$$
\begin{aligned}
& =\frac{A \overline{v \Sigma}_{f 1} \Phi_{1}+A \overline{v \Sigma}_{f 2} \Phi_{2}}{A\left[\bar{\Sigma}_{a 1}+\bar{\Sigma}_{1 \rightarrow 2}\right] \Phi_{1}-A \bar{\Sigma}_{2 \rightarrow 1} \Phi_{2}}
\end{aligned}
$$

In light of the definitions of assembly-averaged fluxes and cross sections, note now that Eq. ( $3 \mathrm{~b}$ ) becomes:

$$
A\left(\bar{\Sigma}_{a 2}+\bar{\Sigma}_{2 \rightarrow 1}\right) \Phi_{2}=A \bar{\Sigma}_{1 \rightarrow 2} \Phi_{1} \Rightarrow \bar{\Sigma}_{a 2} \Phi_{2}=\left(\bar{\Sigma}_{1 \rightarrow 2}-\bar{\Sigma}_{2 \rightarrow 1} \frac{\Phi_{2}}{\Phi_{1}}\right) \Phi_{1} \Rightarrow \Phi_{2}=\frac{\bar{\Sigma}_{1 \rightarrow 2}^{\text {net }}}{\bar{\Sigma}_{a 2}} \Phi_{1},
$$

where we have defined a "net" downscattering cross section:

$$
\bar{\Sigma}_{1 \rightarrow 2}^{\text {net }} \equiv\left(\bar{\Sigma}_{1 \rightarrow 2}-\bar{\Sigma}_{2 \rightarrow 1} \frac{\Phi_{2}}{\Phi_{1}}\right)
$$

Now Eq. (6) can be rewritten: 


$$
\begin{aligned}
k^{(n+1)}= & \frac{\bar{v}_{f 1} \Phi_{1}+\overline{v \Sigma}_{f 2} \frac{\bar{\Sigma}_{1 \rightarrow 2}^{n e t}}{\bar{\Sigma}_{a 2}} \Phi_{1}}{\left[\bar{\Sigma}_{a 1}+\left(\bar{\Sigma}_{1 \rightarrow 2}-\bar{\Sigma}_{2 \rightarrow 1} \frac{\Phi_{2}}{\Phi_{1}}\right)\right] \Phi_{1}}=\frac{\bar{v}_{f 1}}{\bar{\Sigma}_{a 1}+\bar{\Sigma}_{1 \rightarrow 2}^{\text {net }}}+\frac{\bar{\Sigma}_{1 \rightarrow 2}^{\text {net }}}{\bar{\Sigma}_{a 1}+\bar{\Sigma}_{1 \rightarrow 2}^{n e t}} \frac{\bar{\nu}_{f 2}}{\bar{\Sigma}_{a 2}} \\
= & \frac{\overline{v \Sigma}_{f 1}}{\bar{\Sigma}_{r 1}}+\frac{\bar{\Sigma}_{1 \rightarrow 2}^{n e t}}{\bar{\Sigma}_{r 1}} \frac{\overline{v \Sigma}_{f 2}}{\bar{\Sigma}_{a 2}} .
\end{aligned}
$$

[Here we have defined the fast-group removal cross section, $\Sigma_{r 1}$, to be the sum of the absorption plus net downscattering cross sections.] Equation (8) is our first main result:

\section{Regardless of how tightly the $\mathrm{k}$-iteration is converged, Eq. (8) holds as a relationship between $k$ and the two-group constants.}

This is true as long as power iteration is employed in the $\mathrm{k}$ iteration, with Eq. (1b) used as the update equation for $k$.

The next task was to consider a branch case, in which there is a base $k$ calculation and then another $k$ calculation for a different ("branch") state of the assembly. Here we try to determine the relationship between the change in $k$ and the change in the two-group cross sections. Equation (8) makes this a relatively simple task, although the algebraic details are somewhat tedious. The change in $k$ on a branch is:

$$
k_{b}-k=\left[\frac{\overline{v \Sigma}_{f 1}}{\bar{\Sigma}_{r 1}}+\frac{\bar{\Sigma}_{1 \rightarrow 2}^{n e t}}{\bar{\Sigma}_{r 1}} \frac{\overline{v \Sigma}_{f 2}}{\bar{\Sigma}_{a 2}}\right]_{b}-\frac{\overline{v \Sigma}_{f 1}}{\bar{\Sigma}_{r 1}}-\frac{\bar{\Sigma}_{1 \rightarrow 2}^{n e t}}{\bar{\Sigma}_{r 1}} \frac{\overline{v \Sigma}_{f 2}}{\bar{\Sigma}_{a 2}}
$$

where the subscript $b$ represents the "branch" state. Now let us define the change in each group cross section:

$$
\begin{aligned}
& \delta_{f 1} \equiv\left[\overline{v \Sigma}_{f 1}\right]_{b}-\overline{v \Sigma}_{f 1}, \delta_{f 2} \equiv\left[\overline{v \Sigma}_{f 2}\right]_{b}-\overline{v \Sigma}_{f 2}, \\
& \delta_{a 1} \equiv\left[\bar{\Sigma}_{a 1}\right]_{b}-\bar{\Sigma}_{a 1}, \delta_{a 2} \equiv\left[\bar{\Sigma}_{a 2}\right]_{b}-\bar{\Sigma}_{a 2}, \\
& \delta_{12} \equiv\left[\bar{\Sigma}_{1 \rightarrow 2}^{n e t}\right]_{b}-\bar{\Sigma}_{1 \rightarrow 2}^{n e t}, \delta_{r 1} \equiv\left[\bar{\Sigma}_{r 1}\right]_{b}-\bar{\Sigma}_{r 1} .
\end{aligned}
$$

Similarly, we define relative changes in the cross sections:

$$
\begin{aligned}
& \varepsilon_{f 1} \equiv \delta_{f 1} / \overline{v \Sigma}_{f 1}, \varepsilon_{f 2} \equiv \delta_{f 2} / \overline{v \Sigma}_{f 2}, \varepsilon_{12} \equiv \delta_{12} / \bar{\Sigma}_{1 \rightarrow 2}^{\text {net }}, \\
& \varepsilon_{x} \equiv \delta_{x} / \bar{\Sigma}_{x}, x=a 1, a 2 \text {, or } r 1 .
\end{aligned}
$$

Now we can manipulate Eq. (9) as follows.

$$
\begin{aligned}
k_{b}-k & =\frac{1}{\bar{\Sigma}_{r 1}}\left[\frac{\overline{v \Sigma}_{f 1}\left(1+\varepsilon_{f 1}\right)}{1+\varepsilon_{r 1}}-\overline{v \Sigma}_{f 1}+\frac{\bar{\Sigma}_{1 \rightarrow 2}^{\text {net }}\left(1+\varepsilon_{12}\right)}{1+\varepsilon_{r 1}} \frac{\overline{v \Sigma}_{f 2}\left(1+\varepsilon_{f 2}\right)}{\bar{\Sigma}_{a 2}\left(1+\varepsilon_{a 2}\right)}-\bar{\Sigma}_{1 \rightarrow 2}^{n e t} \frac{\overline{v \Sigma}_{f 2}}{\bar{\Sigma}_{a 2}}\right] \\
& =\frac{1}{\bar{\Sigma}_{r 1}}\left[\bar{v}_{f 1}\left(\frac{\left(1+\varepsilon_{f 1}\right)}{1+\varepsilon_{r 1}}-1\right)+\bar{\Sigma}_{1 \rightarrow 2}^{n e t} \frac{\overline{v \Sigma}_{f 2}}{\bar{\Sigma}_{a 2}}\left(\frac{\left(1+\varepsilon_{12}\right)}{1+\varepsilon_{r 1}} \frac{\left(1+\varepsilon_{f 2}\right)}{\left(1+\varepsilon_{a 2}\right)}-1\right)\right] \\
& =\frac{\overline{v \Sigma}_{f 1}}{\bar{\Sigma}_{r 1}}\left(\frac{\varepsilon_{f 1}-\varepsilon_{r 1}}{1+\varepsilon_{r 1}}\right)+\frac{\bar{\Sigma}_{1 \rightarrow 2}^{n e t}}{\bar{\Sigma}_{r 1}} \frac{\bar{v}_{f 2}}{\bar{\Sigma}_{a 2}}\left(\frac{\varepsilon_{12}+\varepsilon_{f 2}+\varepsilon_{f 2} \varepsilon_{12}-\varepsilon_{r 1}-\varepsilon_{a 2}-\varepsilon_{r 1} \varepsilon_{a 2}}{\left(1+\varepsilon_{r 1}\right)\left(1+\varepsilon_{a 2}\right)}\right)
\end{aligned}
$$


Let us define $\alpha$, a number between 0 and 1 , as follows:

$$
\alpha k=\frac{\overline{v \Sigma}_{f 1}}{\bar{\Sigma}_{r 1}} \text { and }(1-\alpha) k=\frac{\bar{\Sigma}_{1 \rightarrow 2}^{n e t}}{\bar{\Sigma}_{r 1}} \frac{\bar{v}_{f 2}}{\bar{\Sigma}_{a 2}} .
$$

Then Eq. (12) becomes

$$
k_{b}-k=\alpha k\left(\frac{\varepsilon_{f 1}-\varepsilon_{r 1}}{1+\varepsilon_{r 1}}\right)+(1-\alpha) k\left(\frac{\varepsilon_{12}+\varepsilon_{f 2}+\varepsilon_{f 2} \varepsilon_{12}-\varepsilon_{r 1}-\varepsilon_{a 2}-\varepsilon_{r 1} \varepsilon_{a 2}}{\left(1+\varepsilon_{r 1}\right)\left(1+\varepsilon_{a 2}\right)}\right),
$$

or

$$
\left(k_{b}-k\right)=k \frac{\left[\alpha\left(\varepsilon_{f 1}-\varepsilon_{r 1}\right)\left(1+\varepsilon_{a 2}\right)+(1-\alpha)\left(\varepsilon_{12}+\varepsilon_{f 2}+\varepsilon_{f 2} \varepsilon_{12}-\varepsilon_{r 1}-\varepsilon_{a 2}-\varepsilon_{r 1} \varepsilon_{a 2}\right)\right]}{\left(1+\varepsilon_{r 1}\right)\left(1+\varepsilon_{a 2}\right)} .
$$

It follows that the ratio of the HELIOS branch $\Delta \mathrm{k}$ to the CASMO branch $\Delta \mathrm{k}$ is:

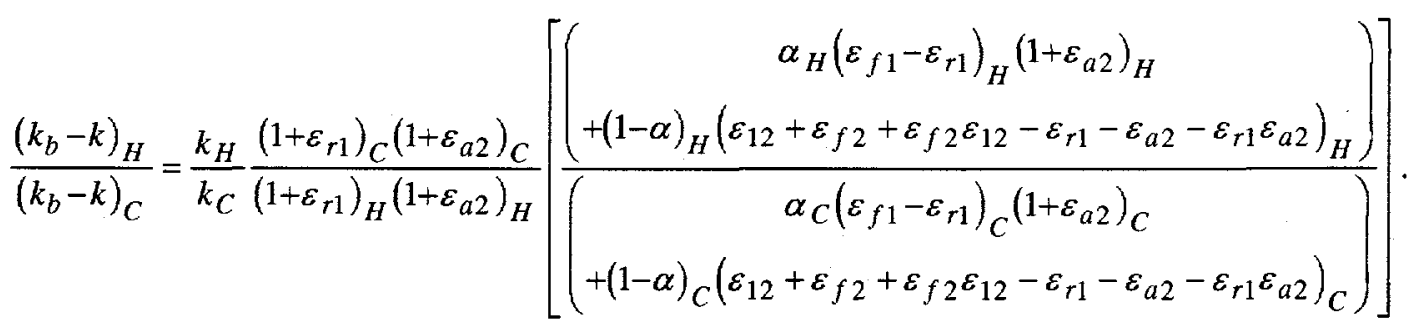

Intuitively, one might have expected that the ratio $\left(k_{b}-k\right)_{\mathrm{H}} /\left(k_{b}-k\right)_{\mathrm{C}}$ on the left side of the equation would depend fundamentally upon ratios of changes in cross sections, such as $\left(\delta_{a 2}\right)_{\mathrm{H}^{\prime}} /\left(\delta_{a 2}\right)_{\mathrm{C}}$, or perhaps upon ratios of relative changes in cross sections, such as $\left(\varepsilon_{a 2}\right)_{\mathrm{H}} /\left(\varepsilon_{a 2}\right)_{\mathrm{C}}$. However, an examination of the right side of equation (16) suggests that this is not the case - instead, the $\Delta k$ ratio depends upon ratios of combinations of relative changes and also upon ratios of base-case quantities. Some of these combinations are actually differences of relative changes in cross sections. This leaves open the interesting possibility that the ratio of MTCs computed by the two codes can be much different than the ratio of the change (between branch and base cases) in any cross section, even though (as we showed above) each $k$ depends in a simple and direct way upon the two-group cross sections. This phenomenon is observed in Table II above. For example, at zero burnup this table shows that the ratio $\left(k_{b^{-}}\right)_{\mathrm{H}^{\prime}} /\left(k_{b^{-}}\right.$ $\left.{ }^{k}\right)_{\mathrm{C}}$ is 1.95 , even though all of the ratios of cross section changes, $\left(\delta_{X}\right)_{\mathrm{H}} /\left(\delta_{x}\right)_{\mathrm{C}}$, are between 0.91 and 1.0.

To verify that the MTC ratios reported in Table XII are in fact consistent with the two-group cross sections that the codes are outputting, we have selected a representative LEU assembly and a representative burnup step (40 GWD/MTU) and carefully examined the two-group cross sections from the two codes. For the chosen case we find the following ratios of changes in two-group cross sections:

$$
\begin{aligned}
& \left(\delta_{f 1}\right)_{H} /\left(\delta_{f 1}\right)_{C}=0.9642 \\
& \left(\delta_{f 2}\right)_{H} /\left(\delta_{f 2}\right)_{C}=0.9167 \\
& \left(\delta_{a 1}\right)_{H} /\left(\delta_{a 1}\right)_{C}=0.9365 \\
& \left(\delta_{a 2}\right)_{H} /\left(\delta_{a 2}\right)_{C}=0.9797
\end{aligned}
$$




$$
\begin{aligned}
& \left(\delta_{r 1}\right)_{H} /\left(\delta_{r 1}\right)_{C}=0.9924 \\
& \left(\delta_{12}\right)_{H} /\left(\delta_{12}\right)_{C}=0.9991
\end{aligned}
$$

Note that the two codes agree on most of the cross section changes to within $4 \%$, and on all of them to within $9 \%$. We now calculate the terms that appear in Eq. (16):

$$
\begin{aligned}
& \frac{k_{H}}{k_{C}}=1.0006 \\
& \alpha_{H}\left(\varepsilon_{f 1}-\varepsilon_{r 1}\right)_{H}\left(1+\varepsilon_{a 2}\right)_{H}=-0.00786 \\
& \alpha_{C}\left(\varepsilon_{f 1}-\varepsilon_{r 1}\right)_{C}\left(1+\varepsilon_{a 2}\right)_{C}=-0.00770 \\
& (1-\alpha)_{H}\left(\varepsilon_{12}+\varepsilon_{f 2}+\varepsilon_{f 2} \varepsilon_{12}-\varepsilon_{r 1}-\varepsilon_{a 2}-\varepsilon_{r 1} \varepsilon_{a 2}\right)_{H}=0.01033 \\
& (1-\alpha)_{C}\left(\varepsilon_{12}+\varepsilon_{f 2}+\varepsilon_{f 2} \varepsilon_{12}-\varepsilon_{r 1}-\varepsilon_{a 2}-\varepsilon_{r 1} \varepsilon_{a 2}\right)_{C}=0.00923 \\
& \frac{\alpha_{H}\left(\varepsilon_{f 1}-\varepsilon_{r 1}\right)_{H}\left(1+\varepsilon_{a 2}\right)_{H}+(1-\alpha)_{H}\left(\varepsilon_{12}+\varepsilon_{f 2}+\varepsilon_{f 2} \varepsilon_{12}-\varepsilon_{r 1}-\varepsilon_{a 2}-\varepsilon_{r 1} \varepsilon_{a 2}\right)_{H}}{\alpha_{C}\left(\varepsilon_{f 1}-\varepsilon_{r 1}\right)_{C}\left(1+\varepsilon_{a 2}\right)_{C}+(1-\alpha)_{C}\left(\varepsilon_{12}+\varepsilon_{f 2}+\varepsilon_{f 2} \varepsilon_{12}-\varepsilon_{r 1}-\varepsilon_{a 2}-\varepsilon_{r 1} \varepsilon_{a 2}\right)_{C}}=\frac{0.002462}{0.001530}=1.61 \\
& \frac{\left(1+\varepsilon_{r 1}\right)_{C}\left(1+\varepsilon_{a 2}\right)_{C}}{\left(1+\varepsilon_{r 1}\right)_{H}\left(1+\varepsilon_{a 2}\right)_{H}}=1.0004
\end{aligned}
$$

If we insert these numbers into Eq. (16) we obtain:

$$
\frac{\left(k_{b}-k\right)_{H}}{\left(k_{b}-k\right)_{C}}=(1.0006)(1.0004)(1.61)=1.61 \text {. }
$$

There are several things worth noting. First, the two codes agree to within a few percent on the change in each cross section as a function of the change in temperature. Second, even the differences of the relative changes in cross section are in reasonable agreement - Eqs. (18b) and (18c) agree within $2 \%$ and Eqs. (18d) and (18e) agree within $11 \%$. Third, the values of $(18 \mathrm{~b})$ and $(18 \mathrm{c})$ are negative whereas those of (18d) and (18e) are positive; thus, when the terms are combined as in (18f), we basically have a difference of differences of relative changes, and this is where the codes do not agree. This results in MTCs that differ by more than $60 \%$. 


\section{Appendix B. HELIOS Input File: MOX, high fissile, 24 WABA, 89 groups (hmhwh89h.inp)}

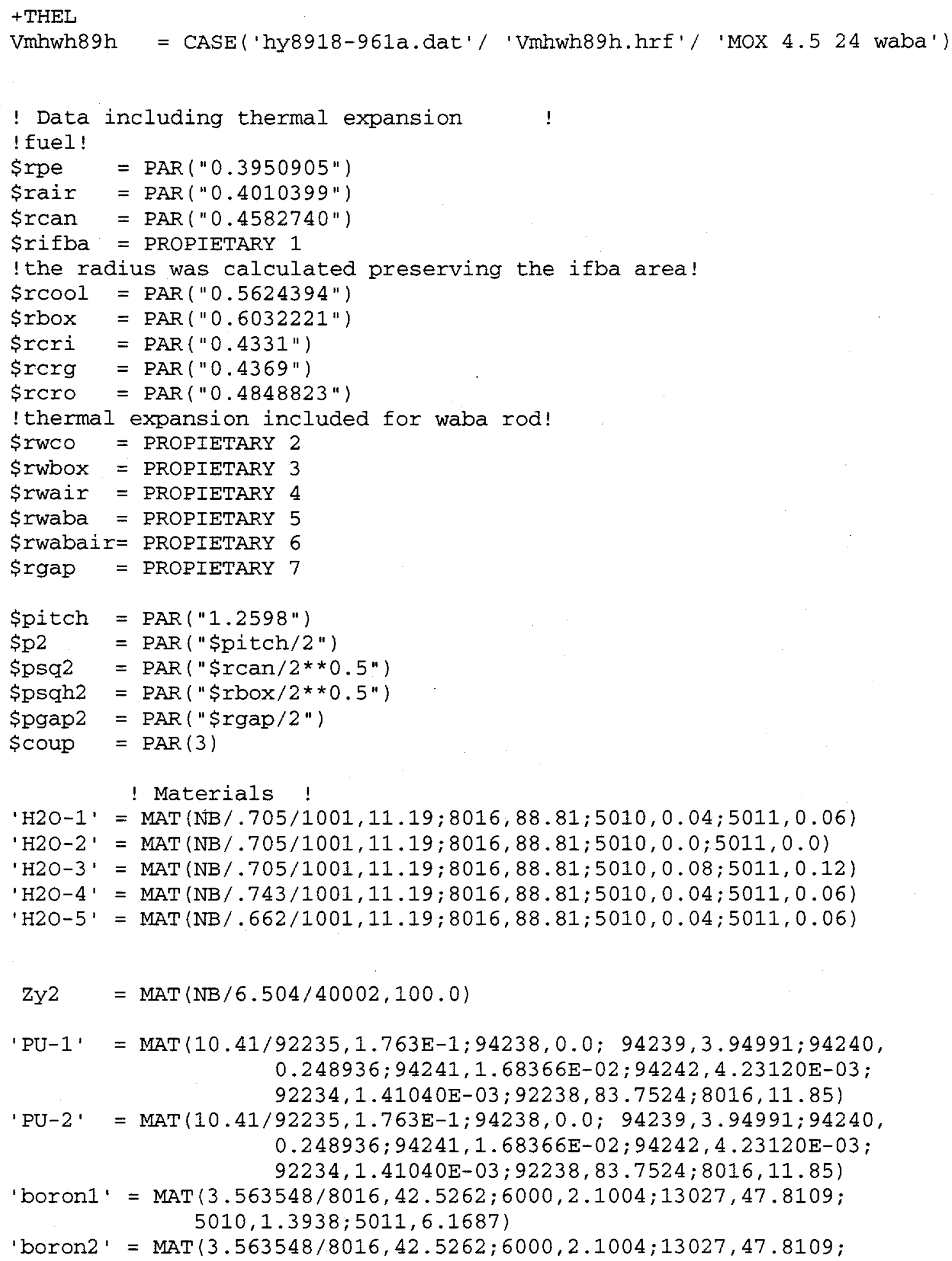


$5010,1.3938 ; 5011,6.1687)$

'air'= MAT $(\mathrm{NB} / .001 / 8016,100)$

! Geometry !

Pin = CCS (\$rpe, \$rair, \$rcan//fuel, gap, clad)

Whole $=\operatorname{CCS}(\$ r c o o l, \$ r b o x / /$ water, $\mathrm{clad})$

Ipin = CCS (\$rpe, \$rifba, \$rair, \$rcan//fuel, ifba, gap, clad)

Bpin = CCS (\$rwco, \$rwbox, \$rwair, \$rwaba, \$rwabair, \$rcro, \$rcool, \$rbox//water, clad, gap, crod, gap, clad, water, clad)

$\$ \mathrm{ce} 11=\operatorname{PAR}(("-\$ \mathrm{p} 2 ", "-\$ \mathrm{p} 2 ")("-\$ \mathrm{p} 2 ", \$ \mathrm{p} 2)(\$ \mathrm{p} 2, \$ \mathrm{p} 2) \quad(\$ \mathrm{p} 2, "-\$ \mathrm{p} 2 ") \quad !$ nodes $1-4 !$ $(0, "-\$ p 2 ") \quad("-\$ p 2 ", 0) \quad(0, \$ p 2) \quad(\$ p 2,0) \quad(\$ r \operatorname{can}, 0) \quad(0, "-\$ r \operatorname{can} ") \quad("-\$ r c a n ", 0)$ (0, \$rcan) (\$psq2, \$psq2) (\$psq2, "-\$psq2") ("-\$psq2", "-\$psq2") ("-\$psq2", \$psq2) /4, cool/Pin $(0,0) / 1,6,11,15$, cool; 6,2,16,11, cool; 2,7,12,16, cool; $7,3,13,12, \operatorname{cool} ; 3,8,9,13, \operatorname{cool} ; 8,4,14,9, \operatorname{cool} ; 4,5,10,14$, cool)

$\$$ ice11 = PAR ("-\$p2", "-\$p2") ("-\$p2", \$p2) $(\$ \mathrm{p} 2, \$ \mathrm{p} 2)(\$ \mathrm{p} 2, "-\$ \mathrm{p} 2 ") \quad$ !nodes $1-4 !$ $(0, "-\$ p 2 ") \quad("-\$ p 2 ", 0) \quad(0, \$ p 2) \quad(\$ p 2,0) \quad(\$ r c a n, 0) \quad(0, "-\$ r c a n ") \quad("-\$ r c a n ", 0)$ (0, \$rcan) (\$psq2, \$psq2) (\$psq2, "-\$psq2") ("-\$psq2", "-\$psq2") ("-\$psq2", \$psq2) 14, cool/Ipin $(0,0) / 1,6,11,15$, cool; 6,2,16,11, cool;

$2,7,12,16, \operatorname{cool} ; 7,3,13,12, \operatorname{coo} 1 ; 3,8,9,13, \operatorname{cool} ; 8,4,14,9, \operatorname{cool} ; 4,5,10,14, \operatorname{cool})$

$\$ w c e 11=\operatorname{PAR}(("-\$ \mathrm{p} 2 ", "-\$ \mathrm{p} 2 ")("-\$ \mathrm{p} 2 ", \$ \mathrm{p} 2)(\$ \mathrm{p} 2, \$ \mathrm{p} 2)(\$ \mathrm{p} 2, "-\$ \mathrm{p} 2 ") \quad$ !nodes $1-4 !$ $(0, "-\$ p 2 ") \quad("-\$ p 2 ", 0)(0, \$ p 2) \quad(\$ p 2,0)(\$ r b o x, 0)(0, "-\$ r b o x ") \quad("-\$ r b o x ", 0)$

$(0, \$$ rbox) (\$psqh2, \$psqh2) (\$psqh2, "-\$psqh2") ("-\$psqh2" , "\$psqh2")

("-\$psqh2" , \$psqh2)/4, cool/Whole $(0,0) / 1,6,11,15$, cool; 6, 2, 16,11, cool;

$2,7,12,16, \operatorname{cool} ; 7,3,13,12, \operatorname{cool} ; 3,8,9,13, \operatorname{cool} ; 8,4,14,9, \operatorname{cool} ; 4,5,10,14, \operatorname{cool})$

$\$ \mathrm{bce} 11=\operatorname{PAR}(("-\$ \mathrm{p} 2 ", "-\$ \mathrm{p} 2 ")("-\$ \mathrm{p} 2 ", \$ \mathrm{p} 2)(\$ \mathrm{p} 2, \$ \mathrm{p} 2)(\$ \mathrm{p} 2, "-\$ \mathrm{p} 2 ") \quad$ !nodes $1-4 !$ $(0, "-\$ p 2 ") \quad("-\$ p 2 ", 0)(0, \$ p 2) \quad(\$ p 2,0) \quad(\$ \operatorname{rbox}, 0) \quad(0, "-\$ r b o x ") \quad("-\$ \operatorname{rbox} ", 0)$

(0,\$rbox) (\$psqh2, \$psqh2) (\$psqh2, "-\$psqh2") ("-\$psqh2 ", "-\$psqh2")

("-\$psqh2 " \$psqh2) /4, cool/Bpin $(0,0) / 1,6,11,15, \operatorname{cool} ; 6,2,16,11$, cool;

$2,7,12,16, \operatorname{cool} ; 7,3,13,12, \operatorname{cool} ; 3,8,9,13, \operatorname{cool} ; 8,4,14,9, \operatorname{cool} ; 4,5,10,14, \mathrm{co01})$

\$wgap = PAR ("-\$pgap2","-\$p2") ("-\$pgap2", \$p2) (\$pgap2, \$p2) (\$pgap2, "-\$p2")

$/ 4, \operatorname{cool} / / 1$

$\$ \mathrm{cel} 12=\operatorname{PAR}(("-\$ \mathrm{p} 2 ", "-\$ \mathrm{p} 2 ")("-\$ \mathrm{p} 2 ", 0)(\$ \mathrm{p} 2,0) \quad(\$ \mathrm{p} 2, "-\$ \mathrm{p} 2 ")$

$(0, "-\$ p 2 ") \quad(\$ r c a n, 0)(0, "-\$ r c a n ")("-\$ r c a n ", 0)(\$ p s q 2, "-\$ p s q 2 ")$

("-\$psq2","-\$psq2") /4, cool/Pin $(0,0) 3 / 3,4,9,6, \operatorname{cool} ; 4,5,7,9$, cool;

$5,1,10,7, \operatorname{cool})$

$\$$ icel12 = PAR $("-\$ \mathrm{p} 2 ", "-\$ \mathrm{p} 2 ")("-\$ \mathrm{p} 2 ", 0)(\$ \mathrm{p} 2,0)(\$ \mathrm{p} 2, "-\$ \mathrm{p} 2 ")$

$(0, "-\$ p 2 ")(\$ r c a n, 0)(0, "-\$ r c a n ")("-\$ r c a n ", 0)(\$ p s q 2, "-\$ p s q 2 ")$

("-\$psq2", "-\$psq2") /4,cool/Ipin $(0,0)$ 4/ 3,4,9,6,cool; 4, 5, 7,9, cool;

$5,1,10,7, \operatorname{cool})$

$\$ w c e l 12=\operatorname{PAR}(("-\$ p 2 ", "-\$ p 2 ")("-\$ p 2 ", 0)(\$ p 2,0)(\$ p 2, "-\$ p 2 ")$

$(0, "-\$ p 2 ") \quad(\$ r b o x, 0) \quad(0, "-\$ r b o x ") \quad("-\$ r b o x ", 0) \quad(\$ p s q h 2, "-\$ p s q h 2 ")$

("-\$psqh2" , "-\$psqh2")/4, cool/Whole $(0,0) 2 / 3,4,9,6, \operatorname{cool} ; 4,5,7,9$, cool;

$5,1,10,7, \mathrm{co01})$

$\$ \mathrm{bce} 112=\operatorname{PAR}(("-\$ \mathrm{p} 2 ", "-\$ \mathrm{p} 2 ")("-\$ \mathrm{p} 2 ", 0)(\$ \mathrm{p} 2,0)(\$ \mathrm{p} 2, "-\$ \mathrm{p} 2 ")$

$(0, "-\$ p 2 ") \quad(\$ r b o x, 0) \quad(0, "-\$ r b o x ") \quad("-\$ r b o x ", 0) \quad(\$ p s q h 2, "-\$ p s q h 2 ")$

("-\$psqh2" , "-\$psqh2")/4, cool/Bpin $(0,0) \quad 8 / 3,4,9,6, \operatorname{cool;~4,5,7,9,~cool;~}$

$5,1,10,7$, cool) 


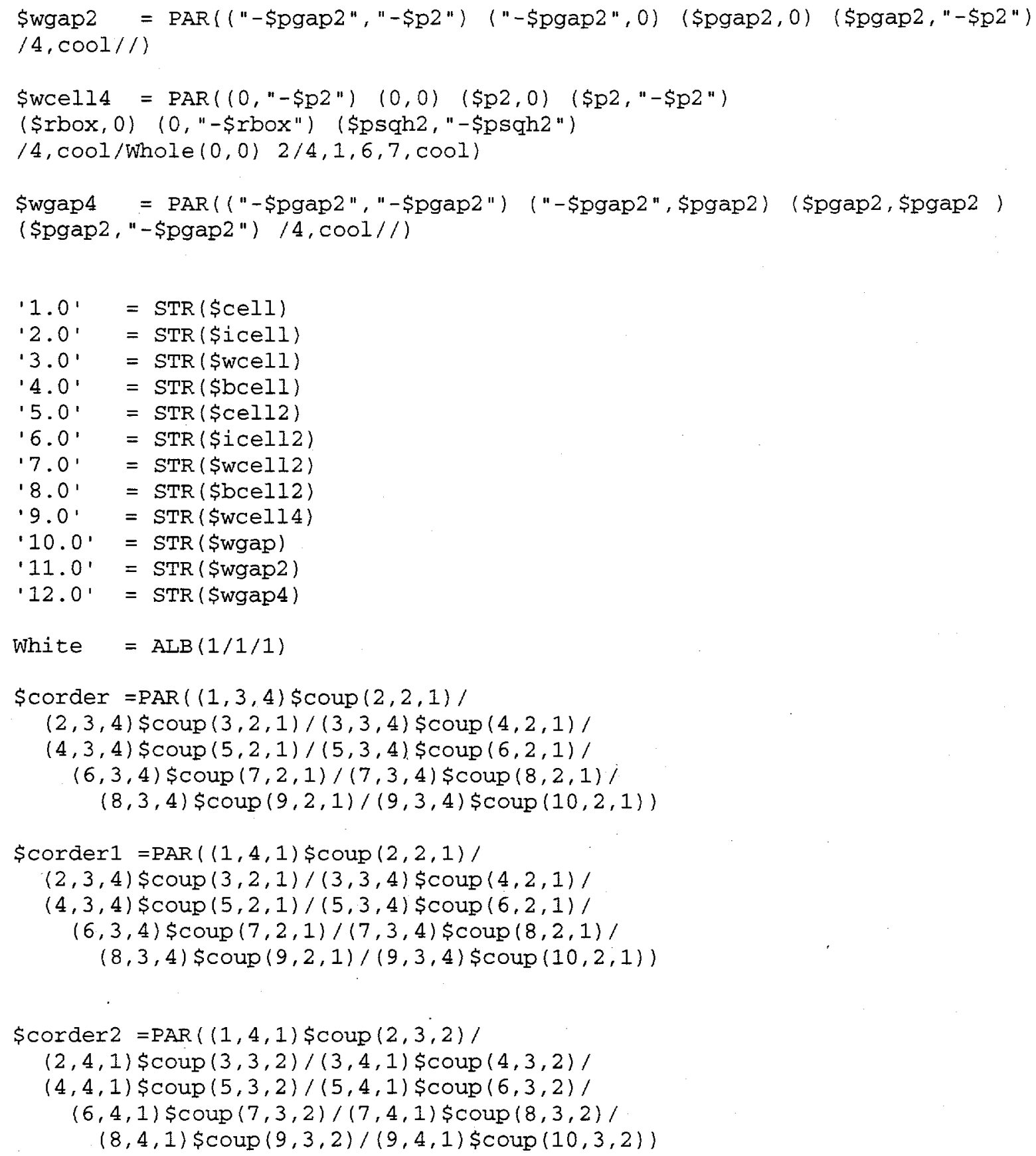




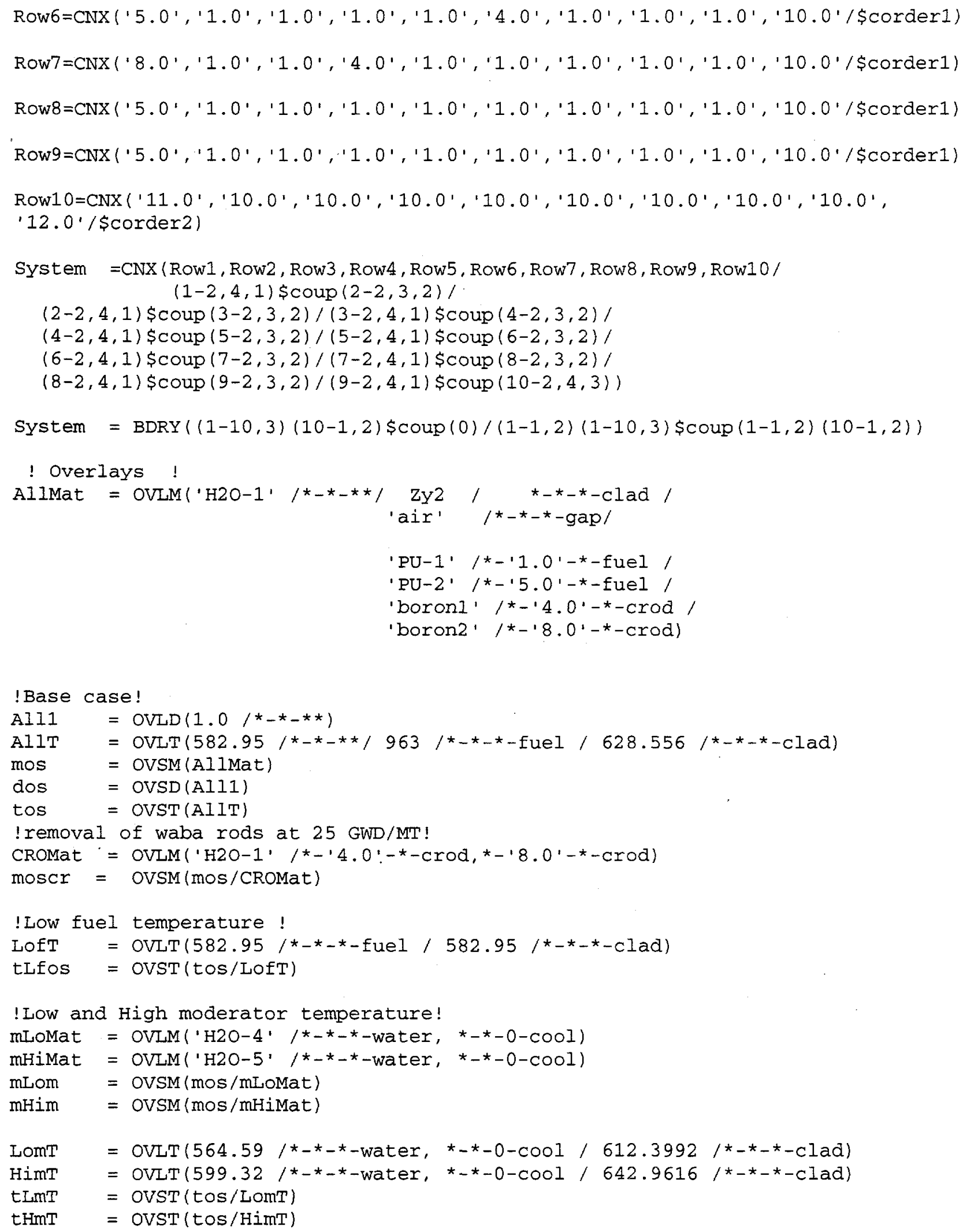

! Low and High boron concentration( 0 and 2000ppm)! 


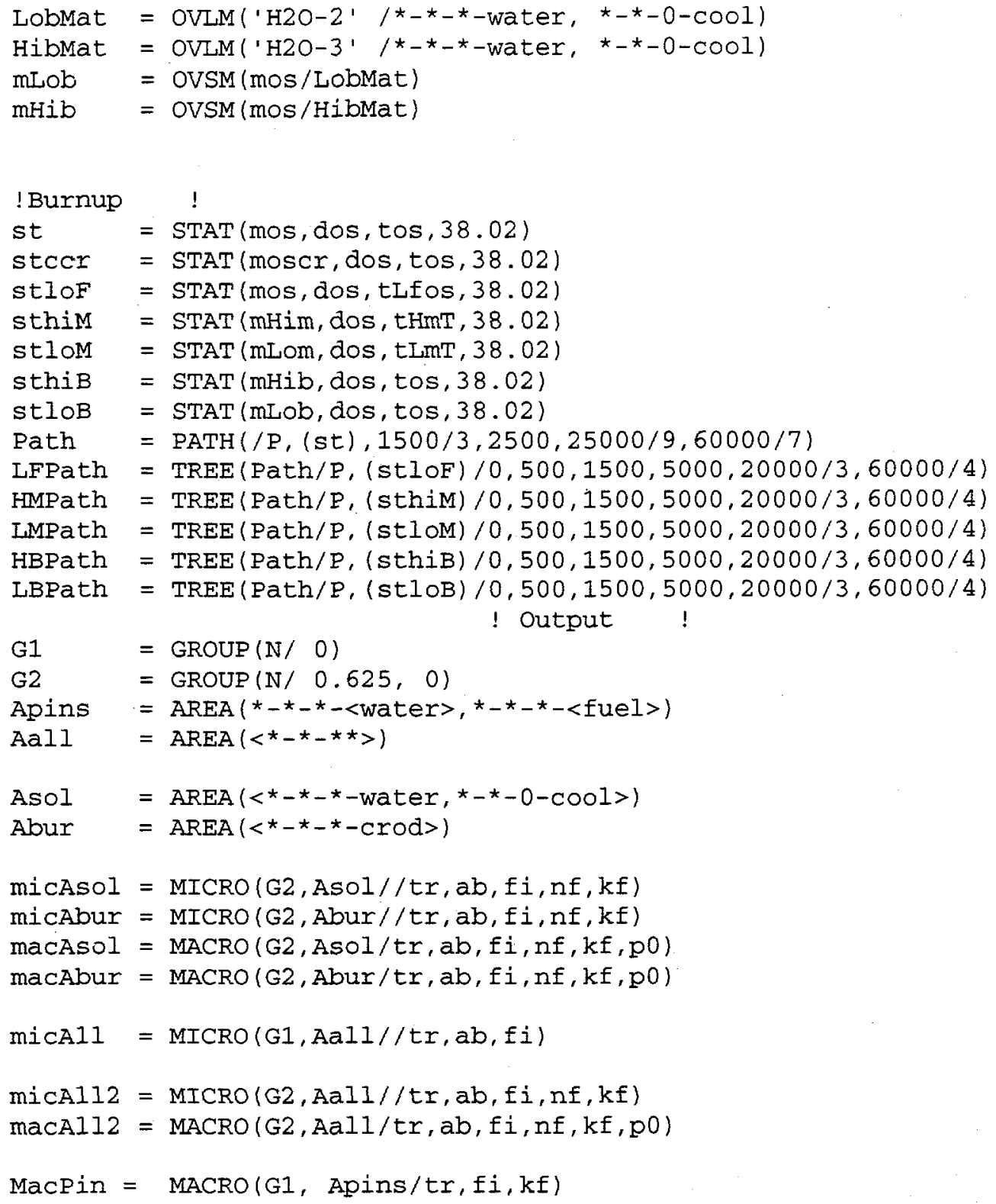


$(10-9,2,1) \quad(10-10,2,1))$

CurCorner $=$ CUR $(\mathrm{G} 2, \mathrm{NW}, \mathrm{SW}, \mathrm{SE}, \mathrm{NE})$

Curside $=$ CUR (G2, Interior, Exterior)

Vmhwh89h $=\operatorname{RUN}()$ 


\section{Appendix C. HELIOS Input File: MOX, LEU, 3.5\%, 104 IFBA (hu35104i.inp)}

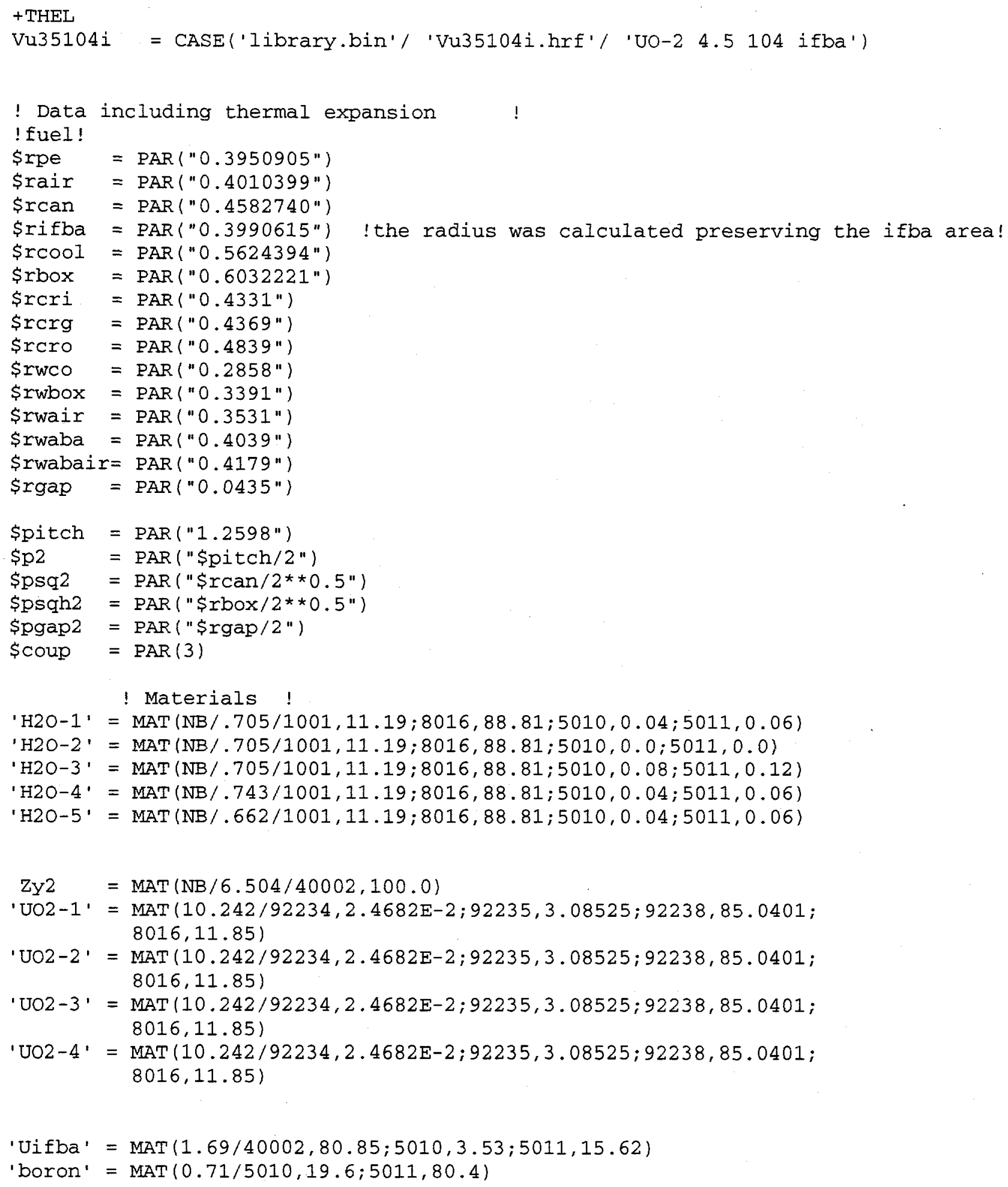




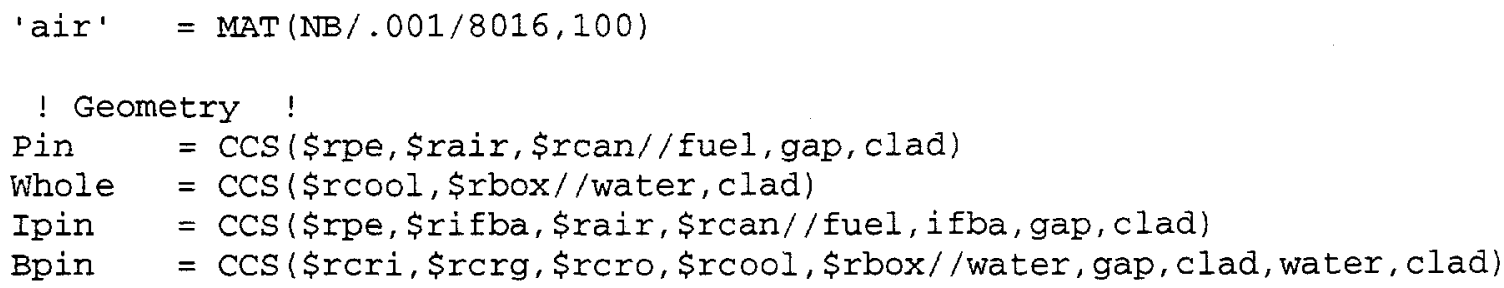

$\$ w c e 11=\operatorname{PAR}(("-\$ \mathrm{p} 2 ", "-\$ \mathrm{p} 2 ")("-\$ \mathrm{p} 2 ", \$ \mathrm{p} 2)(\$ \mathrm{p} 2, \$ \mathrm{p} 2) \quad(\$ \mathrm{p} 2, "-\$ \mathrm{p} 2 ")$ !nodes $1-4 !$ $(0, "-\$ p 2 ") \quad("-\$ p 2 ", 0) \quad(0, \$ p 2) \quad(\$ p 2,0) \quad(\$ r b o x, 0) \quad(0, "-\$ r b o x ") \quad("-\$ r b o x ", 0)$ $(0, \$ r b o x)$ (\$psqh2, \$psqh2) (\$psqh2, "-\$psqh2") ("-\$psqh2", "-\$psqh2") ("-\$psqh2", \$psqh2) /4, cool/Whole $(0,0) / 1,6,11,15, \operatorname{cool} ; 6,2,16,11$, cool; $2,7,12,16, \operatorname{cool} ; 7,3,13,12, \operatorname{cool} ; 3,8,9,13, \operatorname{cool} ; 8,4,14,9, \operatorname{cool} ; 4,5,10,14, \operatorname{cool})$

$\$ b c e 11=\operatorname{PAR}(("-\$ \mathrm{p} 2 ", "-\$ \mathrm{p} 2 ")("-\$ \mathrm{p} 2 ", \$ \mathrm{p} 2)(\$ \mathrm{p} 2, \$ \mathrm{p} 2)(\$ \mathrm{p} 2, "-\$ \mathrm{p} 2 ") \quad$ !nodes $1-4 !$ $(0, "-\$ p 2 ") \quad("-\$ p 2 ", 0)(0, \$ p 2) \quad(\$ p 2,0) \quad(\$ r b o x, 0) \quad(0, "-\$ r b o x ") \quad("-\$ r b o x ", 0)$ (0,\$rbox) (\$psqh2, \$psqh2) (\$psqh2, "-\$psqh2") ("-\$psqh2", "-\$psqh2 ") ("-\$psqh2", \$psqh2) /4, cool/Whole (0,0)/1,6,11,15, cool; 6, 2,16,11, c001; $2,7,12,16, \operatorname{cool} ; 7,3,13,12, \operatorname{cool} ; 3,8,9,13, \operatorname{cool} ; 8,4,14,9, \operatorname{cool} ; 4,5,10,14, \operatorname{cool})$

$\$ w g a p=\operatorname{PAR}(("-\$ p g a p 2 ", "-\$ p 2 ")("-\$ p g a p 2 ", \$ p 2)(\$ p g a p 2, \$ p 2)(\$ p g a p 2, "-\$ p 2 ")$ $/ 4, \operatorname{cool} / / 1$

$\$ c e 112=\operatorname{PAR}(("-\$ \mathrm{p} 2 ", "-\$ \mathrm{p} 2 ")("-\$ \mathrm{p} 2 ", 0)(\$ \mathrm{p} 2,0)(\$ \mathrm{p} 2, "-\$ \mathrm{p} 2 ")$ $(0, "-\$ p 2 ") \quad(\$ r c a n, 0)(0, "-\$ r c a n ") \quad("-\$ r c a n ", 0) \quad(\$ p s q 2, "-\$ p s q 2 ")$ ("-\$psq2", "-\$psq2") /4, cool/Pin $(0,0) 3 / 3,4,9,6$, cool; 4,5,7,9, cool; $5,1,10,7, \operatorname{coo} 1)$

$\$$ ice112 = PAR $(("-\$ p 2 ", "-\$ p 2 ")("-\$ p 2 ", 0)(\$ p 2,0)(\$ p 2, "-\$ p 2 ")$ $(0, "-\$ p 2 ") \quad(\$ r \operatorname{can}, 0) \quad(0, "-\$ r c a n ") \quad("-\$ r c a n ", 0) \quad(\$ p s q 2, "-\$ p s q 2 ")$ ("-\$psq2", "-\$psq2")/4, cool/Ipin $(0,0) 4 / 3,4,9,6$, cool; 4,5,7,9, cool; $5,1,10,7, \mathrm{co0})$

$\$ w c e 112=\operatorname{PAR}(("-\$ \mathrm{p} 2 ", "-\$ \mathrm{p} 2 ")("-\$ \mathrm{p} 2 ", 0)(\$ \mathrm{p} 2,0)(\$ \mathrm{p} 2, "-\$ \mathrm{p} 2 ")$ $(0, "-\$ p 2 ") \quad(\$ r b o x, 0) \quad(0, "-\$ r b o x ") \quad("-\$ r b o x ", 0) \quad(\$ p s q h 2, "-\$ p s q h 2 ")$ ("-\$psqh2", "-\$psqh2")/4, cool/Whole (0,0) 2/3,4,9,6, cool; 4, 5, 7, 9, cool; $5,1,10,7, \mathrm{cool})$

$\$ \mathrm{bce} 112=\operatorname{PAR}(("-\$ \mathrm{p} 2 ", "-\$ \mathrm{p} 2 ")("-\$ \mathrm{p} 2 ", 0)(\$ \mathrm{p} 2,0)(\$ \mathrm{p} 2, "-\$ \mathrm{p} 2 ")$ $(0, "-\$ p 2 ") \quad(\$ r b o x, 0) \quad(0, "-\$ r b o x ")("-\$ r b o x ", 0) \quad(\$ p s q h 2, "-\$ p s q h 2 ")$ ("-\$psqh2", "-\$psqh2") /4, cool/Whole $(0,0) 2 / 3,4,9,6$, cool; 4,5,7,9, cool; $5,1,10,7, \mathrm{cool})$

$\$$ wgap2 = PAR (("-\$pgap2", "-\$p2") ("-\$pgap2",0) (\$pgap2,0) (\$pgap2,"-\$p2") /4, $\mathrm{COOl} / / 1$ 


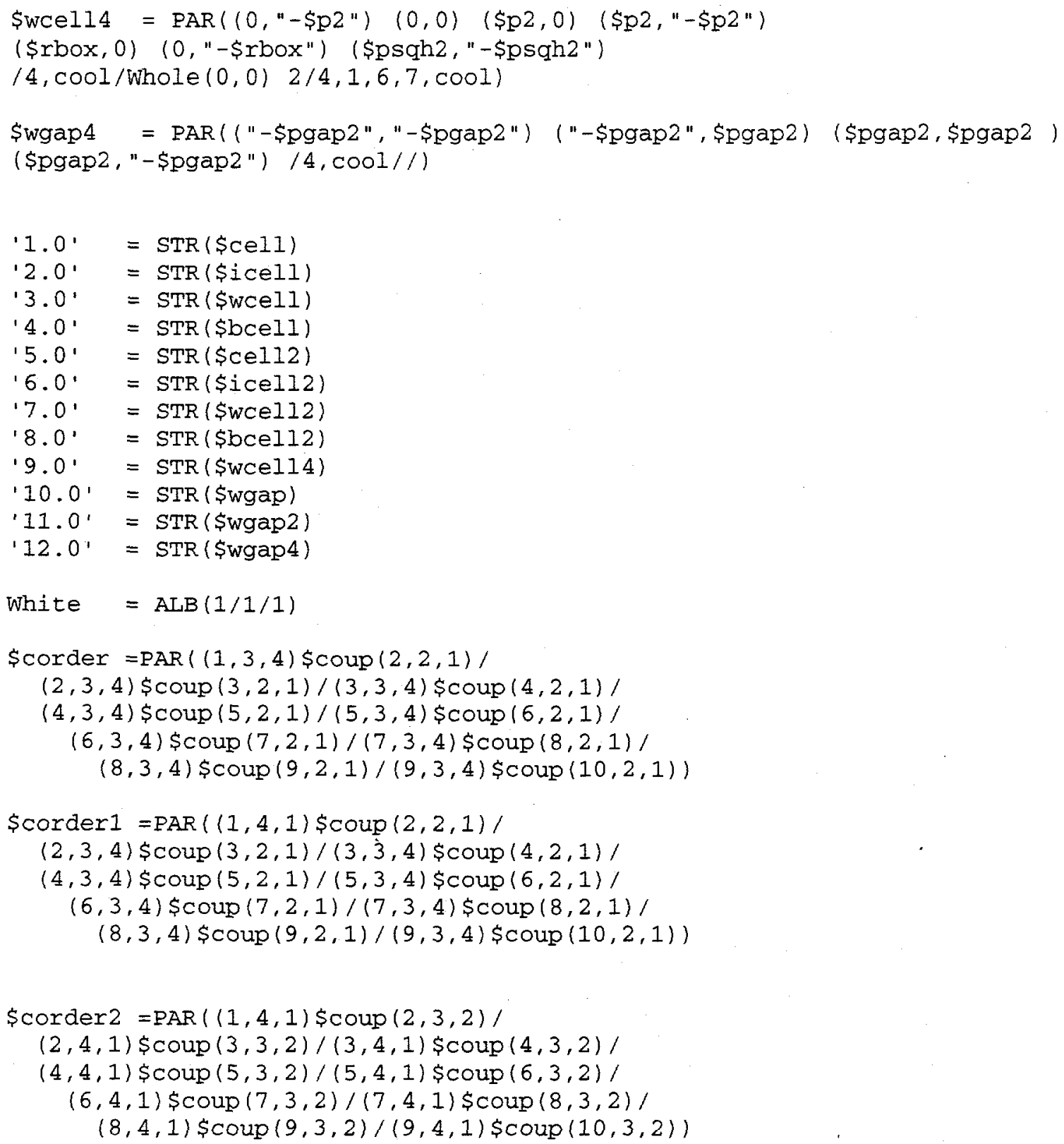

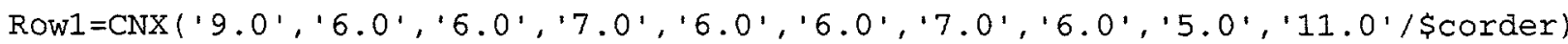

Row2 $=\operatorname{CNX}\left(' 6.0^{\prime}, ' 1.0^{\prime}, ' 1.0^{\prime}, ' 2.0^{\prime}, ' 1.0^{\prime}, ' 1.0^{\prime}, ' 2.0^{\prime}, ' 1.0^{\prime}, ' 1.00^{\prime}, 10.0 ' / \$ \operatorname{corder} 1\right)$ $\operatorname{Row} 3=\operatorname{CNX}\left({ }^{\prime} 6.0^{\prime}, \prime^{\prime} 1.0^{\prime}, ' 1.0^{\prime}, ' 2.0^{\prime}, ' 1.0^{\prime},{ }^{\prime} 1.0^{\prime}, ' 2.0^{\prime}, ' 1.0^{\prime}, 1^{\prime} 1.0^{\prime}, ' 10.0^{\prime} / \$ \operatorname{corder} 1\right)$ Row4 $=\operatorname{CNX}\left(' 7.0^{\prime}, ' 2.0^{\prime}, ' 2.0^{\prime}, ' 3.0^{\prime}, ' 2.0^{\prime}, ' 2.0^{\prime}, ' 3.0^{\prime}, ' 2.0^{\prime}, ' 1.0^{\prime}, 110.0^{\prime} / \$ \operatorname{corder} 1\right)$ Row5 $=\operatorname{CNX}\left({ }^{\prime} 6.0^{\prime}, ' 1.0^{\prime},{ }^{\prime} 1.0^{\prime}, ' 2.0^{\prime}, ' 1.0^{\prime}, ' 2.0^{\prime}, ' 2.0^{\prime}, ' 1.0^{\prime}, ' 1.0^{\prime}, ' 10.00^{\prime} \$ \operatorname{corder} 1\right)$ Row6 $=\operatorname{CNX}\left({ }^{\prime} 6.0^{\prime}, ' 1.0^{\prime}, ' 1.0^{\prime}, ' 2.0^{\prime}, ' 2.0^{\prime}, ' 3.0^{\prime}, ' 2.0^{\prime}, ' 1.0^{\prime}, ' 1.0^{\prime}, ' 10.00^{\prime} \$ \mathrm{corder} 1\right)$ 


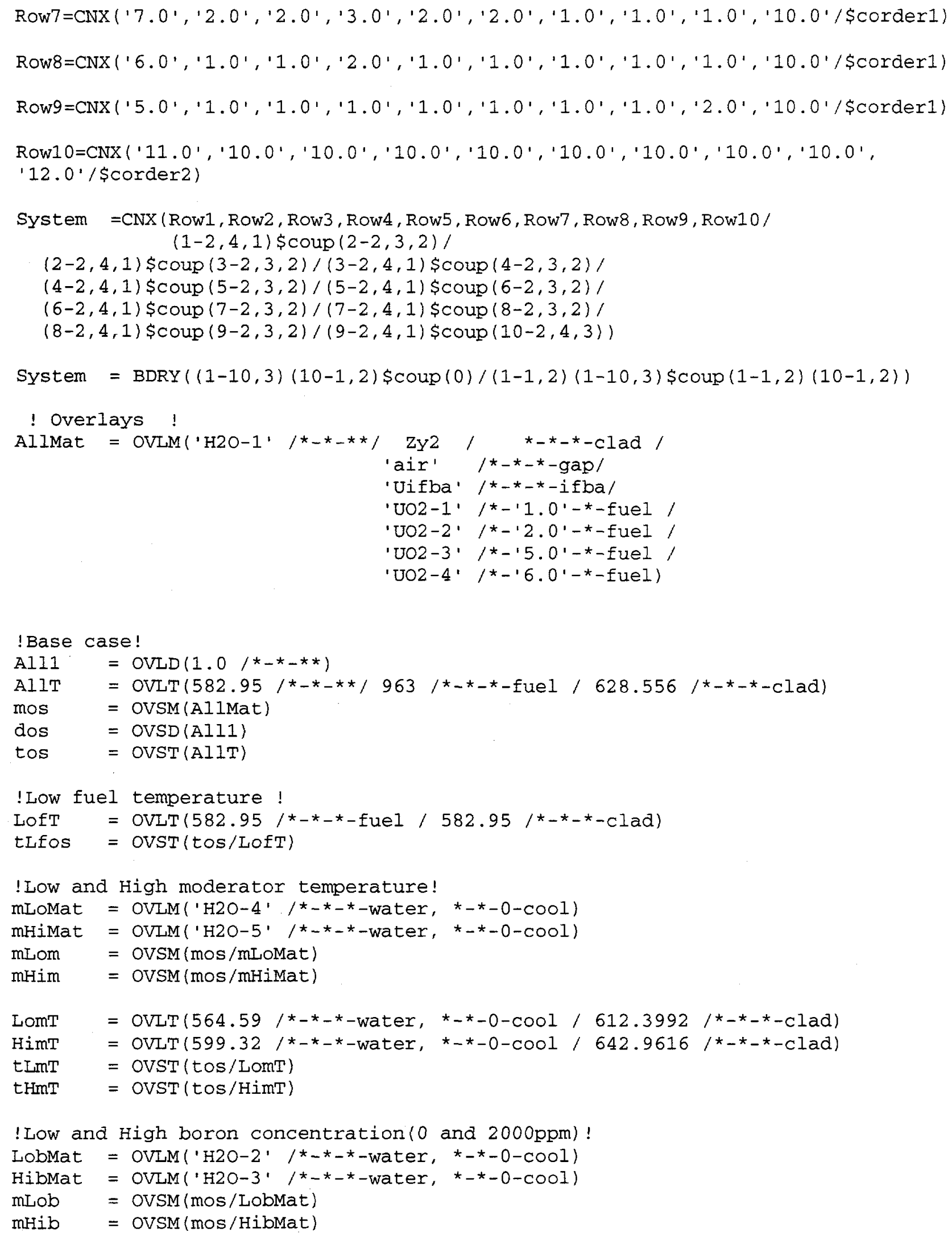




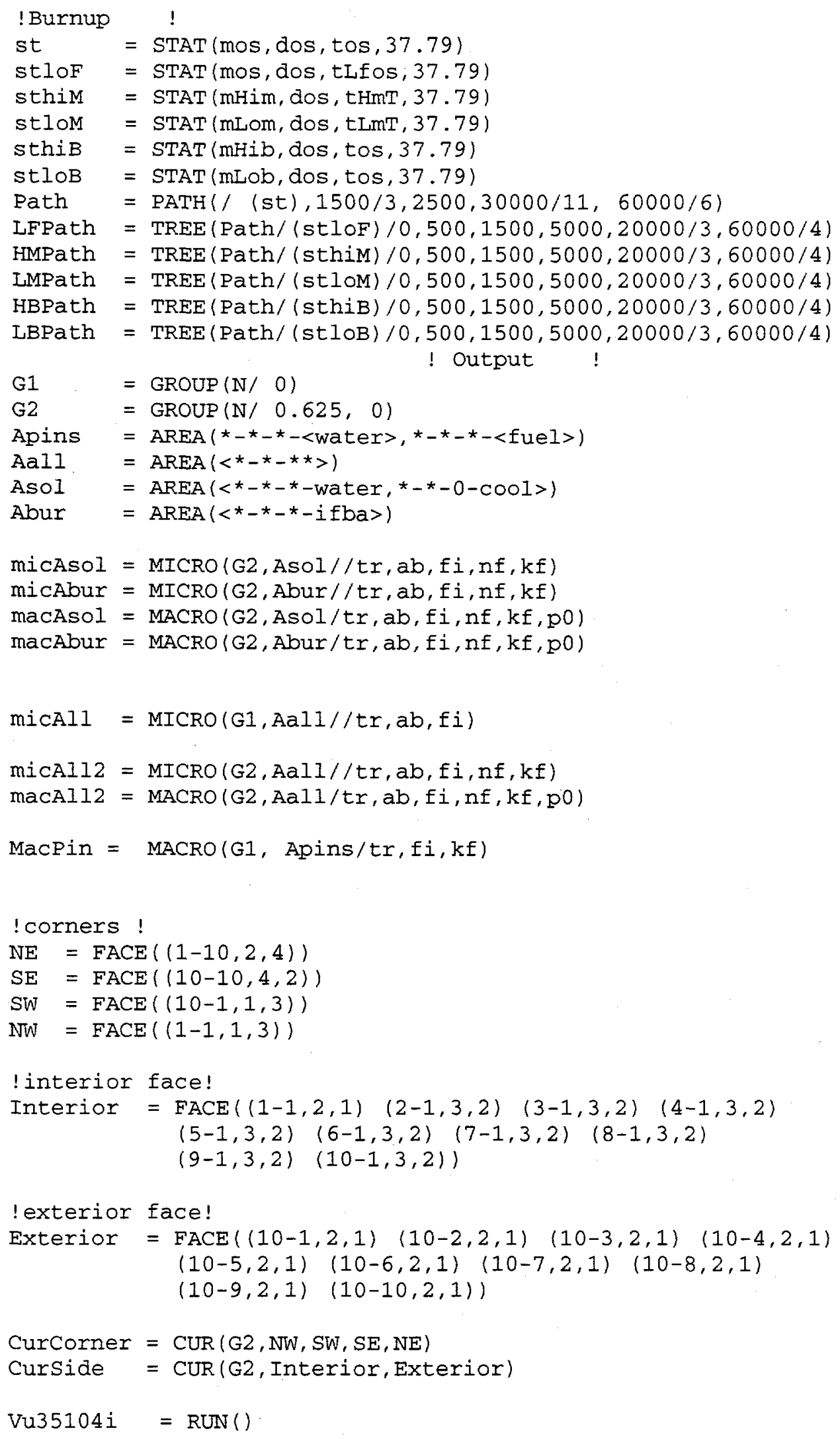




\section{Appendix D. HELIOS Input File: Reflector (hmhwhref34.inp)}

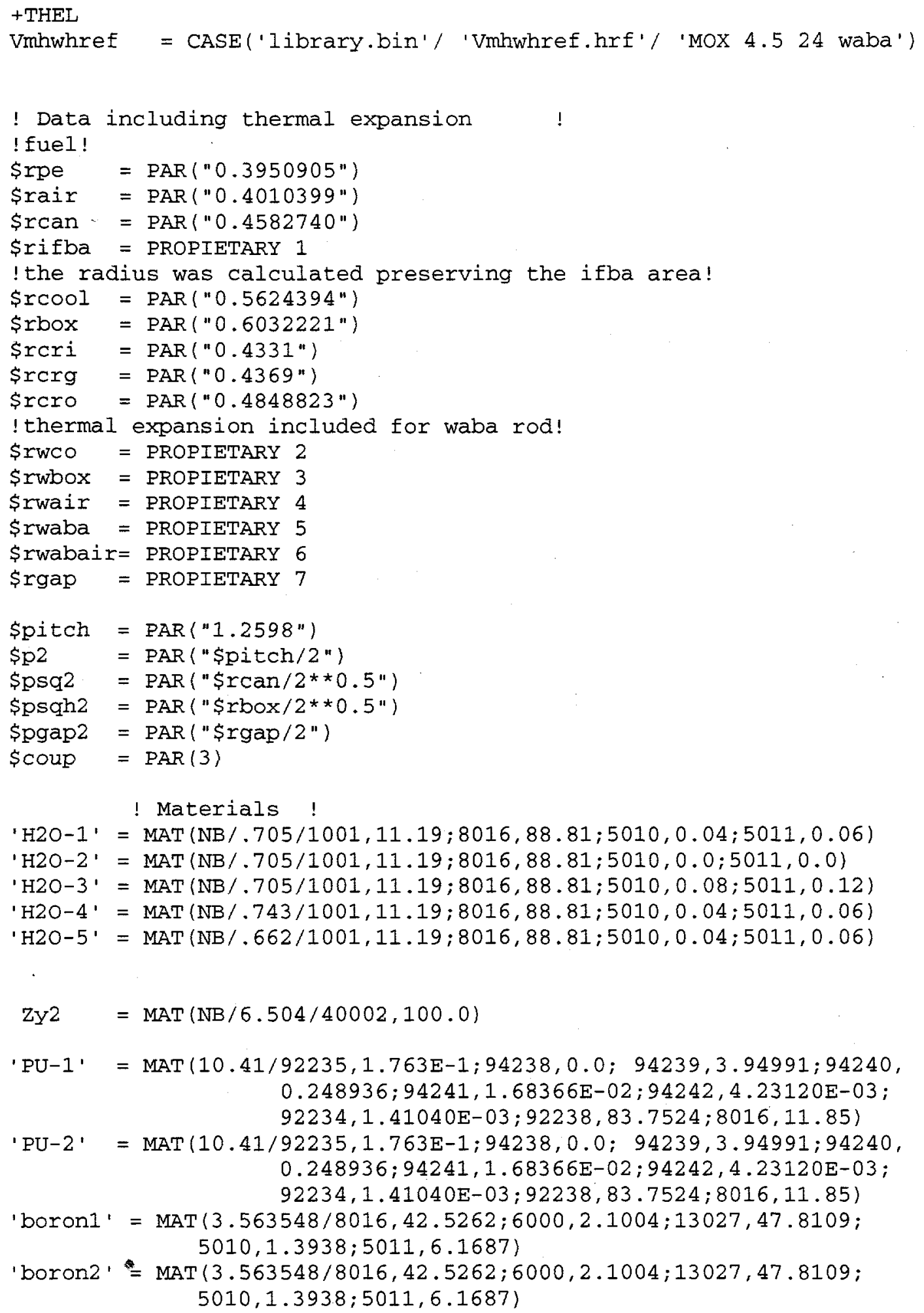


$\begin{array}{ll}\text { 'air' } & =\operatorname{MAT}(\mathrm{NB} / .001 / 8016,100) \\ \text { 'CRS' } & =\operatorname{MAT}(\mathrm{NB} / 7.92 / 14000,0.51 ; 24000,17.40 ; 25055,1.99 ; 26000,\end{array}$

$68.35 ; 28000,11.70)$

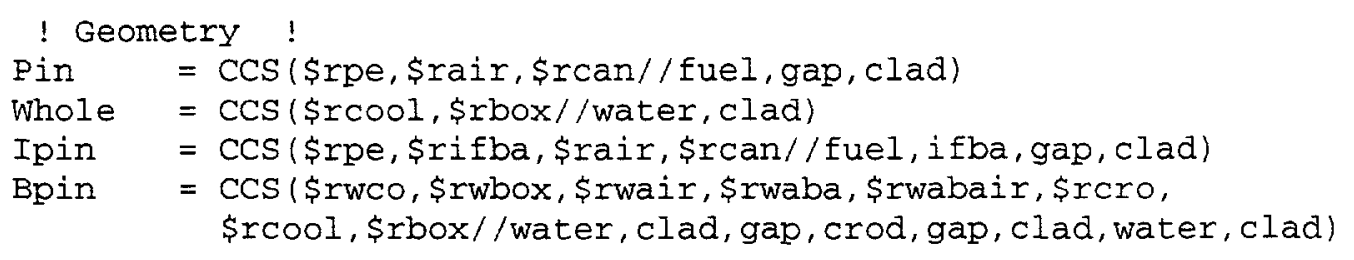

$\$ c e 11=\operatorname{PAR}(("-\$ p 2 ", "-\$ p 2 ")("-\$ p 2 ", \$ p 2)(\$ p 2, \$ p 2)(\$ p 2, "-\$ p 2 ") \quad !$ nodes $1-4 !$

$(0, "-\$ p 2 ") \quad("-\$ p 2 ", 0)(0, \$ p 2) \quad(\$ p 2,0) \quad(\$ r c a n, 0) \quad(0, "-\$ r c a n ") \quad("-\$ r c a n ", 0)$

$(0, \$ r c a n) \quad(\$ p s q 2, \$ p s q 2) \quad(\$ p s q 2, "-\$ p s q 2 ") \quad("-\$ p s q 2 ", "-\$ p s q 2 ")$ ("-\$psq2", \$psq2)

/4, cool/Pin $(0,0) / 1,6,11,15, \operatorname{cool} ; 6,2,16,11, \operatorname{cool} ; 2,7,12,16$, cool;

$7,3,13,12, \operatorname{cool} ; 3,8,9,13, \mathrm{cool} ; 8,4,14,9, \operatorname{cool} ; 4,5,10,14, \mathrm{cool})$

$\$$ icel1 = $\operatorname{PAR}(("-\$ \mathrm{p} 2 ", "-\$ \mathrm{p} 2 ")("-\$ \mathrm{p} 2 ", \$ \mathrm{p} 2)(\$ \mathrm{p} 2, \$ \mathrm{p} 2)(\$ \mathrm{p} 2, "-\$ \mathrm{p} 2 ") \quad$ !nodes $1-4 !$ $(0, "-\$ p 2 ") \quad("-\$ p 2 ", 0) \quad(0, \$ p 2) \quad(\$ p 2,0) \quad(\$ r \operatorname{can}, 0) \quad(0, "-\$ r c a n ") \quad("-\$ r c a n ", 0)$

$(0, \$ r c a n) \quad(\$ p s q 2, \$ p s q 2) \quad(\$ p s q 2, "-\$ p s q 2 ") \quad("-\$ p s q 2 ", "-\$ p s q 2 ") \quad$ (" -\$psq2 ", \$psq2)

4, cool/Ipin $(0,0) / 1,6,11,15$, cool; 6,2,16,11, cool;

$2,7,12,16, \operatorname{cool} ; 7,3,13,12, \operatorname{cool} ; 3,8,9,13, \operatorname{cool} ; 8,4,14,9, \operatorname{cool} ; 4,5,10,14, \mathrm{co01})$

$\$ w c e 11=\operatorname{PAR}("-\$ p 2 ", "-\$ p 2 ")("-\$ p 2 ", \$ p 2)(\$ p 2, \$ p 2)(\$ p 2, "-\$ p 2 ") \quad$ !nodes $1-4 !$

$(0, "-\$ p 2 ") \quad("-\$ p 2 ", 0)(0, \$ p 2) \quad(\$ p 2,0) \quad(\$ r b o x, 0) \quad(0, "-\$ r b o x ") \quad("-\$ r b o x ", 0)$

(0,\$rbox) (\$psqh2, \$psqh2) (\$psqh2,"-\$psqh2") ("-\$psqh2", "-\$psqh2")

("-\$psqh2 " \$psqh2)/4, cool/Whole $(0,0) / 1,6,11,15$, cool; 6, 2, 16, 11, cool;

$2,7,12,16, \operatorname{cool} ; 7,3,13,12, \operatorname{cool} ; 3,8,9,13, \operatorname{cool} ; 8,4,14,9, \operatorname{cool} ; 4,5,10,14, \operatorname{cool})$

$\$ \mathrm{bce} 11=\operatorname{PAR}(("-\$ \mathrm{p} 2 ", "-\$ \mathrm{p} 2 ")("-\$ \mathrm{p} 2 ", \$ \mathrm{p} 2) \quad(\$ \mathrm{p} 2, \$ \mathrm{p} 2) \quad(\$ \mathrm{p} 2, "-\$ \mathrm{p} 2 ") \quad$ !nodes $1-4 !$ $(0, "-\$ p 2 ") \quad("-\$ p 2 ", 0) \quad(0, \$ p 2) \quad(\$ p 2,0) \quad(\$ r b o x, 0) \quad(0, "-\$ r b o x ") \quad("-\$ r b o x ", 0)$

$(0, \$ r b o x)$ (\$psqh2, \$psqh2) (\$psqh2, "-\$psqh2") ("-\$psqh2", "-\$psqh2")

("-\$psqh2" , \$psqh2) /4, cool/Bpin $(0,0) / 1,6,11,15, \operatorname{cool} ; 6,2,16,11$, cool;

$2,7,12,16, \operatorname{coo} 1 ; 7,3,13,12, \operatorname{cool} ; 3,8,9,13, \operatorname{cool} ; 8,4,14,9, \operatorname{cool} ; 4,5,10,14, \operatorname{cool})$

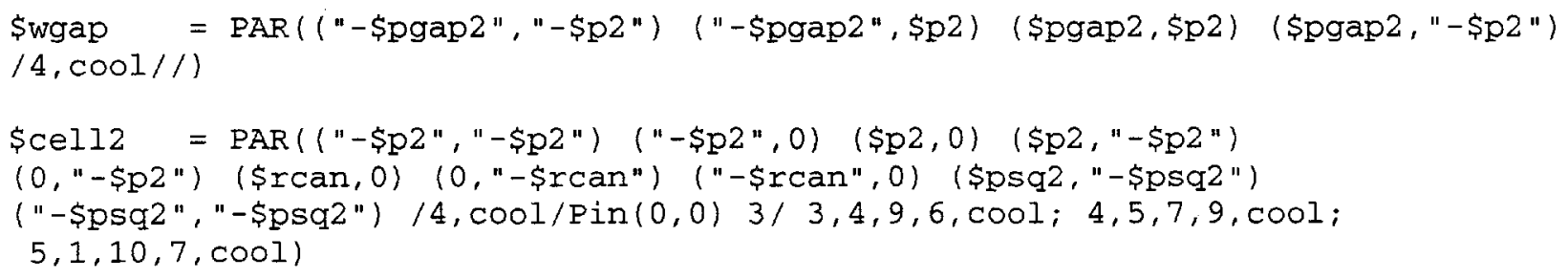

$\$$ icel12 = PAR ( " $-\$ p 2 ", "-\$ p 2 ")("-\$ p 2 ", 0)(\$ p 2,0)(\$ p 2, "-\$ p 2 ")$

$(0, "-\$ p 2 ") \quad(\$ r c a n, 0) \quad(0, "-\$ r c a n ") \quad("-\$ r c a n ", 0) \quad(\$ p s q 2, "-\$ p s q 2 ")$

("-\$psq2", "-\$psq2")/4, cool/Ipin (0,0) 4/ 3,4,9,6, cool; 4,5,7,9, cool;

$5,1,10,7, \mathrm{COO} 1)$

$\$ w c e 112=\operatorname{PAR}(("-\$ p 2 ", "-\$ p 2 ")("-\$ p 2 ", 0)(\$ p 2,0)(\$ p 2, "-\$ p 2 ")$

$(0, "-\$ p 2 ") \quad(\$ r b o x, 0) \quad(0, "-\$ r b o x ") \quad("-\$ r b o x ", 0) \quad(\$ p s q h 2, "-\$ p s q h 2 ")$

("-\$psqh2", "-\$psqh2")/4, cool/Whole $(0,0) 2 / 3,4,9,6, \operatorname{cool} ; 4,5,7,9$, cool;

$5,1,10,7, \mathrm{cool})$

$\$$ bcel12 = PAR ( $("-\$ p 2 ", "-\$ p 2 ")("-\$ p 2 ", 0) \quad(\$ p 2,0) \quad(\$ p 2, "-\$ p 2 ")$

$(0, "-\$ p 2 ")(\$ r b o x, 0)(0, "-\$ r b o x ") \quad("-\$ r b o x ", 0)(\$ p s q h 2, "-\$ p s q h 2 ")$

("-\$psqh2","-\$psqh2")/4, cool/Bpin (0,0) 8/3,4,9,6, cool; 4,5,7,9, cool; 


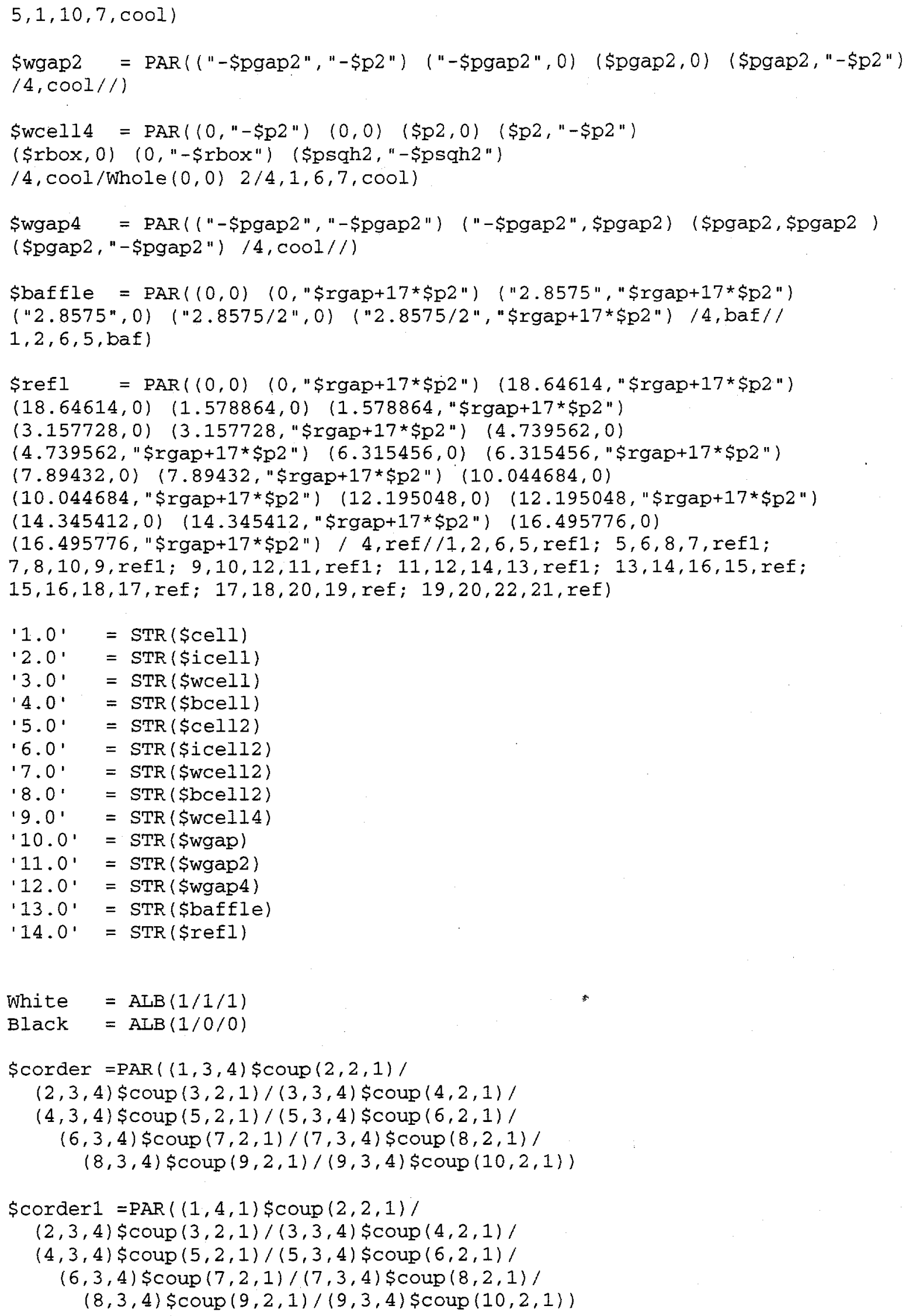




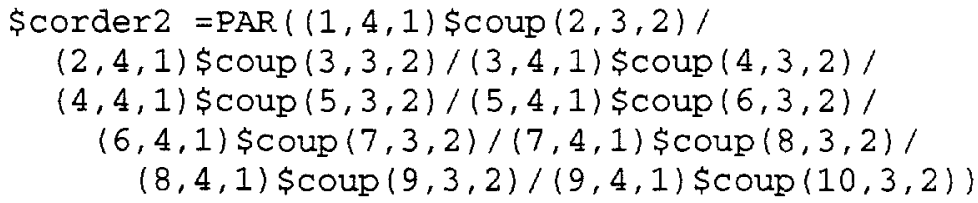

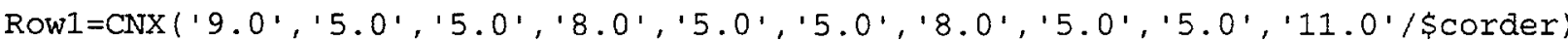

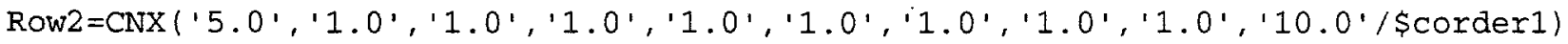

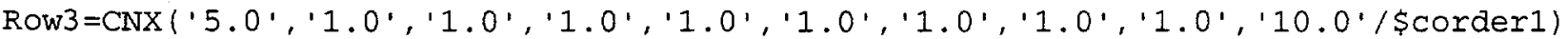

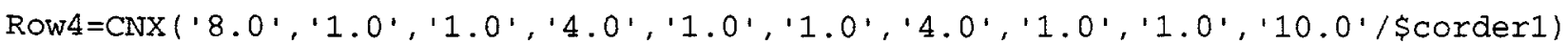

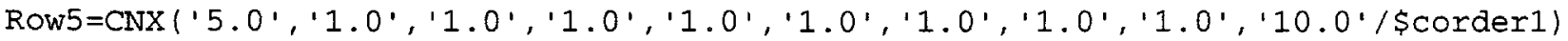

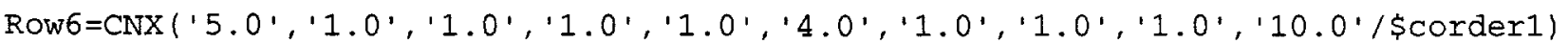

Row $7=\operatorname{CNX}\left({ }^{\prime} 8.0^{\prime}, \prime^{\prime} 1.0^{\prime}, ' 1.0^{\prime}, ' 4.0^{\prime}, ' 1.0^{\prime}, ' 1.0^{\prime}, ' 1.0^{\prime}, ' 1.0^{\prime}, ' 1.0^{\prime}, ' 10.0^{\prime} / \$ \operatorname{corder} 1\right)$

Row8 $=\operatorname{CNX}\left({ }^{\prime} 5.0^{\prime},{ }^{\prime} 1.0^{\prime},{ }^{\prime} 1.0^{\prime},{ }^{\prime} 1.0^{\prime}, ' 1.0^{\prime}, ' 1.0^{\prime}, ' 1.0^{\prime}, ' 1.0^{\prime}, 1^{\prime} 0^{\prime}, ' 10.0^{\prime} / \$ \operatorname{corder} 1\right)$

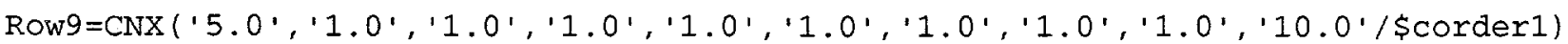

Row10 $=\operatorname{CNX}\left(' 11.0^{\prime}, ' 10.0^{\prime}, ' 10.0^{\prime}, 110.0^{\prime}, ' 10.0^{\prime}, ' 10.0^{\prime}, ' 10.0^{\prime}, ' 10.0^{\prime}, ' 10.0^{\prime}\right.$, $12.0 \cdot /$ \$corder2)

System =CNX (Row1, Row2, Row3, Row4, Row5, Row6, Row7, Row8, Row9, Row10, '13.0', '14.0'/ $(1-2,4,1) \$ \operatorname{coup}(2-2,3,2) /$

$(2-2,4,1) \$ \operatorname{coup}(3-2,3,2) /(3-2,4,1) \$ \operatorname{coup}(4-2,3,2) /$

$(4-2,4,1) \$ \operatorname{coup}(5-2,3,2) /(5-2,4,1) \$ \operatorname{coup}(6-2,3,2) /$

$(6-2,4,1) \$ \operatorname{coup}(7-2,3,2) /(7-2,4,1) \$ \operatorname{coup}(8-2,3,2) /$

$(8-2,4,1) \$ \operatorname{coup}(9-2,3,2) /(9-2,4,1) \$ \operatorname{coup}(10-2,4,3) /$

$(10-10,1,4) \$ \operatorname{coup}(11,1,(0, " \$ \operatorname{rgap} ")) /(11,3,4) \$ \operatorname{coup}(12,2,1))$

System = BDRY $((12,4,3) \$ \operatorname{coup}($ White $) /(12,3,4) \$ \operatorname{coup}(B$ lack $))$

! Overlays !

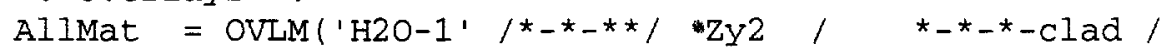

'air' /*-*-*-gap/

'PU-1'/*-'1.0'-*-fuel /

'PU-2' $/{ }^{*}-$ ' $^{\prime}$. O'-*-fuel $/$

'boronl' $/ t^{*}-4.0 \cdot-*-\operatorname{crod} /$

'boron2' $/ *_{-} \cdot 8.0 *-{ }^{*} \operatorname{crod} /$

'CRS' $/ *_{-*}-0-$ baf)

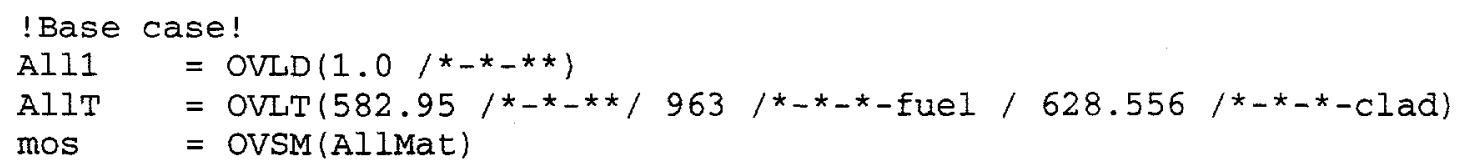




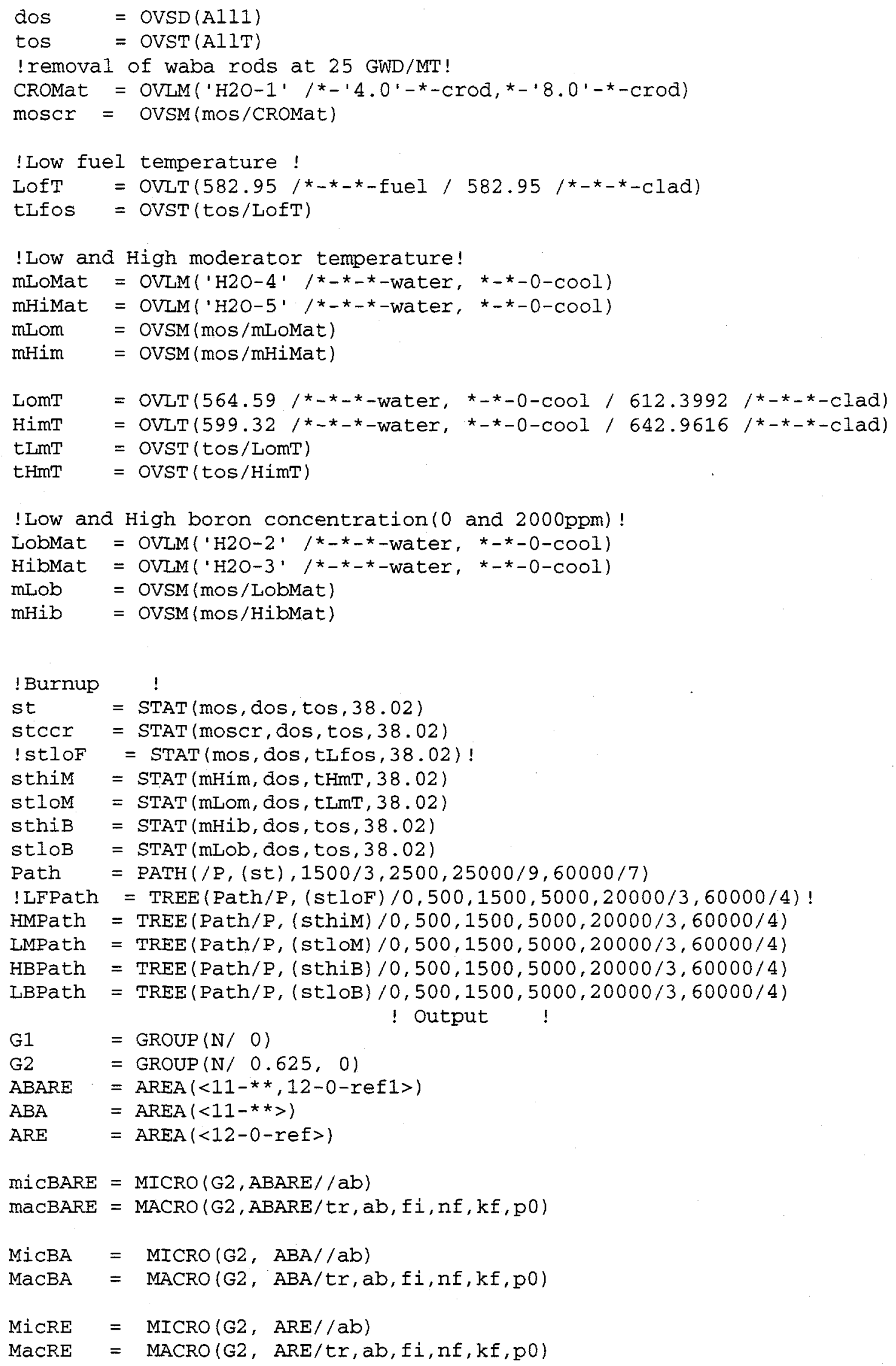




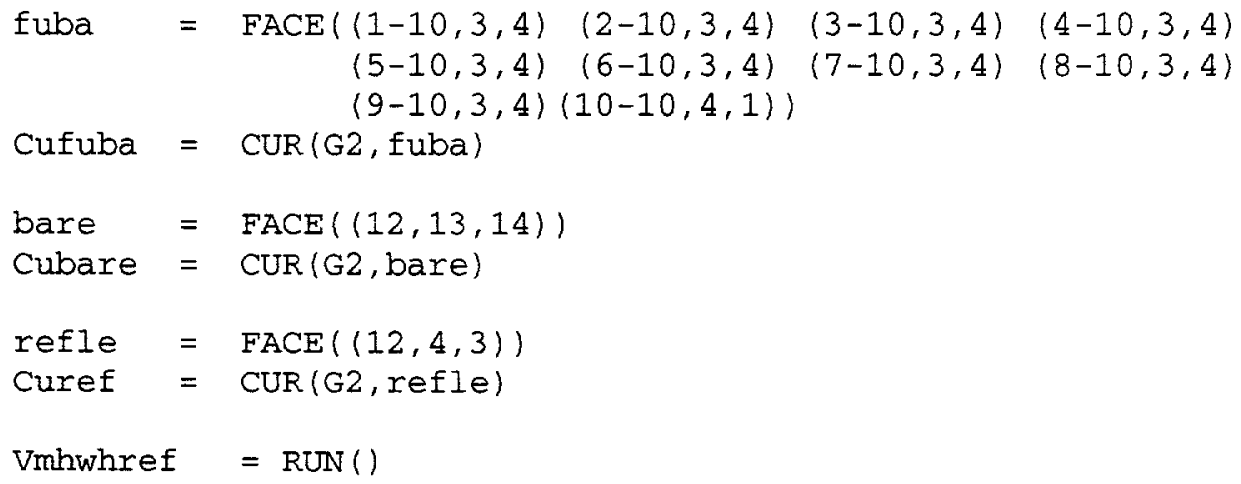




\section{Appendix E. Zenith Input: Fuel Assemblies (zmhwh89g1.inp)}

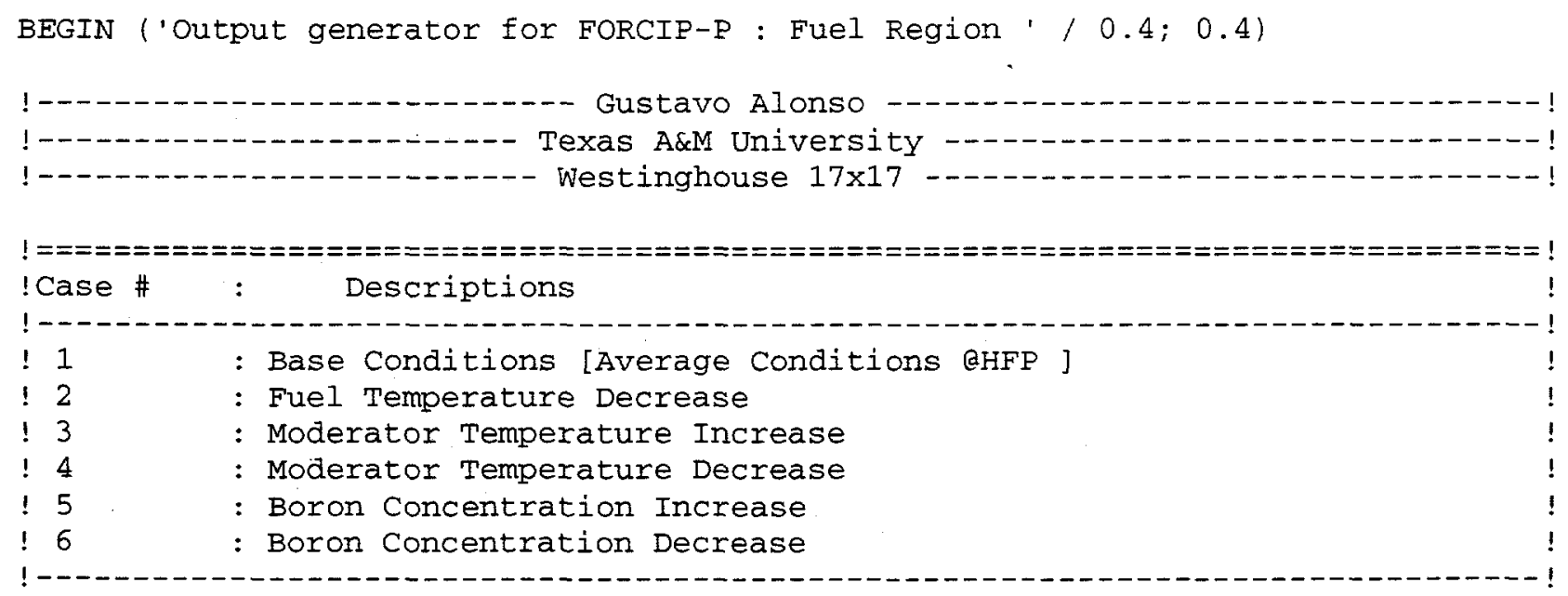

\begin{tabular}{|c|c|c|}
\hline !File \# & File Name & ! \\
\hline & - - - - - - & $----------!$ \\
\hline$! 1$ & : Vuhhi.hrf & ! \\
\hline$! 2$ & : Vuhmi.hrf & $!$ \\
\hline 3 & : Vuhni.hrf & $!$ \\
\hline$! 4$ & : Vulhi.hrf & $!$ \\
\hline 5 & : Vulmi.hre & $!$ \\
\hline$! 6$ & : Vulni.hrf & ! \\
\hline 7 & : Vmhwh89h.hrf & $!$ \\
\hline 8 & : Vmhwl89g.hrf & $!$ \\
\hline 9 & : Vmlwh89g.hrf & ! \\
\hline 10 & : Vmlwl $89 \mathrm{~g} \cdot \mathrm{hrf}$ & ! \\
\hline 11 & : Vmhwn89g.hrf & ! \\
\hline 12 & : Vmlwn89g.hrf & ! \\
\hline
\end{tabular}

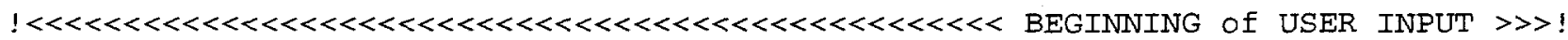

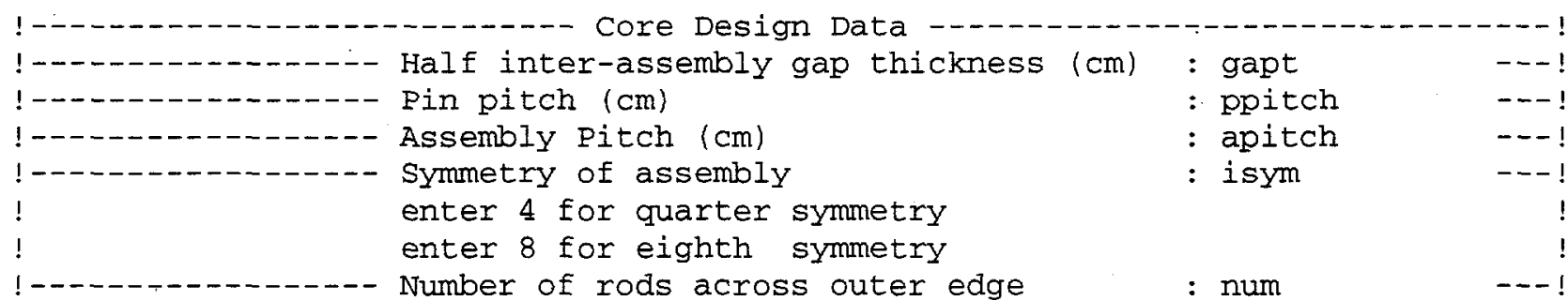

$\begin{array}{ll}\text { gapt } & =\operatorname{FOR}(0.0217621) \\ \text { ppitch } & =\operatorname{FOR}(1.2623574) \\ \text { apitch } & =\operatorname{FOR}(21.5036) \\ \text { isym } & =\operatorname{FOR}(8) \\ \text { num } & =\operatorname{FOR}(17)\end{array}$




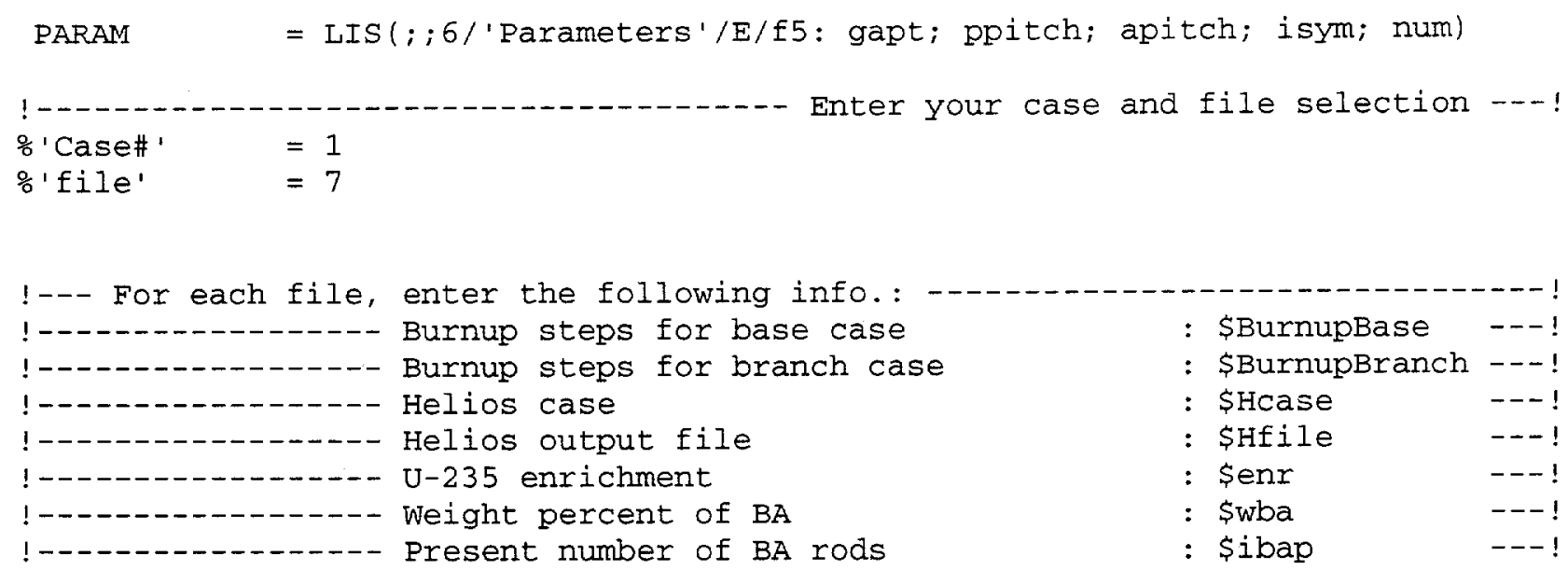

oif ('file'.eq.1) then

$\$$ BurnupBase $=\operatorname{PAR}(0,500,1000,1500,2500,5000,7500,10000,12500$, $15000,17500,20000,22500,25000,27500,30000,35000$, $40000,45000,50000,55000,60000)$

$\$$ BurnupBranch $=\operatorname{PAR}(0,500,1500,5000,10000,15000,20000$,

$30000,40000,50000,60000)$

\$Hcase $\quad=$ PAR ('Vuhhi')

\$Hfile $\quad=$ PAR ('Vuhhi.hrf')

C1 $\quad$ IMP (HELIOS; \$Hcase $/$ \$Hfile)

$\begin{array}{lll}\text { enr } & =\operatorname{FOR}(4.5) & \\ \text { wba } & =\operatorname{FOR}(0.000) & \\ \text { ibap } & =\operatorname{FOR}(128) & \text { ! present number of BA rods ! } \\ \text { FILEPARAM } & =\text { LIS (/'Parameters /E/f5: enr; fO: wba; ibap) }\end{array}$

ondif

sif ('file'.eq.2) then

\$BurnupBase $=\operatorname{PAR}(0,500,1000,1500,2500,5000,7500,10000,12500$, $15000,17500,20000,22500,25000,27500,30000,35000$, $40000,45000,50000,55000,60000)$

$\$$ BurnupBranch $=\operatorname{PAR}(0,500,1500,5000,10000,15000,20000$,

\$Hcase $\quad=$ PAR ('Vuhmi')

\$Hfile $\quad=$ PAR ('Vuhmi.hrf')

$\mathrm{C} 1=\operatorname{IMP}($ HELIOS; \$Hcase $/$ Hfile)

enr $\quad=$ FOR $(4.5)$

wba $\quad=$ FOR $(0.000)$

ibap $\quad=$ FOR (64)

FILEPARAM = LIS (/'Parameters'/E/f5: enr; f0: wba; ibap)

sendif

oif ('file'.eq.3) then

\$BurnupBase $=\operatorname{PAR}(0,500,1000,1500,2500,5000,7500,10000,12500$, $15000,17500,20000,22500,25000,27500,30000,35000$, $40000,45000,50000,55000,60000)$

$\$$ BurnupBranch $=\operatorname{PAR}(0,500,1500,5000,10000,15000,20000$,

\$Hcase $\quad=\operatorname{PAR}($ 'Vuhni') 


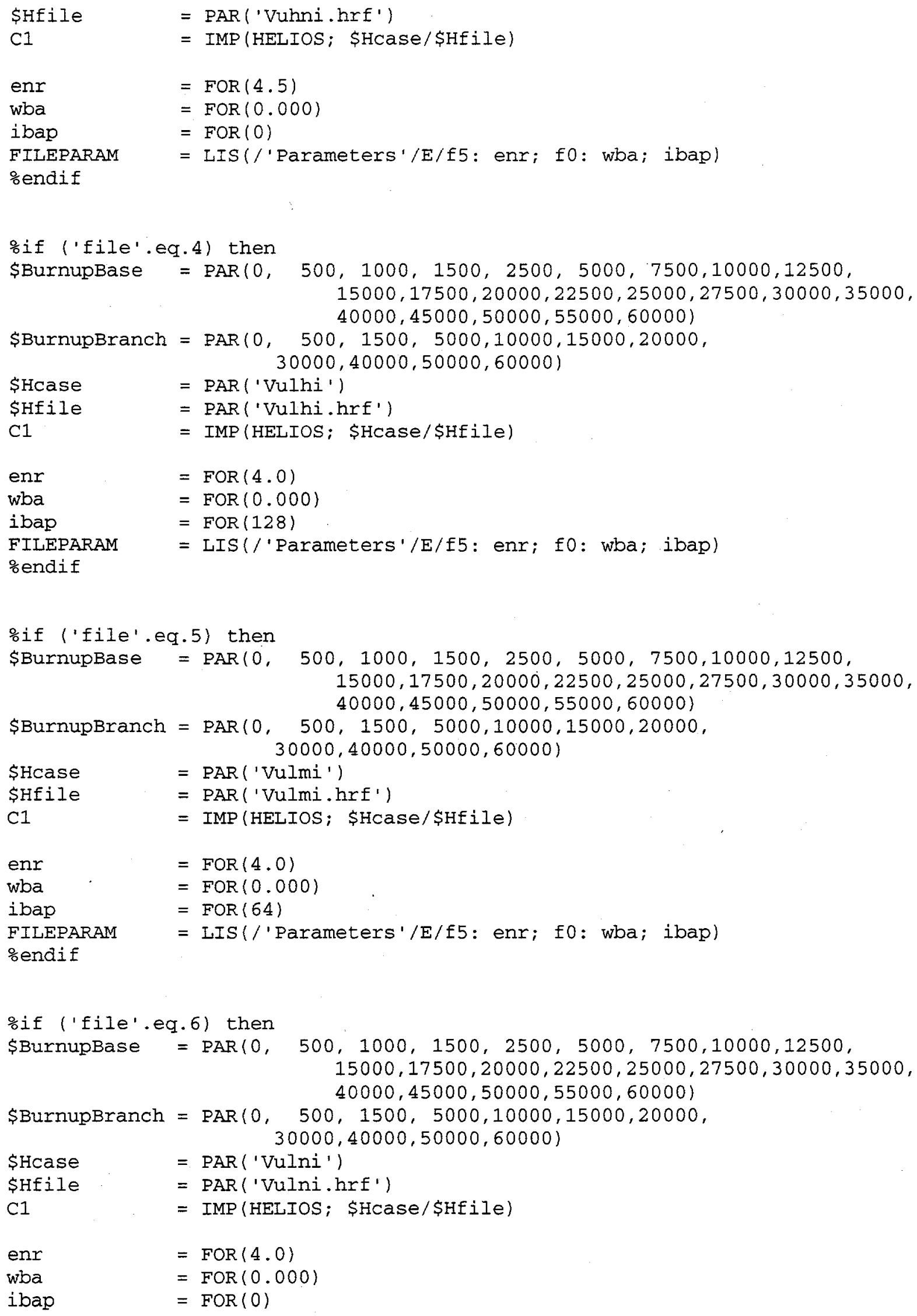




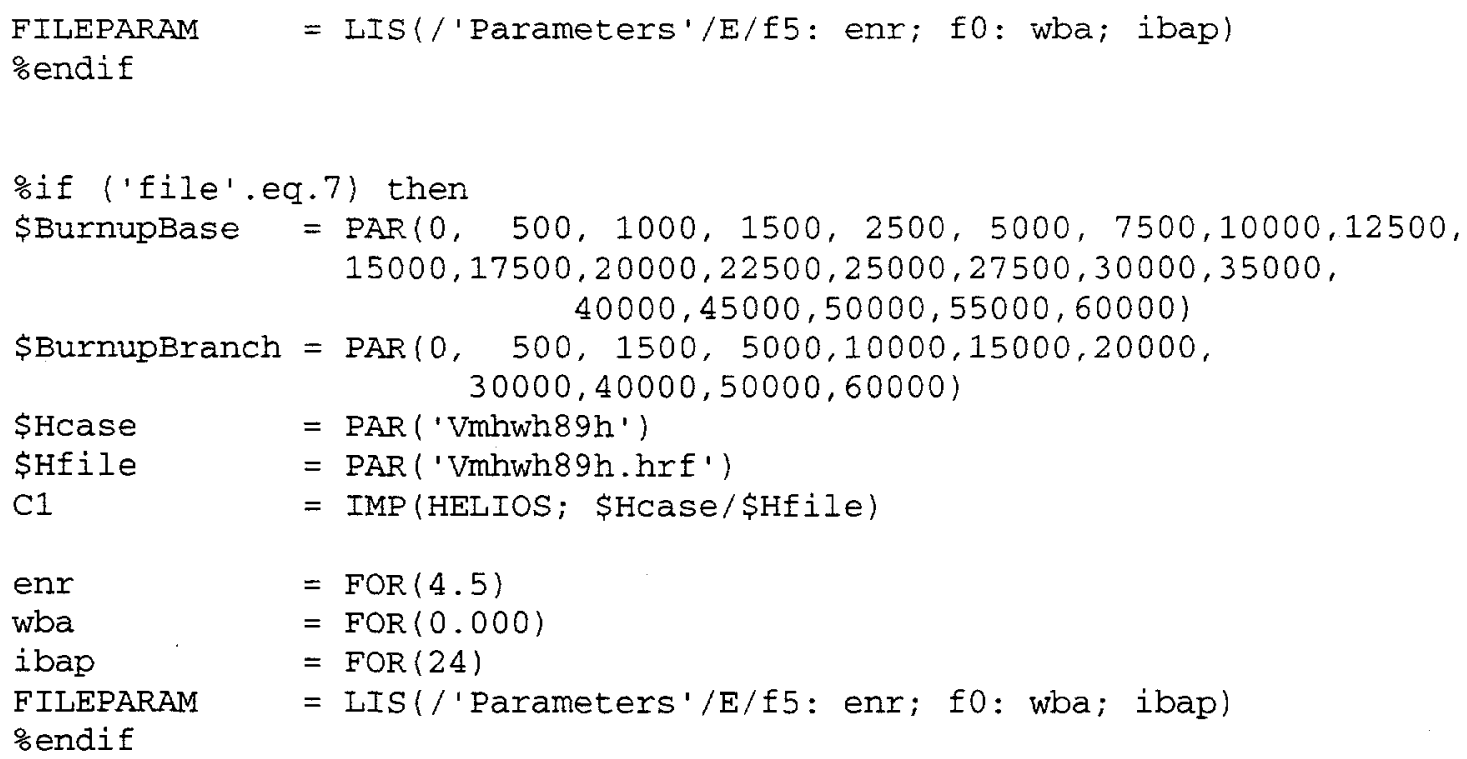



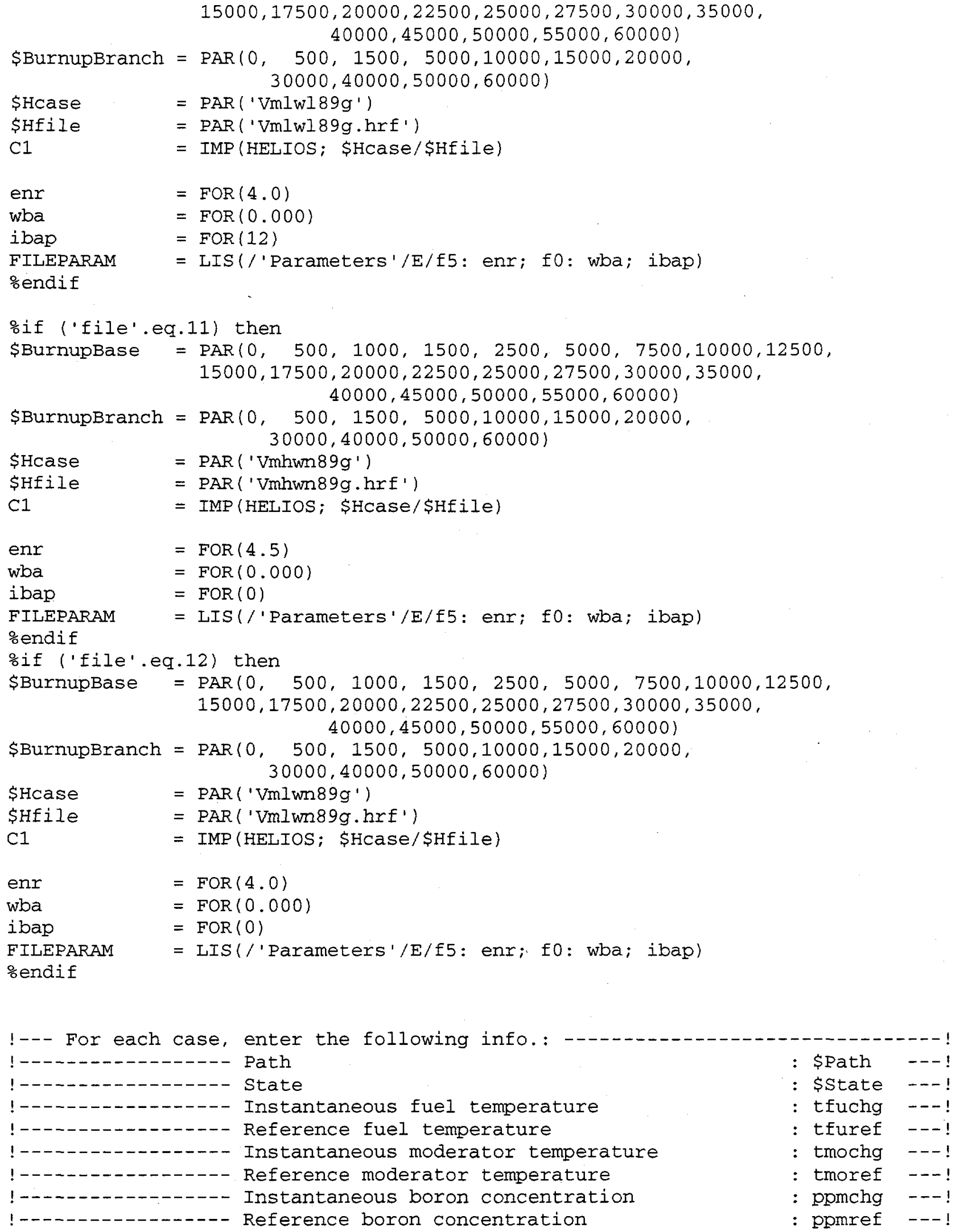
$\begin{array}{ll}\text { tfuref } & =\operatorname{FOR}(963) \\ \text { tmochg } & =\operatorname{FOR}(564.59) \\ \text { tmoref } & =\operatorname{FOR}(582.95) \\ \text { ppmchg } & =\operatorname{FOR}(1000) \\ \text { ppmref } & =\operatorname{FOR}(1000) \\ \text { CASEPARAM } & =\operatorname{IIS}(; ; 6 / \text { 'Parameters. }\end{array}$

sendif

/E/f2:tfuchg; tfuref; tmochg; tmoref;ppmchg; ppmref)

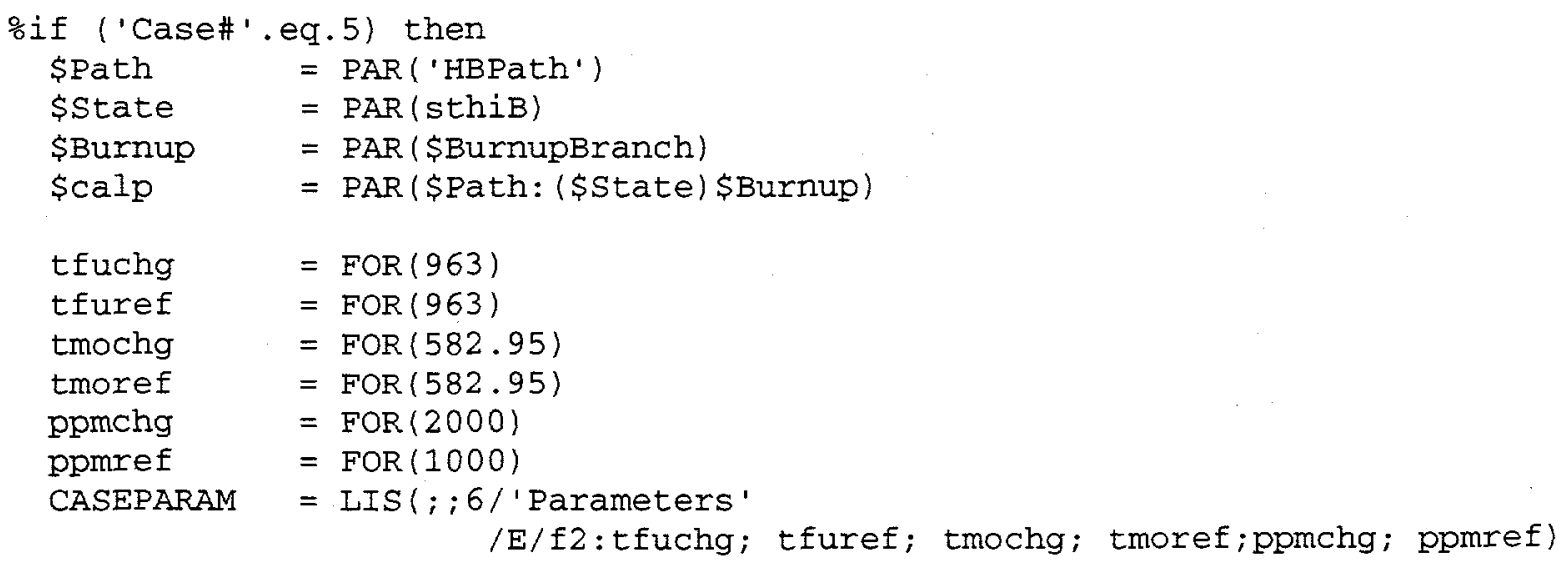

\%endif

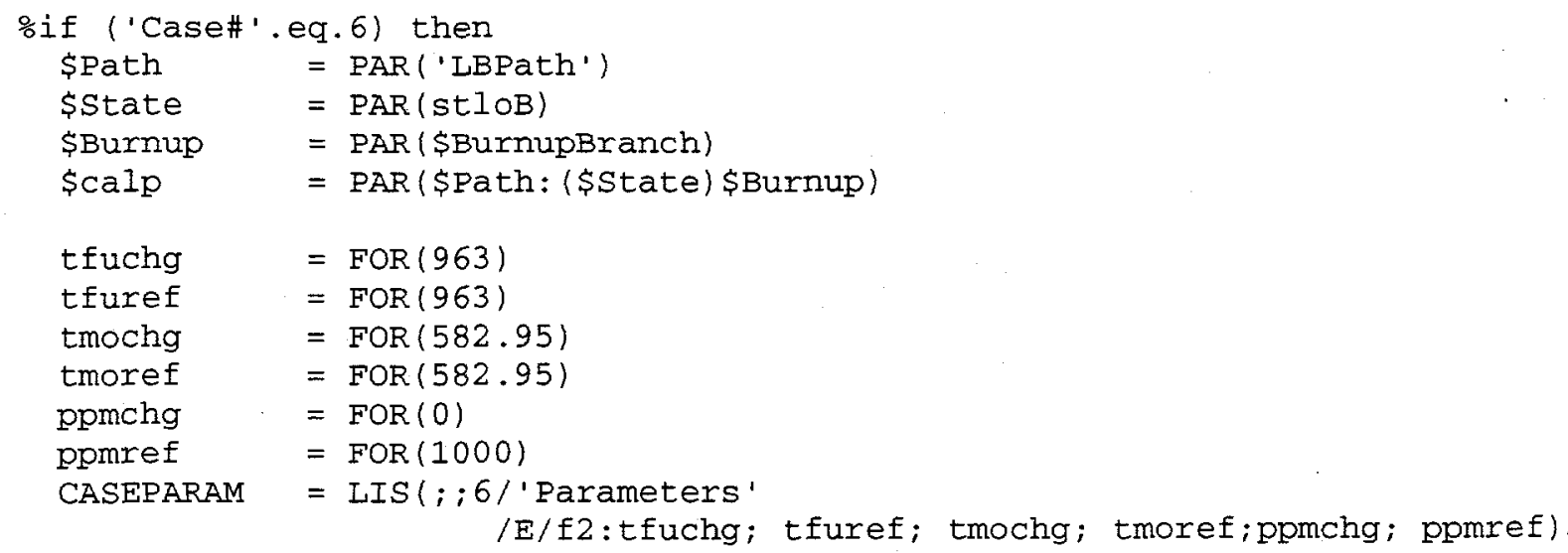

\%endif

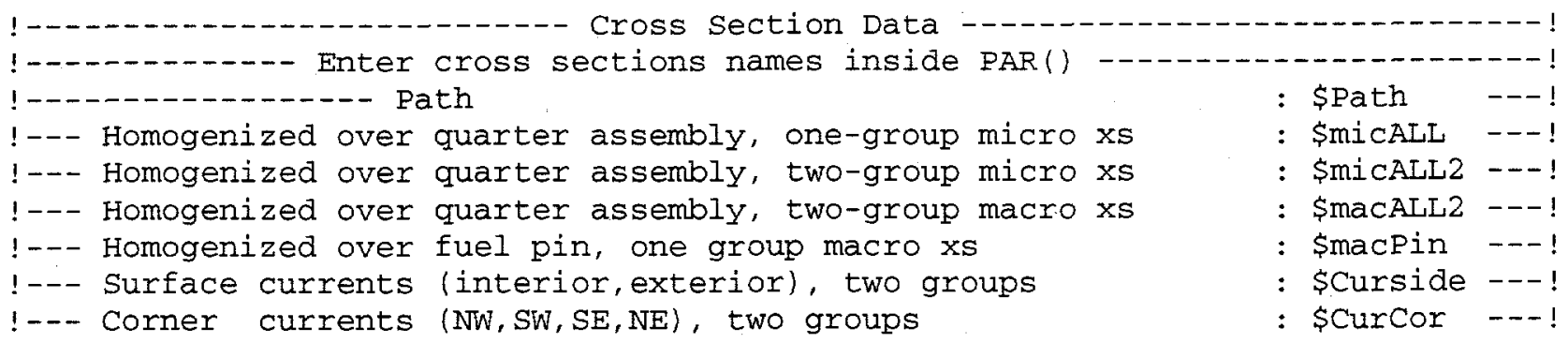

$\begin{array}{ll}\$ m i c A L L & =\text { PAR ('micAll') } \\ \$ \text { micALL2 } & =\text { PAR('micAll2') } \\ \text { \$macALL2 } & =\text { PAR ('macAll2') } \\ \text { \$macPin } & =\text { PAR('MacPin') }\end{array}$ 


$\begin{array}{ll}\text { \$micAsol } & =\operatorname{PAR} \text { ('micAsol') } \\ \text { \$macAsol } & =\operatorname{PAR} \text { ('macAsol') } \\ \text { \$micAbur } & =\operatorname{PAR} \text { ('micAbur') } \\ \text { \$macAbur } & =\operatorname{PAR} \text { ('macAbur') } \\ \text { \$CurSide } & =\operatorname{PAR} \text { ('CurSide') } \\ \text { \$CurCor } & =\operatorname{PAR} \text { ('CurCorner') }\end{array}$

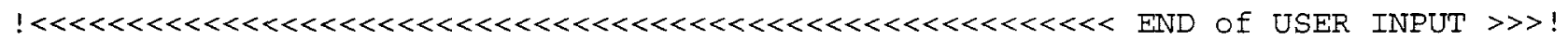
!No need to change anything below except when $<<<$ notice $>>$ sign appears

bu

$=\operatorname{SEL}(u b u r n / M A C / C 1 ;$ macALL $2 / \$ c a l p)$

! (1) ADF !

jpsid

jmsid

$\mathrm{Ex}$

Sides

$\mathrm{ADF}$

$=\operatorname{SEL}(j \mathrm{p} / \mathrm{CUR} / \mathrm{C1}$; CurSide/\$Calp)

$=\operatorname{SEL}(\mathrm{jm} / \mathrm{CUR} / \mathrm{Cl}$; SCurSide/\$calp)

$=\operatorname{SEL}(\mathrm{fx} / \mathrm{MAC} / \mathrm{C1} ;$ \$macALL2/\$calp $)$

$=\operatorname{FOR}(2 *(j p s i d+j m s i d) / f x)$

= LIS (/'Assembly Discontinuity Factors' /E/f0:bu;e5:Sides)

! (2) CDF !

jpcor $\quad=\operatorname{SEL}(j p / C U R / C l ; \$ C u r C o r / \$ C a l p)$

jmcor $\quad$ SEL $(j m / C U R / C 1 ; \$ C u r C o r / \$ C a l p)$

Corners $\quad=\operatorname{FOR}(2 *(j p c o r+j m c o r) / f x)$

CDF

= LIS(/'Corner Discontinuity Factors'

/E/f0:bu; e5:Corners)!

\section{! (3) FPYIELDS !}

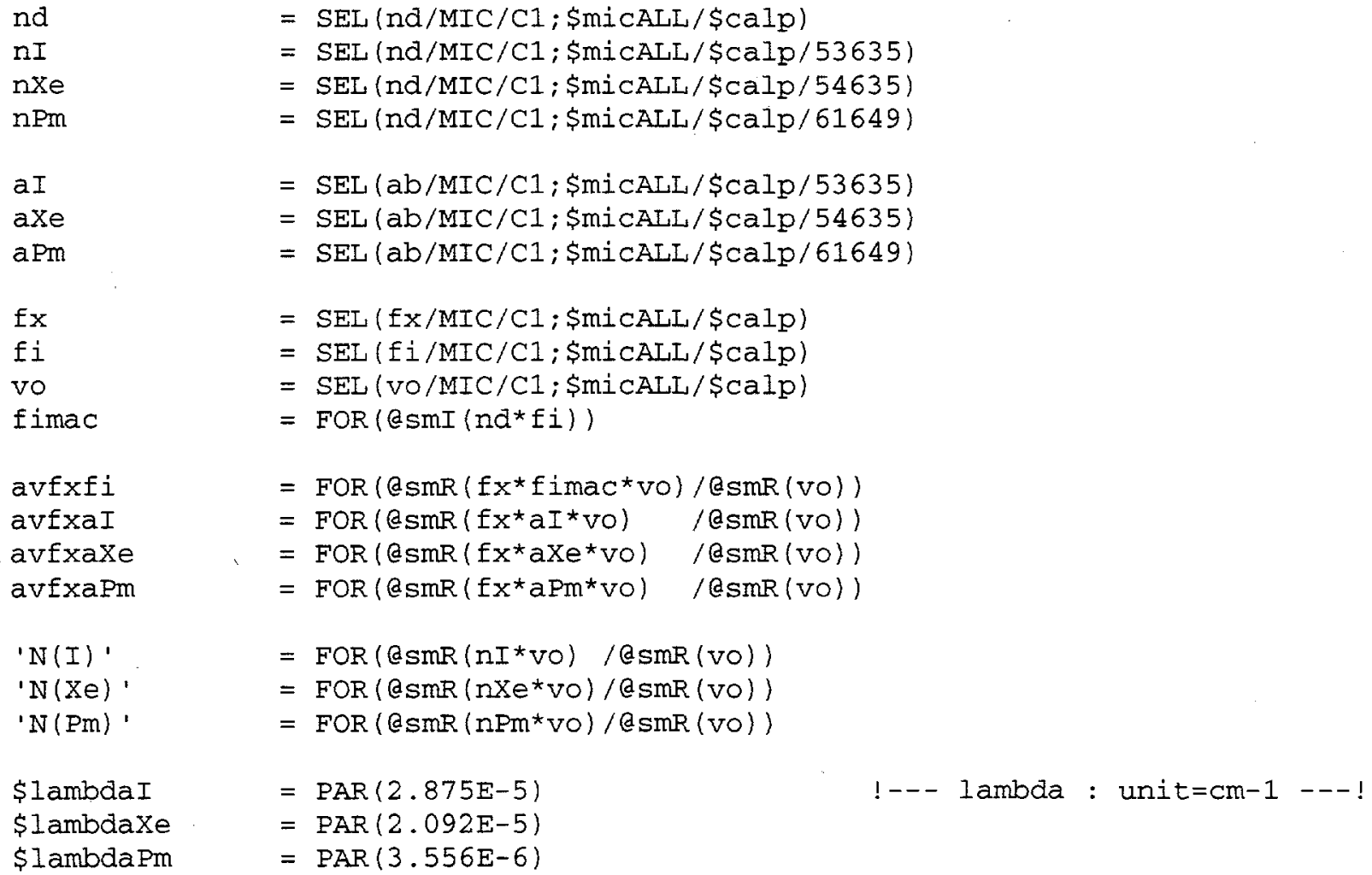




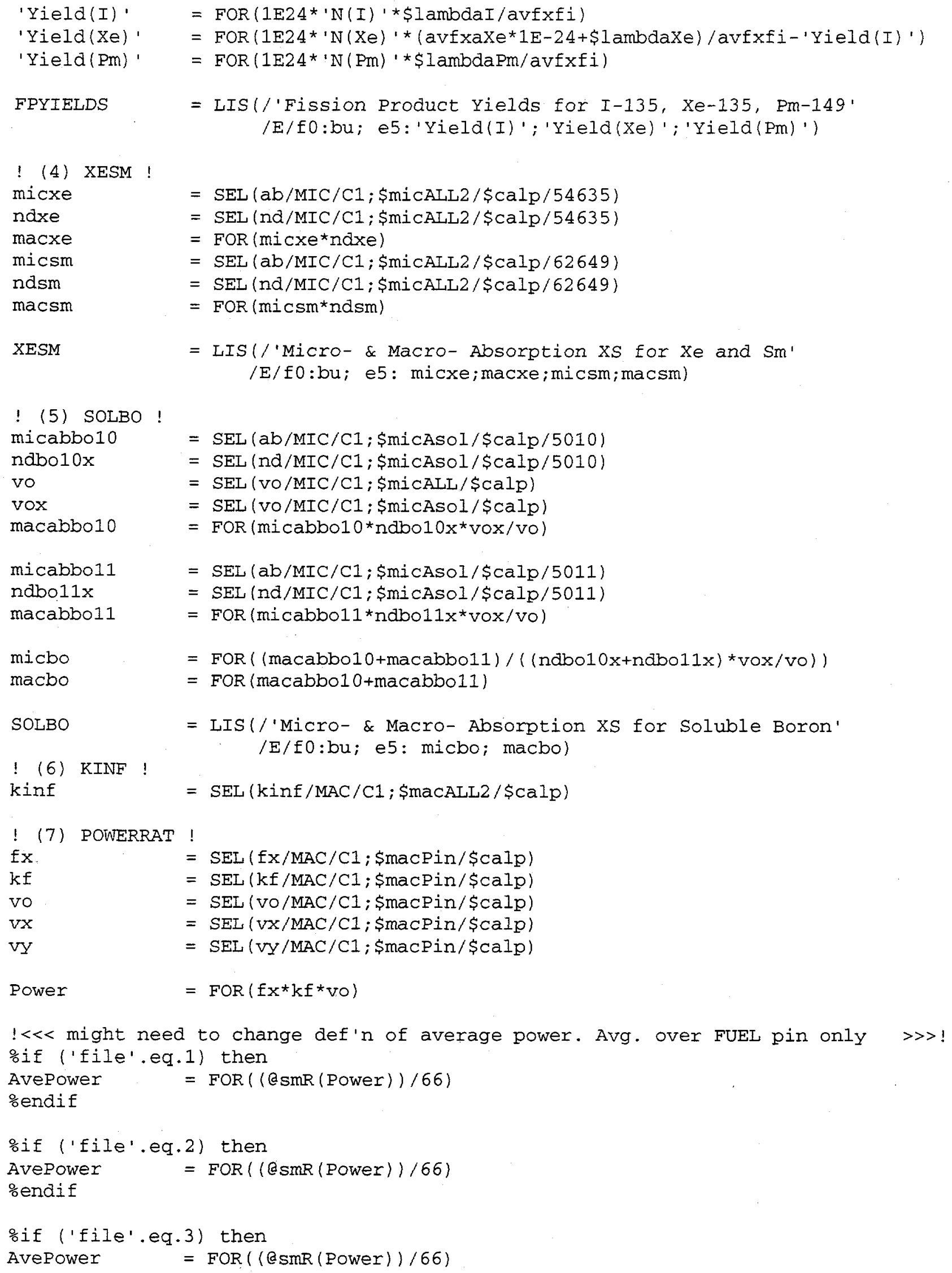




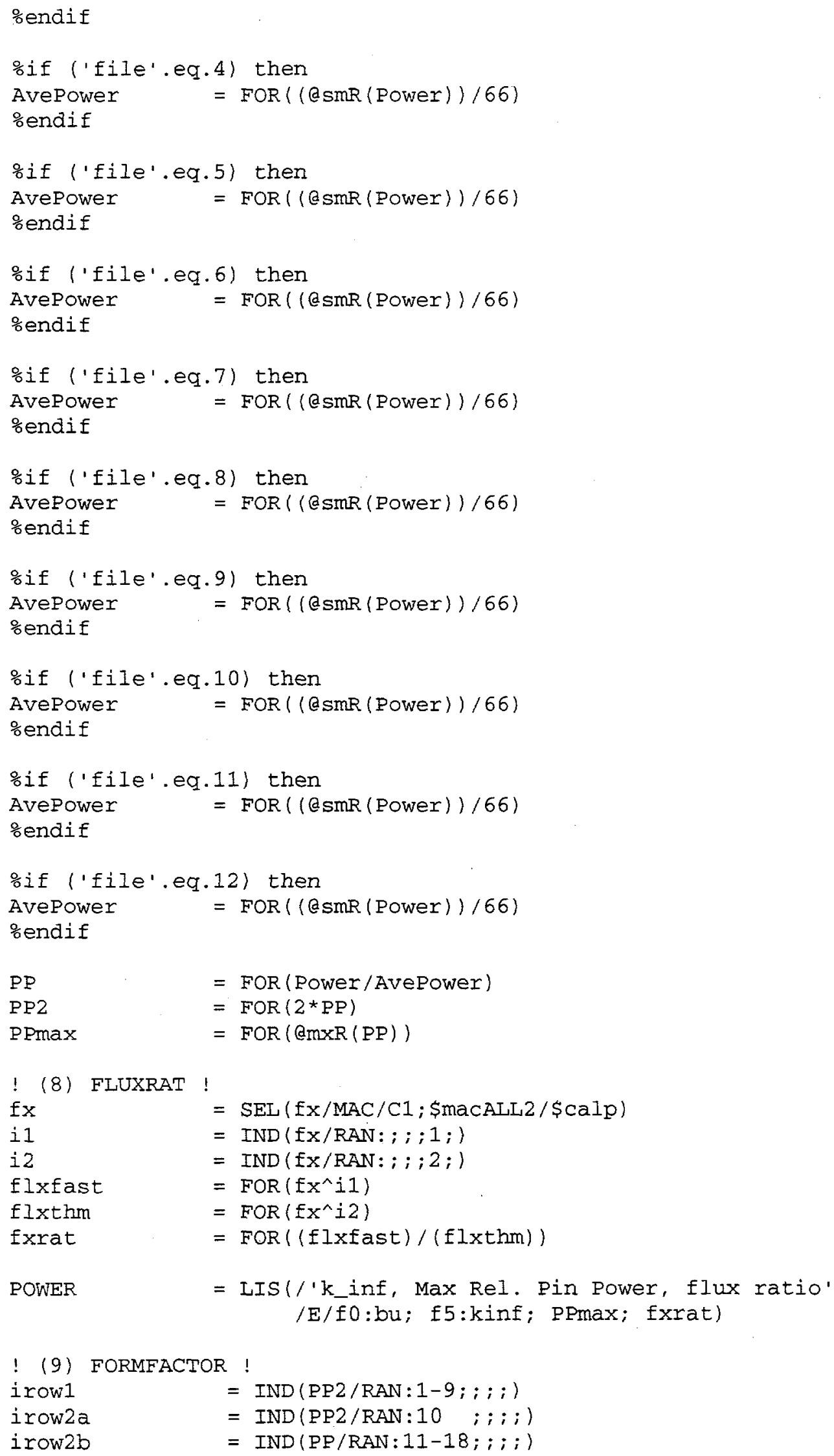




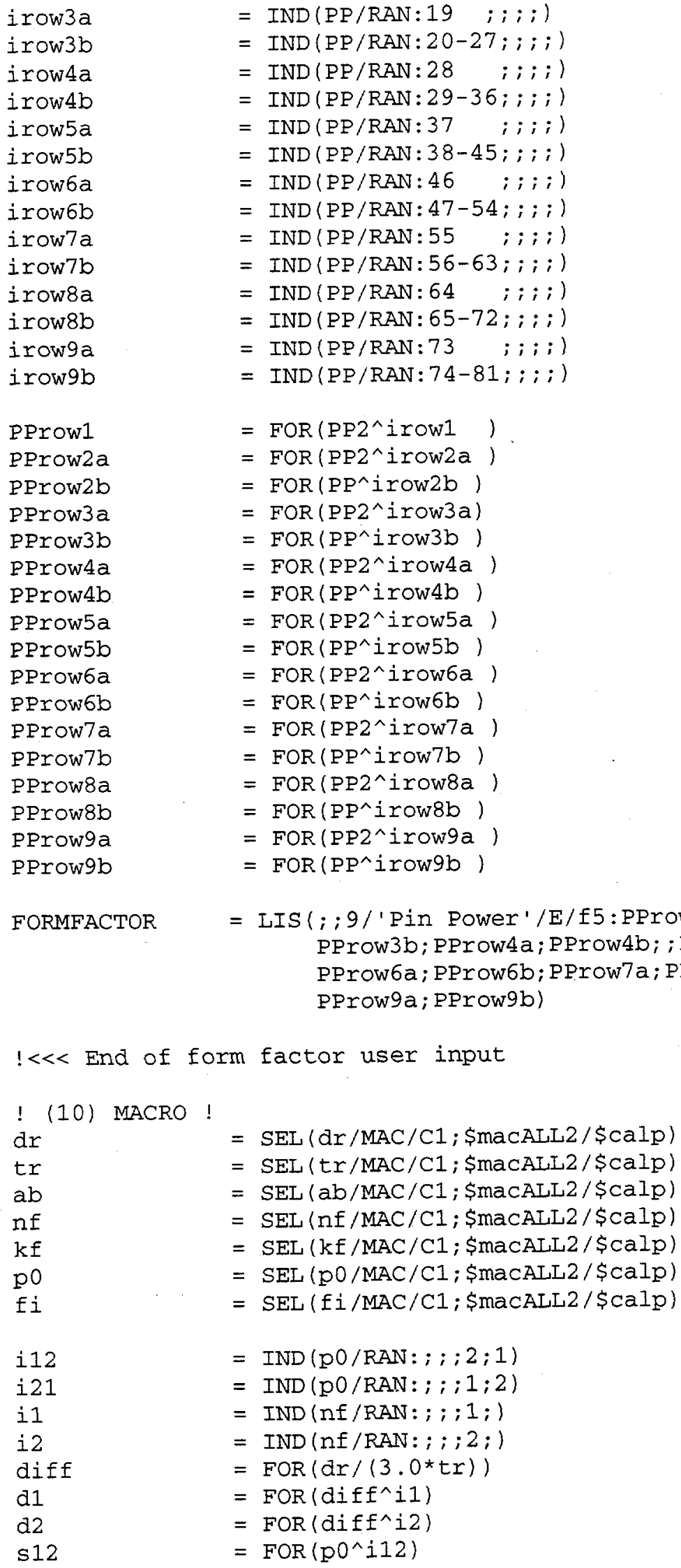

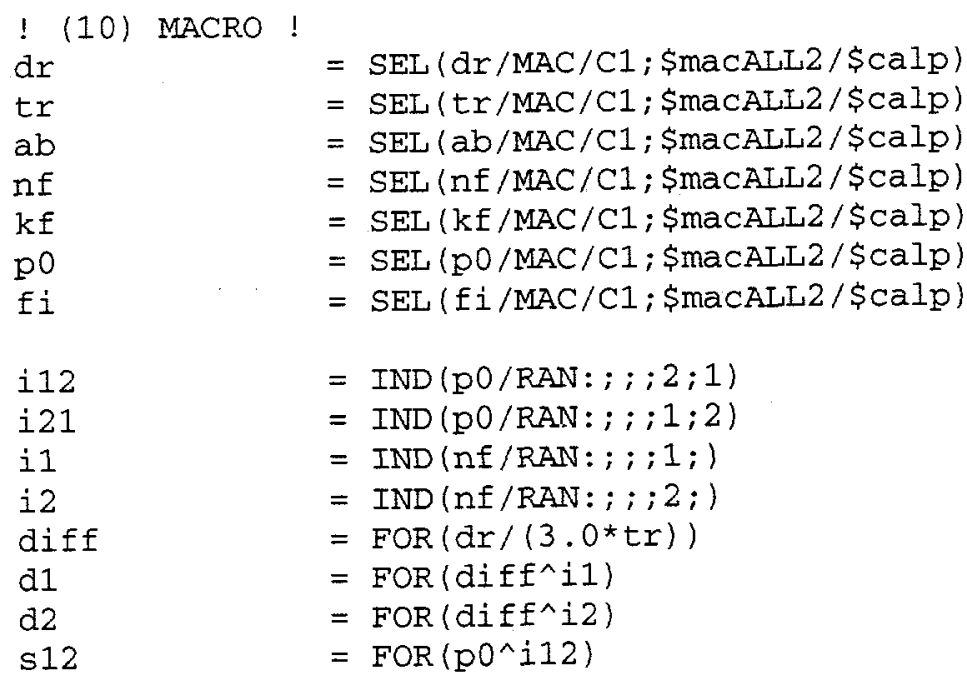




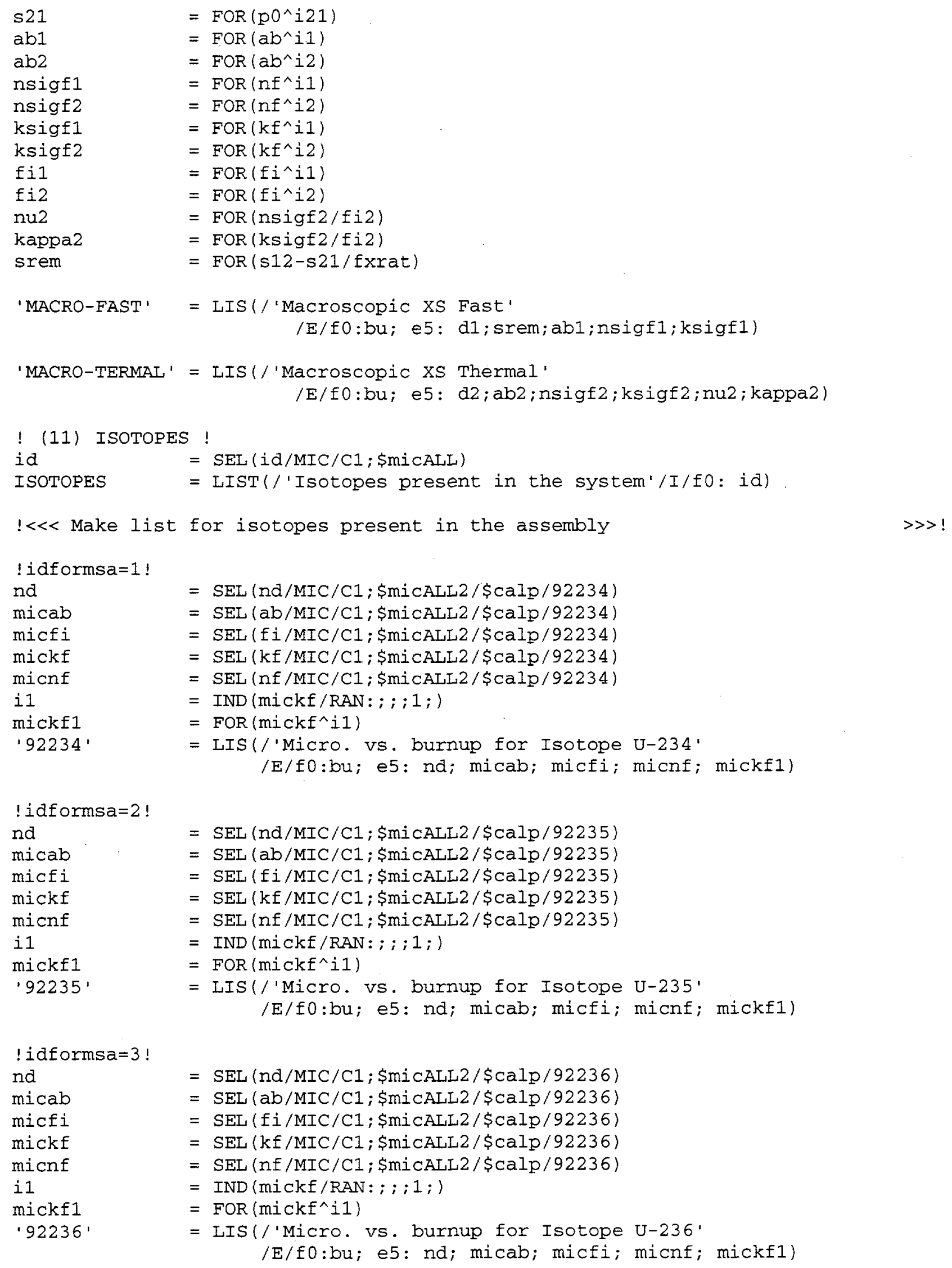


! idformsa $=4$ !

nd

micab

micfi

mickf

$\operatorname{micnf}$

il

mickf1

' $92238^{\prime}$

! idformsa $=5$ !

nd

micab

micfi

mickf

micnf

iI

mickf1

' $93239^{\prime}$

! idformsa $=6$ !

nd

micab

micfi

mickf

$\operatorname{micn} f$

i1

mickf1

' $94239^{\prime}$

! idformsa $=7$ !

nd

micab

micfi

mickf

micnf

i1

mickf1

$.94240^{\circ}$

! idformsa $=8$ !

nd

micab

micfi

mickf

micnf

il

mickf1

' 94241 '

! idformsa $=9$ !
$=\operatorname{SEL}(\mathrm{nd} / \mathrm{MIC} / \mathrm{C} 1 ;$ \$MicALL $2 /$ Scalp $/ 92238)$

$=\operatorname{SEL}(\mathrm{ab} / \mathrm{MIC} / \mathrm{Cl} ;$ \$micALL2 $/$ \$calp/92238)

$=\operatorname{SEL}(\mathrm{fi} / \mathrm{MIC} / \mathrm{C} 1 ;$ MiCALL $2 / \$ \mathrm{Calp} / 92238)$

$=\mathrm{SEL}(\mathrm{kf} / \mathrm{MIC} / \mathrm{Cl} ;$ \$MiCALL $/$ \$Calp $/ 92238)$

$=\operatorname{SEL}(\mathrm{nf} / \mathrm{MIC} / \mathrm{C} 1 ;$ \$miCALI $2 / \$ \mathrm{Calp} / 92238)$

$=\operatorname{IND}(\operatorname{mickf} / \mathrm{RAN}: ; ; ; 1 ;)$

$=$ FOR (mickf^il)

= LIS//Micro. Vs. burnup for Isotope U-238'

/E/f0:bu;e5: nd; micab; micfi; micnf; mickf1)

$=\operatorname{SEL}(\mathrm{nd} / \mathrm{MIC} / \mathrm{Cl} ;$ \$MicALL $2 / \$ \mathrm{Calp} / 93239)$

$=\operatorname{SEL}(\mathrm{ab} / \mathrm{MIC} / \mathrm{C} 1 ;$ MiCALL $2 / \$ \mathrm{Calp} / 93239)$

$=\operatorname{SEL}(\mathrm{fi} / \mathrm{MIC} / \mathrm{C} 1 ;$ \$MiCALL $2 /$ \$Calp $/ 93239)$

$=\operatorname{SEL}(\mathrm{kf} / \mathrm{MIC} / \mathrm{Cl} ;$ \$MiCALL $2 /$ \$Calp/93239)

$=\operatorname{SEL}(\mathrm{nf} / \mathrm{MIC} / \mathrm{C} 1 ;$ \$MiCALL $2 /$ \$Calp $/ 93239)$

$=\operatorname{IND}(\mathrm{mickf} / \mathrm{RAN}: ; ; ; 1 ;)$

$=$ FOR $(\operatorname{mickf\wedge i1})$

= LIS//Micro. VS. burnup for Isotope Np-239

/E/fo:bu; e5: nd; micab; micfi; micnf; mickf1)

$=\operatorname{SEL}(\mathrm{nd} / \mathrm{MIC} / \mathrm{C} 1 ;$ \$MiCALL $2 / \$ \mathrm{Calp} / 94239)$

$=\operatorname{SEL}(\mathrm{ab} / \mathrm{MIC} / \mathrm{C} 1 ;$ \$MiCALL $2 /$ \$Calp $/ 94239)$

$=\operatorname{SEL}(\mathrm{fi} / \mathrm{MIC} / \mathrm{Cl} ;$ \$MiCALL $2 /$ \$Calp $/ 94239)$

$=\operatorname{SEL}(\mathrm{kf} / \mathrm{MIC} / \mathrm{Cl} ;$ \$MiCALL2 $/$ \$Calp $/ 94239)$

$=\operatorname{SEL}(\mathrm{nf} / \mathrm{MIC} / \mathrm{Cl} ;$ \$MiCALL2/\$Calp/94239)

$=\operatorname{IND}(\operatorname{mickf} / \mathrm{RAN}: ; ; ; 1 ;)$

$=$ FOR (mickf^il)

= IIS//Micro. vs. burnup for Isotope Pu-239'

/E/fO:bu; e5: nd; micab; micfi; micnf; mickf1)

$=\operatorname{SEL}(\mathrm{nd} / \mathrm{MIC} / \mathrm{C} 1 ;$ \$MiCALL $2 /$ SCalp $/ 94240)$

$=\operatorname{SEL}(a b / M I C / C 1 ; \$ \operatorname{miCALL} 2 / \$ C a l p / 94240)$

$=\operatorname{SEL}(\mathrm{fi} / \mathrm{MIC} / \mathrm{Cl} ;$ \$miCALL2 $/$ \$Calp $/ 94240)$

$=\operatorname{SEL}(\mathrm{kf} / \mathrm{MIC} / \mathrm{C} 1 ;$ \$MiCALL $2 /$ SCalp $/ 94240)$

$=\operatorname{SEL}(\mathrm{nF} / \mathrm{MIC} / \mathrm{C} 1 ;$ \$MiCALL $2 /$ \$Calp $/ 94240)$

$=\operatorname{IND}(\operatorname{mickf} / \mathrm{RAN}: ; ; ; 1 ;)$

$=$ FOR (mickf^i1)

= IIS (/'Micro. vs. burnup for Isotope Pu-240' /E/E0:bu; e5: nd; micab; micfi; micnf; mickf1)

$=\operatorname{SEL}(\mathrm{nd} / \mathrm{MIC} / \mathrm{Cl} ;$ \$micALL2/\$calp $/ 94241)$

$=\operatorname{SEL}(a b / M I C / C 1 ;$ MiCALL $2 / \$ C a I p / 94241)$

$=\mathrm{SEL}(\mathrm{fi} / \mathrm{MIC} / \mathrm{Cl} ;$ \$miCALL2/\$Calp/94241)

$=\operatorname{SEL}(\mathrm{kf} / \mathrm{MIC} / \mathrm{C} 1 ;$ \$miCALL $2 /$ CaIp $/ 94241)$

$=\operatorname{SEL}(\mathrm{nf} / \mathrm{MIC} / \mathrm{C} 1 ;$ \$micALL $2 / \$ \mathrm{CaIp} / 94241)$

$=\operatorname{IND}(\operatorname{mickf} / \mathrm{RAN}: ; ; ; i ;)$

$=$ FOR (mickf^i1)

= LIS (/'Micro. vs. burnup for Isotope Pu-241'

/E/f0:bu; e5: nd; micab; micfi; micnf; mickf1) 
nd

micab

micfi

mickf

micnf

i 1

mickf1

' 94242 '

! idformsa $=10$ !

nd

micab

micfi

mickf

mienf

i1

mickf1

' $95241^{\prime}$
$=\operatorname{SEL}(\mathrm{nd} / \mathrm{MIC} / \mathrm{C} 1 ; \$ \operatorname{miCALL} 2 / \$ \mathrm{CaIp} / 94242)$

$=\operatorname{SEL}(\mathrm{ab} / \mathrm{MIC} / \mathrm{Cl} ; \$ \operatorname{micALL} 2 / \$ \mathrm{CaIp} / 94242)$

$=\operatorname{SEL}(\mathrm{fi} / \mathrm{MIC} / \mathrm{C1} ;$ \$micALL2 $/$ \$Calp $/ 94242)$

$=\operatorname{SEL}(\mathrm{kf} / \mathrm{MIC} / \mathrm{Cl}$; \$miCALL2/\$calp/94242)

$=\operatorname{SEL}(\mathrm{nf} / \mathrm{MIC} / \mathrm{Cl} ;$ \$micALL2 / \$calp/94242)

$=\operatorname{IND}(\mathrm{mickf} / \mathrm{RAN}: ; ; ; 1 ;)$

$=\operatorname{FOR}(\operatorname{mickf} i 1)$

= IIS(/'Micro. VS. burnup for Isotope Pu-242' /E/f0:bu; e5: nd; micab; micfi; micnf; mickf1)

$=\operatorname{SEL}(\mathrm{nd} / \mathrm{MIC} / \mathrm{Cl} ;$ \$miCALL $2 /$ Scalp $/ 95241)$

$=\operatorname{SEL}(\mathrm{ab} / \mathrm{MIC} / \mathrm{Cl} ;$ \$micALL2/\$calp/95241)

$=\operatorname{SEL}(\mathrm{fi} / \mathrm{MIC} / \mathrm{Cl} ;$ \$miCALL2/\$Calp/95241)

$=\operatorname{SEL}(\mathrm{kf} / \mathrm{MIC} / \mathrm{Cl} ;$ \$micALL2 $/$ \$Calp $/ 95241)$

$=\operatorname{SEL}(\mathrm{nf} / \mathrm{MIC} / \mathrm{Cl} ;$ \$miCALI $2 /$ Salp /95241)

$=\operatorname{IND}(\operatorname{mickf} / \mathrm{RAN}: ; ; ; 1 ;)$

$=$ FOR $(\operatorname{mickf\wedge iI)}$

= LIS //'Micro. vs. burnup for Isotope Am-241'/E/

fo:bu; e5:nd; micab; micfi; micnf; mickf1)

! idformsa $=11$ !

$\mathrm{ndx}$

$=\operatorname{SEL}(\mathrm{nd} / \mathrm{MIC} / \mathrm{Cl} ; \$ \mathrm{miCAbur} / \$ \mathrm{Calp} / 5010)$

vo

$=\operatorname{SEL}(\mathrm{VO} / \mathrm{MIC} / \mathrm{Cl} ;$ \$ $\mathrm{miCALL} / \$ \mathrm{Calp})$

vox

nd

$=\operatorname{SEL}(\mathrm{VO} / \mathrm{MIC} / \mathrm{Cl} ;$ \$miCAbur $/$ \$Calp)

$=$ FOR $\left(\mathrm{ndx}{ }^{\star} \mathrm{VOX} / \mathrm{VO}\right)$

micab

$=\operatorname{SEL}(a b / \mathrm{MIC} / \mathrm{Cl} ;$ \$micAbur $/ \$ \mathrm{Calp} / 5010)$

micfi

$=\operatorname{SEL}(\mathrm{Ii} / \mathrm{MIC} / \mathrm{CI} ;$ \$micAbur $/$ \$CaIp $/ 5010)$

mickf

$=\operatorname{SEL}(\mathrm{kf} / \mathrm{MIC} / \mathrm{Cl} ;$ \$micAbur $/ \$ \mathrm{calp} / 5010)$

$\operatorname{micnf}$

i1

mickf1

$=\operatorname{SEL}(\mathrm{nf} / \mathrm{MIC} / \mathrm{Cl} ;$ \$micAbur/\$CaIp/5010)

$=\operatorname{IND}(\operatorname{mickf} / \mathrm{RAN}: ; ; ; 1 ;)$

' $5010^{\prime}$

$=\operatorname{FOR}(\operatorname{mickf\wedge } i 1)$

= LIS (/'Micro. Vs. burnup for Boron 10' /E/f0:bu; e5: nd; micab; micfi; micnf; mickf1)

! idformosa $=12$ !

$n d x$

vo

$=\operatorname{SEL}(\mathrm{nd} / \mathrm{MIC} / \mathrm{C} 1 ; \$ \mathrm{miCAbur} / \$ \mathrm{Calp} / 5011$ )

vox

nd

$=\operatorname{SEL}(\mathrm{VO} / \mathrm{MIC} / \mathrm{Cl} ;$ \$miCALL $/$ \$Calp $)$

$=\operatorname{SEL}(\mathrm{Vo} / \mathrm{MIC} / \mathrm{Cl} ; \$ \mathrm{miCAbur} / \$ \mathrm{Calp})$

micab

micfi

mickf

micnf

i1

mickf1

$=F O R\left(n d x^{*}\right.$ Vox $/$ Vo $)$

$=\operatorname{SEL}(\mathrm{ab} / \mathrm{MIC} / \mathrm{Cl} ;$ \$micAbur $/ \$ \mathrm{Calp} / 5011)$

$=\operatorname{SEL}(\mathrm{fi} / \mathrm{MIC} / \mathrm{Cl} ;$ \$micAbur $/$ \$Calp $/ 5011)$

$=\operatorname{SEL}(\mathrm{kf} / \mathrm{MIC} / \mathrm{CI} ; \$ \mathrm{miCAbur} / \$ \mathrm{Calp} / 5011)$

$=\operatorname{SEL}(\mathrm{nf} / \mathrm{MIC} / \mathrm{Cl} ;$ \$micAbur $/$ \$calp $/ 5011)$

$=\operatorname{IND}(\operatorname{mickf} / \mathrm{RAN}: ; ; ; 1 ;)$

$=$ FOR (mickf^il)

'5011'

$=$ LIS (/'Micro. VS. burnup for Boron 11 '

/E/fO:bu; e5: nd; micab; micfi; micnf; mickf1)

$! \ll<$ End of isotope micro. xs user input

$>>$ !

END () 


\title{
Appendix F. Zenith File: Reflector (zmhwhref1.inp)
}

\author{
BEGIN ('Output generator for FORCIP-P : Baffle- Reflector Region' / 0.4; 0.4 )

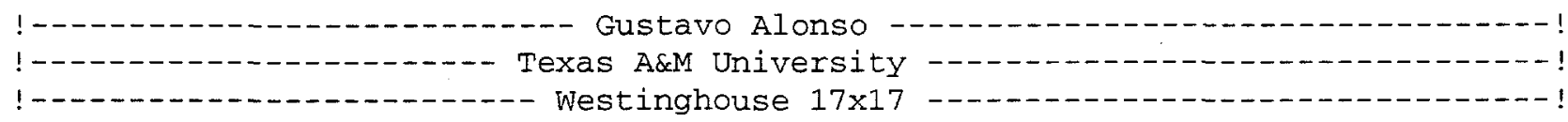

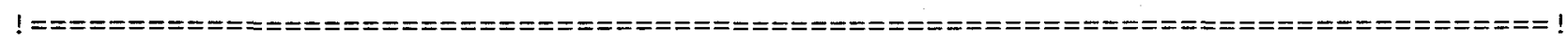

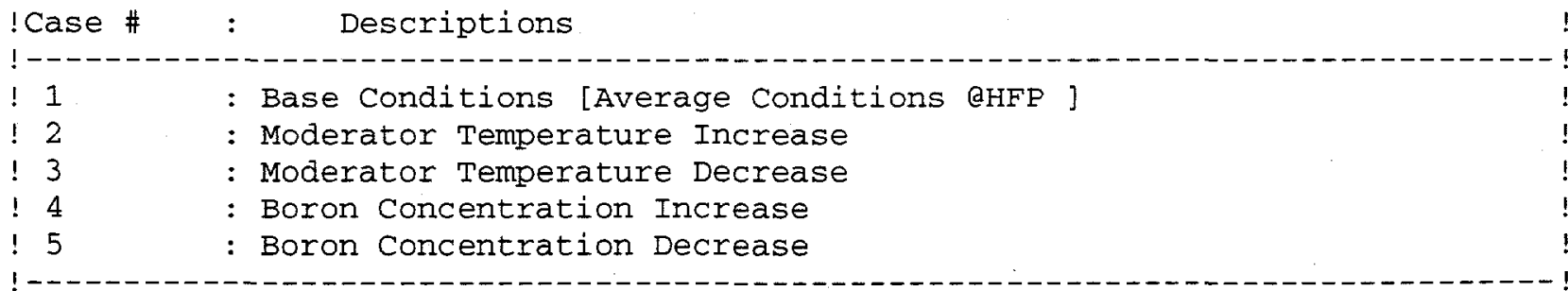 \\ !-- Enter your case selection \\ \%'Case\#' $=1$ \\ $\begin{array}{ll}\text { !- } & \text { : \$BurnupBase } \\ \text { !-- ! } & \text { : \$BurnupBranch ---! } \\ \text { !-- } & \text { : \$Hcase } \\ \end{array}$ \\ \$BurnupBase $\quad=$ PAR $(0)$ \\ $\$$ BurnupBranch $=$ PAR $(0)$ \\ SHcase $\quad$ PAR ('Vmhwhref') \\ \$Hfile $\quad=\operatorname{PAR}$ ('Vmhwhref.hrf') \\ Cl $\quad$ IMP (HELIOS; \$Hcase/\$Hfile) \\ !--- For each case, enter the following info.:

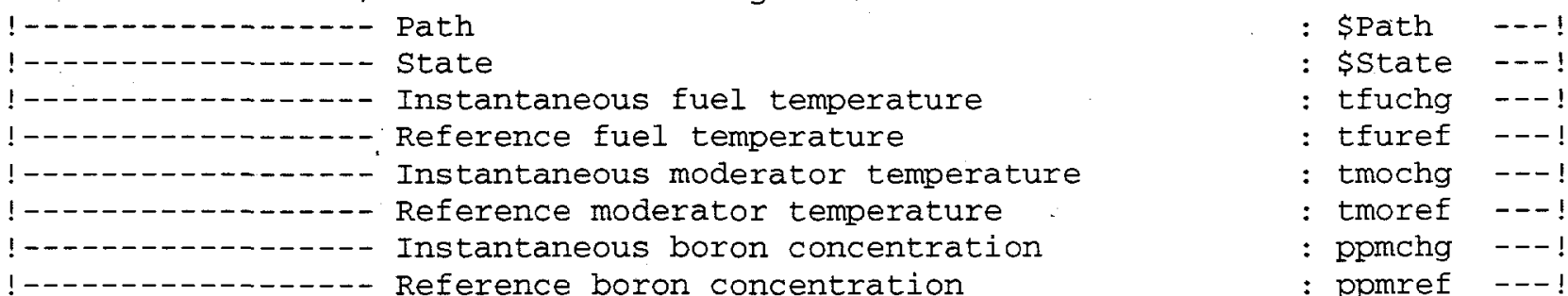 \\ oif ('Case\#'.eq.1) then \\ \$Path $\quad=$ PAR ('Path') \\ \$state $\quad=\operatorname{PAR}(' s t$ ') \\ \$Burnup = PAR (\$BurnupBase) \\ \$calp $\quad=\operatorname{PAR}(\$ P$ ath: $(\$$ State) $\$$ Burnup) \\ tfuchg $\quad=$ FOR (963) \\ tfuref $\quad=$ FOR (963) \\ tmochg $\quad=$ FOR $(582.95)$ \\ tmoref $\quad=$ FOR $(582.95)$ \\ ppmchg $\quad=$ FOR $(1000)$ \\ ppmref $\quad=$ FOR $(1000)$ \\ CASEPARAM $=$ LIS $\left(; ; 6 /\right.$ 'Parameters $^{\prime}$ \\ /E/f0:tfuchg; tfuref; tmochg; tmoref;ppmchg; ppmref)
}


\%endif

oif ('Case\#'.eq.2) then

\$Path = PAR('HMPath')

\$state $=$ PAR (sthim)

\$Burnup = PAR (\$BurnupBranch)

\$Calp = PAR (\$Path: (\$State) \$Burnup)

tfuchg $\quad=$ FOR $(963)$

tfuref $\quad=$ FOR (963)

tmochg $\quad=$ FOR $(599.32)$

tmoref $\quad=$ FOR $(582.95)$

ppmchg $\quad=$ FOR $(1000)$

ppmref $\quad=$ FOR $(1000)$

CASEPARAM = LIS $(; ; 6 /$ 'Parameters'

\%endif

/E/f0:tfuchg; tfuref; tmochg; tmoref;ppmchg; ppmref)

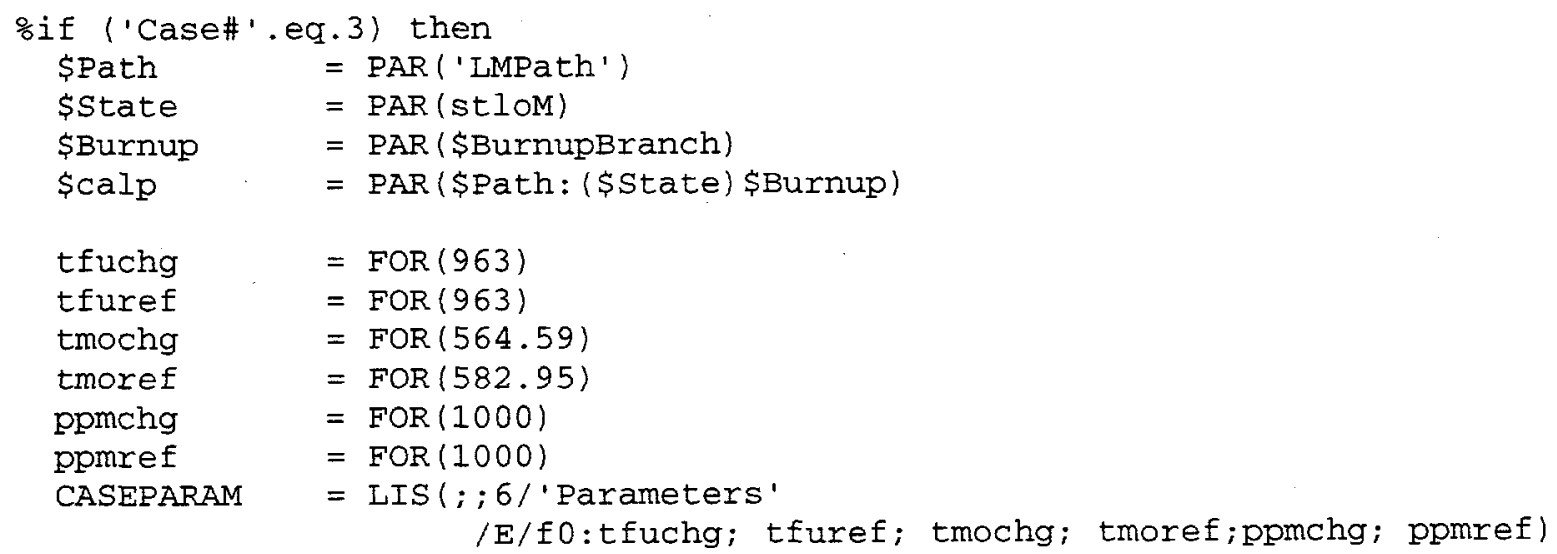

gendif

gif ('Case\#'.eq.4) then

\$Path $\quad$ PAR ('HBPath')

SState $\quad=$ PAR (sthiB)

\$Burnup = PAR (\$BurnupBranch)

$\$$ calp $\quad$ PAR (\$Path: (\$State) \$Burnup)

tfuchg $\quad=$ FOR (963)

tfuref $\quad=$ FOR (963)

tmochg $\quad=$ FOR $(582.95)$

tmoref $\quad=$ FOR $(582.95)$

ppmchg $\quad=$ FOR $(2000)$

ppmref $\quad=$ FOR $(1000)$

CASEPARAM $=$ LIS $(; ; 6 /$ 'Parameters

\%endif

oif ('Case\#'.eq.5) then

\$Path = PAR ('LBPath')

\$state $\quad=$ PAR (stloB)

\$Burnup = PAR (\$BurnupBranch)

\$calp $=\operatorname{PAR}$ (\$Path: (\$State) \$Burnup)

tfuchg $=$ FOR (963) 


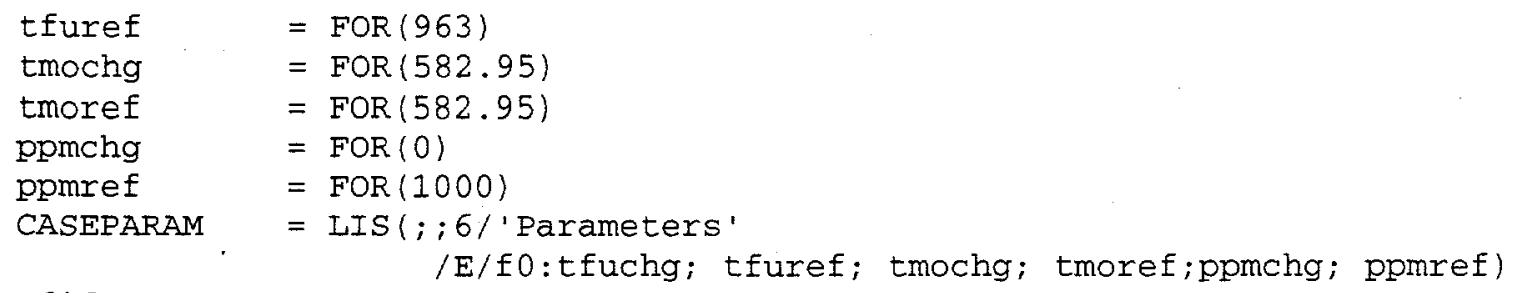




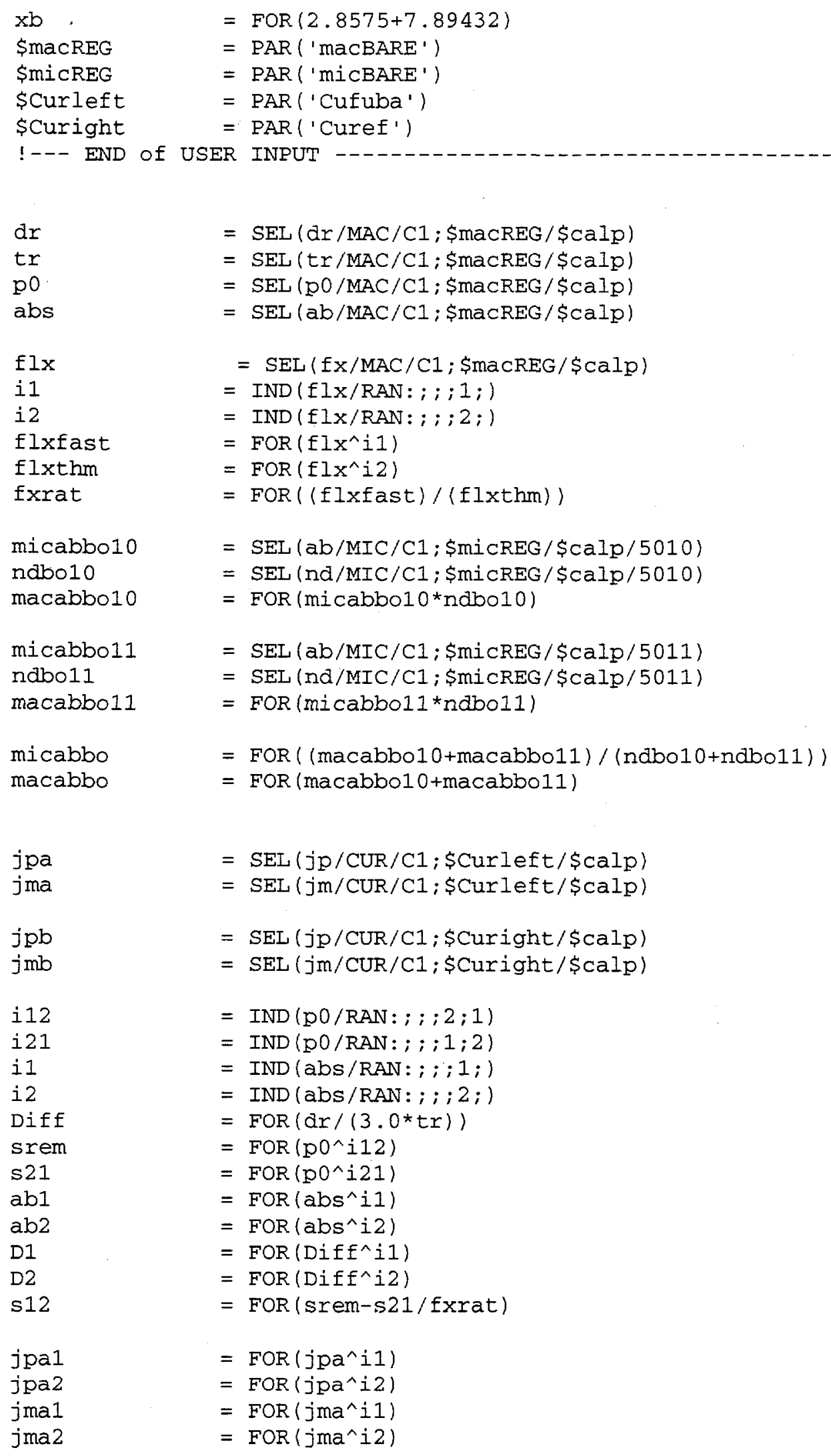



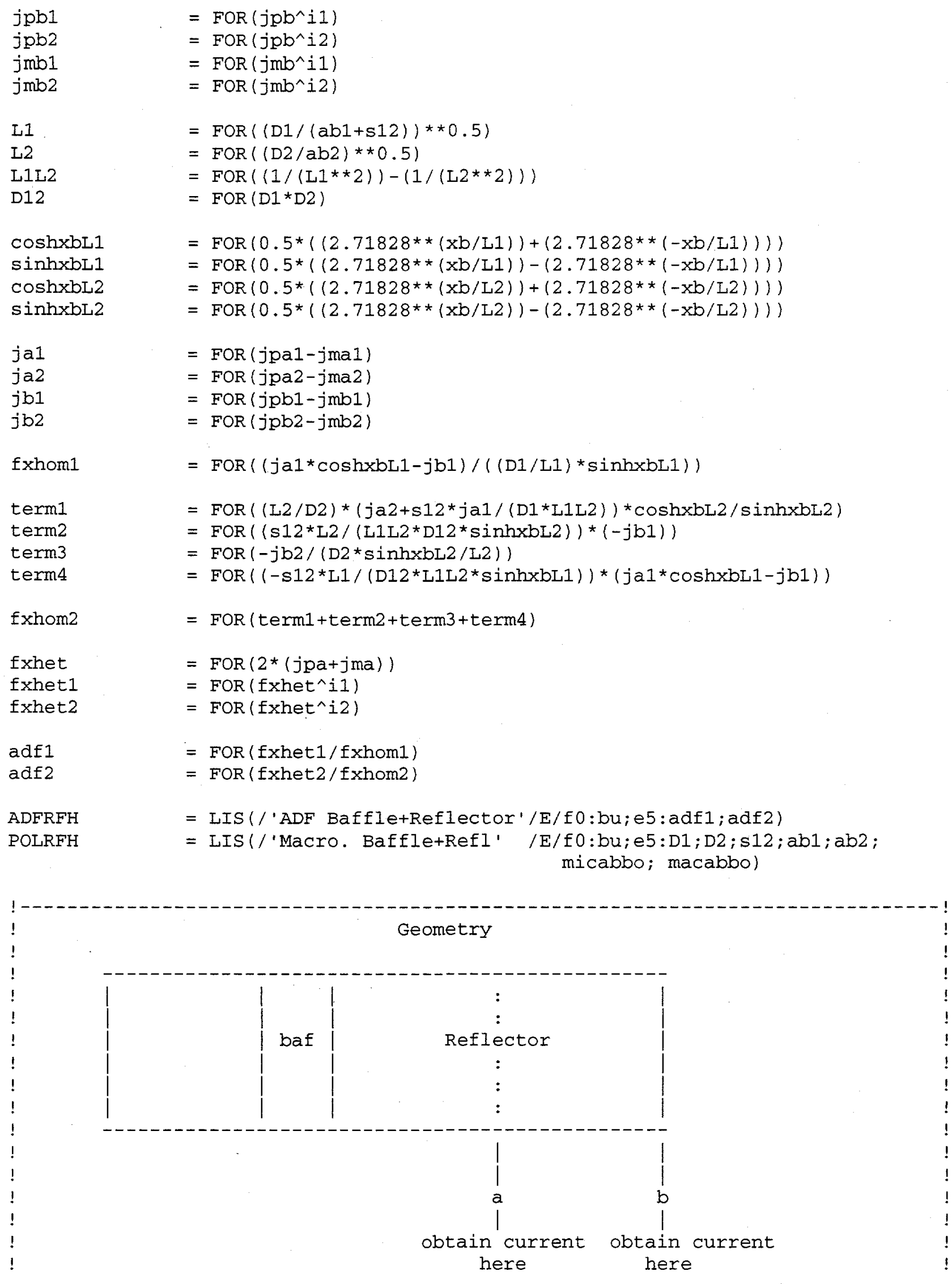
!

! Homogenize region is bounded by surface a and b

! - - -

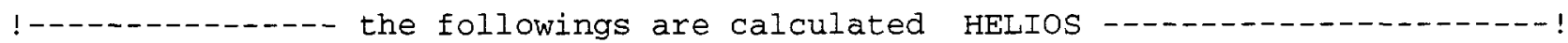

jpal : outward current at fuel-baffle interface (fast)

! jpa2 : outward current at fuel-baffle interface (thermal)

!mal : inward current at fuel-baffle interface (fast)

jma2 : inward current at fuel-baffle interface (thermal)

jpb1 : outward current at $1 / 2$ reflector interface (fast)

jpb2 : outward current at $1 / 2$ reflector interface (thermal)

jmbl : inward current at $1 / 2$ reflector interface (fast)

jmb2 : inward current at $1 / 2$ reflector interface (thermal)

! ab1 : absorption xs (fast)

ab2 : absorption xs (thermal)

! s12 : downscatter

! d1 : diffusion coefficient (fast)

! d2 : diffusion coefficient (thermal)

!

!-- USER INPUT -

! $\mathrm{xb} \quad$ : width of the homogenized region

! \$macREG : 2-group, macro. XS homogenized over region between a and b

! \$micREG : 2-group, micro. XS homogenized over region between a and b

! \$Curleft : 2-group currents on surface a

! \$Curight : 2-group currents on surface b

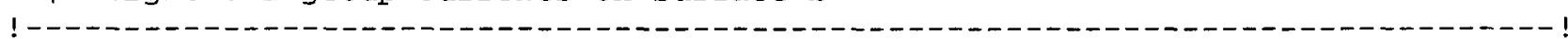

$\mathrm{xb}$

\$MacREG

\$micREG

\$Curleft

scuright

! - - END of

dr

tr

po

abs

$\mathrm{f} 1 \mathrm{x}$

i1

i2

flxfast

flxthm

fxrat

micabbo10

nabo10

macabbo 10

micabbo11

ndbo11

macabbo 11

micabbo

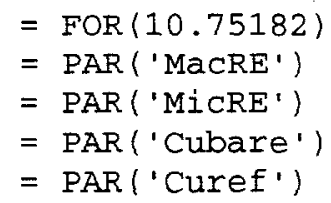

$=\operatorname{FOR}((\operatorname{macabbo10}+\operatorname{macabbo11}) /(\mathrm{nabo} 10+n d b o 11))$ 


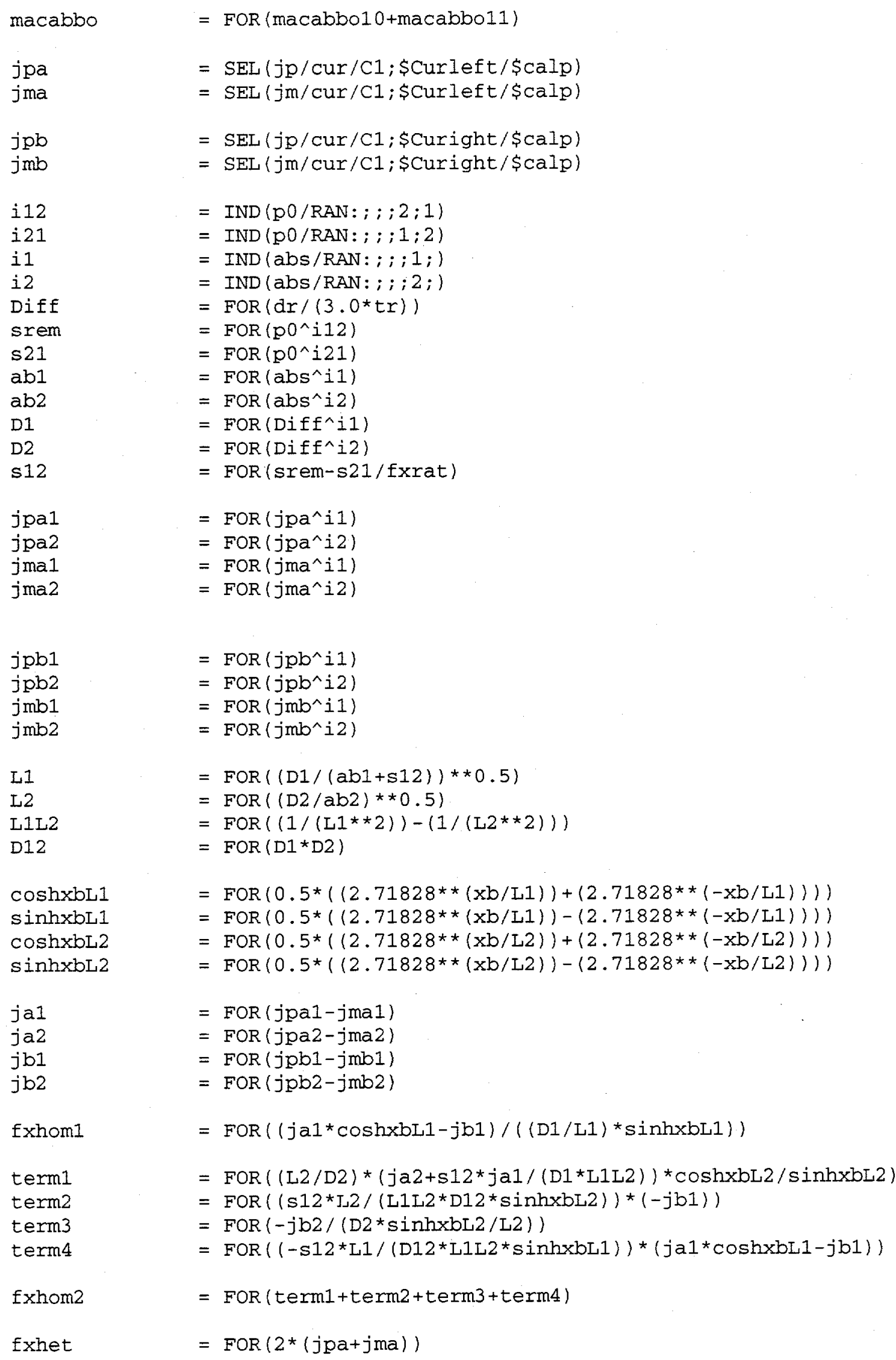

fxhom1

$=$ FOR $((j a 1 * \cosh \times b L 1-j b 1) /((D 1 / L 1) * \sinh x b L 1))$

term 1

$=\operatorname{FOR}((\mathrm{L} 2 / \mathrm{D} 2) *(j a 2+\mathrm{s} 12 * j \mathrm{a} 1 /(\mathrm{D} 1 * \mathrm{~L} 1 \mathrm{~L} 2)) * \operatorname{coshxbL} 2 / \operatorname{sinhxbL} 2)$

term2

term3

term4

$=\operatorname{FOR}((\mathrm{s} 12 * \mathrm{~J}\lrcorner 2 /(\mathrm{L} 1 \mathrm{~L} 2 * \mathrm{D} 12 * \sinh \times \mathrm{bL} 2)) *(-j \mathrm{~b} 1))$

$=\operatorname{FOR}(-j \mathrm{~b} 2 /(\mathrm{D} 2 * \sinh \mathrm{xbL} 2 / \mathrm{L} 2))$

$=\operatorname{FOR}\left(\left(-\mathrm{s} 12 * \mathrm{~L} 1 /\left(\mathrm{D} 12 * \operatorname{L} 1 \mathrm{~L} 2{ }^{*} \sinh \times b L 1\right)\right) *\left(j a 1{ }^{*} \cosh \times b L 1-j b 1\right)\right)$

fxhom2

$=\operatorname{FOR}($ term $1+$ term $2+$ term $3+$ term 4$)$

Exhet

$=F O R(2 *(j p a+j m a))$ 


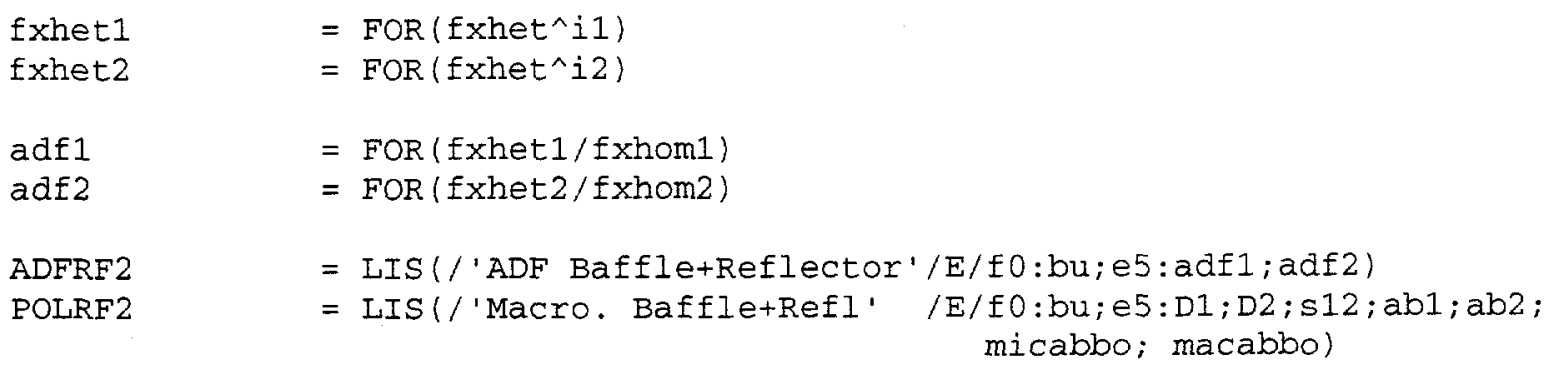

$\operatorname{END}()$ 


\section{INTERNAL DISTRIBUTION}

\author{
1. M. D. DeHart \\ 2. R. J. Ellis \\ 3. J. C. Gehin \\ 4. S. R. Greene \\ 5. S. A. Hodge \\ 6. D. T. Ingersoll \\ 7. M. A. Kuliasha \\ 8. S. B. Ludwig \\ 9. G. E. Michaels \\ 10. D. L. Moses \\ 11. B. D. Murphy
}

\author{
12. D. G. O'Connor \\ 13-17. R. T. Primm III \\ 18. C. C. Southmayd \\ 19-23. D. J. Spellman \\ 24. R. M. Westfall \\ 25. K. A. Williams \\ 26. B. A. Worley \\ 27. Central Research Library \\ 28. FMDP Library \\ 29-30. ORNL Laboratory Records (OSTI) \\ 31. ORNL Laboratory Records-RC
}

\section{EXTERNAL DISTRIBUTION}

32. M. L. Adams, Department of Nuclear Engineering, Texas A\&M University, Zachry 129, College Station, TX 77843

33. Dave Alberstein, LANL, P.O. Box 1663, MS-K575, Los Alamos, NM 87545

34. G. Alonszo, Department of Nuclear Engineering, Texas A\&M University, Zachry 129, College Station, TX 77843

35. Richard D. Ankney, Westinghouse Electric Company, P.O. Box 355, Pittsburgh, PA 15230-0355

36. Imelda Ariani, Department of Nuclear Engineering, P.O. Box 7909, North Carolina State University, Raleigh, North Carolina 27695-7909

37. Tim Barr, U.S. Department of Energy, Chicago Operations Office, 9700 S. Cass Avenue, Chicago, IL 60439

38. H. R. Canter, Office of Fissile Materials Disposition, U.S. Department of Energy, MD-1/2, 1000 Independence Avenue SW, Washington, DC 20585

39. G. S. Chang, INEEL, P.O. Box 1625, MS-3885, Idaho Falls, ID 83415-3885

40. A. I. Cygelman, U.S. Department of Energy, 1000 Independence Avenue SW, Forrestal Building 3F043, Washington, DC 20585

41. L. Groves, Sandia National Laboratories, P.O. Box 969, Livermore, CA 94551

42. D. Harrison, U.S. Department of Energy, 101 Convention Center Drive, Suite P200, Las Vegas, NV 89109

43. G. Holman, Lawrence Livermore National Laboratory, P.O. Box 808, Livermore, CA 94551

44. C. Jaeger, Sandia National Laboratories, P.O. Box 5800, Albuquerque, NM 78185-0759

45. Frank Motley, LANL, P.O. Box 1663, MS-K575, Los Alamos, NM 87545

46-50. Office of the ORNL Site Manager, U.S. Department of Energy, Oak Ridge National Laboratory, P.O. Box 2008, Oak Ridge, TN 37831

51. D. Peko, U.S. Department of Energy, 1000 Independence Avenue SW, Forrestal Building 3F042, Washington, DC 20585

52. P. T. Rhoads, Office of Fissile Materials Disposition, U.S. Department of Energy, MD-4, 1000 Independence Avenue SW, Washington, DC 20585

53. G. P. Rudy, U.S. Department of Energy, 1000 Independence Avenue SW, Forrestal Building 7B192, Washington, DC 20585

54. J. M. Ryskamp, INEEL, P.O. Box 1625, MS-3885, Idaho Falls, ID 83415-3885

55. Robert Selby, U.S. Department of Energy, Chicago Operations Office, 9700 S. Cass Avenue, Chicago, IL 60439

56. J. Thompson, Office of Fissile Materials Disposition, U.S. Department of Energy, MD-4, 1000 Independence Avenue SW, Forrestal Building 3F043, Washington, DC 20585

57. Dr. Paul Turinsky, Department of Nuclear Engineering, North Carolina State University, Raleigh, North Carolina 27695-7909

58-78. Angela L. Woods, Technical Editor, Amarillo National Resource Center for Plutonium, $600 \mathrm{~S}$. Tyler, Suite 800, Amarillo, Texas 79101 